\title{
The Evolution and Diversification of Sex: From Sex to the Sexes
}

\author{
by \\ Lindsay Jackson Derraugh
}

A thesis submitted to the Faculty of Graduate and Postdoctoral Affairs in partial fulfillment of the requirements for the degree of

Master of Science

in

Biological Science

Carleton University

Ottawa, Ontario

2012

Lindsay Jackson Derraugh 
Library and Archives

Canada

Published Heritage

Branch

395 Wellington Street

Ottawa ON K1A ON4

Canada
Bibliothèque et

Archives Canada

Direction du

Patrimoine de l'édition

395 , rue Wellington

Ottawa ON K1A ON4

Canada
Your file Votre référence

ISBN: 978-0-494-87834-7

Our file Notre référence

ISBN: 978-0-494-87834-7

\section{NOTICE:}

The author has granted a nonexclusive license allowing Library and Archives Canada to reproduce, publish, archive, preserve, conserve, communicate to the public by telecommunication or on the Internet, loan, distrbute and sell theses worldwide, for commercial or noncommercial purposes, in microform, paper, electronic and/or any other formats.

The author retains copyright ownership and moral rights in this thesis. Neither the thesis nor substantial extracts from it may be printed or otherwise reproduced without the author's permission.
AVIS:

L'auteur a accordé une licence non exclusive permettant à la Bibliothèque et Archives Canada de reproduire, publier, archiver, sauvegarder, conserver, transmettre au public par télécommunication ou par l'Internet, prêter, distribuer et vendre des thèses partout dans le monde, à des fins commerciales ou autres, sur support microforme, papier, électronique et/ou autres formats.

L'auteur conserve la propriété du droit d'auteur et des droits moraux qui protege cette thèse. $\mathrm{Ni}$ la thèse ni des extraits substantiels de celle-ci ne doivent être imprimés ou autrement reproduits sans son autorisation.
In compliance with the Canadian Privacy Act some supporting forms may have been removed from this thesis.

While these forms may be included in the document page count, their removal does not represent any loss of content from the thesis.
Conformément à la loi canadienne sur la protection de la vie privée, quelques formulaires secondaires ont été enlevés de cette thèse.

Bien que ces formulaires aient inclus dans la pagination, il n'y aura aucun contenu manquant. 


\begin{abstract}
I have developed meta-syntheses and a meta-analysis of evolution of sex and the sexes. I answer whether femaleness and maleness exists universally across all metazoans or if these labels are social constructs. I hypothesize that the sexes can be universally defined in haploids (roughly sperm and egg nuclei, at least in animals), therefore anisogamy may have only evolved once. I propose a new mechanism of selection, namely postplasmogamic, pre-karyogamic sexual selection (mate choice by haploids in the microcosm of an egg cell), which shows that sexual selection may play a larger role than originally thought in sessile taxa. I hypothesize that automictic gynogenesis is an evolutionary bridge from amphimixis to automictic parthenogenesis. I test this hypothesis by mapping onto a phylogeny all gynogenetic and related parthenogenetic metazoans.
\end{abstract}




\section{Acknowledgements}

First and foremost, I'd like to thank my supervisor Dr. Root Gorelick, for seeing something in me that others overlooked. I am truly honoured to have been mentored by such a forward thinking eccentric. Thanks to my mum, Liz Jackson, for believing in me even at times when she probably shouldn't have. To my grandfather, Robert Jackson, for his ongoing infectious pursuit of knowledge, personal improvement, and self-reflection. To my lab mates, Dani, Sanoji, and Zoë, Krystal, and Abdool, Ross Young, and especially my partner in crime, the passionately moral Jessica Carpinone. To my big sister Leigh-Leigh, my laotong Jean-Pool, my soldier Miranda, and my enabler Kybo. 


\section{Table of Contents}

Abstract

Acknowledgments

Contributions 1

Glossary 3

Chapter 1. Introduction 4

Chapter 2. Fundamental differences between females and males? 12

$\begin{array}{ll}\text { Abstract } & 12\end{array}$

$\begin{array}{ll}\text { Introduction } & 13\end{array}$

$\begin{array}{ll}\text { Definitions } & 15\end{array}$

$\begin{array}{ll}\text { Deconstruction } & 16\end{array}$

$\begin{array}{ll}\text { Sexual difference in diploid individuals } & 17\end{array}$

$\begin{array}{ll}\text { Sexual differences in haploid individuals } & 19\end{array}$

Sexual differences between eggs and sperm $\quad 21$

$\begin{array}{ll}\text { Reconstruction } & 23\end{array}$

$\begin{array}{ll}\text { Concluding Remarks } & 27\end{array}$

Chapter 3. Post-plasmogamic pre-karyogamic sexual selection:

$\begin{array}{ll}\text { Mate choice inside an egg cell } & 30\end{array}$

$\begin{array}{ll}\text { Abstract } & 30\end{array}$

Introduction $\quad 30$

Post-plasmogamic pre-karyogamic sexual selection has the potential to exist

Can different nuclei within a single egg cell behave independently? $\quad 34$

Do nuclei within a single egg cell have detectable differences? 37

Implications of post-plasmogamic pre-karyogamic sexual selection for $\begin{array}{ll}\text { alternative sexual systems } & 42\end{array}$

Implications of post-plasmogamic pre-karyogamic sexual selection for polysperms

Implications of post-plasmogamic pre-karyogamic sexual selection for gynogens 
Implications of post-plasmogamic pre-karyogamic sexual selection for androgens $\quad 45$

Concluding Remarks 46

Chapter 4. Phylogenetic relationship of automictic reproductive systems:

Amphimixis, gynogenesis, parthenogenesis, and the gynogenetic bridge hypothesis 49

Abstract 49

Introduction $\quad 49$

Methods $\quad 54$

Results and concluding remarks $\quad 56$

Chapter 5. Discussion $\quad 64$

References $\quad 71$

Appendix A. All parthenogenetic and gynogenetic phyla, classes, and orders in the animal kingdom (references included) 81

Appendix B. Gorelick, Derraugh, Carpinone, Bertram (2011). Postplasmogamic, pre-karyogamic sexual selection: Mate choice inside an egg cell. Ideas in Ecology and Evolution, 4: 14-23. 93

Notice of copyright terms 103

\section{Tables and Figures}

Figure 1.1: Restoration of diploidy in automictic parthenogens 6

Figure 1.2: Restpration of diploidy in automictic gynogens 11

Figure 4.1: Evolutionary pregress from amphimixis to parthenogenesis $\quad 54$

Figure 4.3: Detailed phylogeny of relavent nematode genera 63

Figure 4.2: Detailed phylogeny of all orders in the phyla containing gynogenetic species 62

Figure 5.1: Proposed evolutionary bridges from amphimixis to parthenogenesis 69

Table 4.1: Summary of gynogenetic and parthenogenetic relationships 57

Table 4.2: Gynogenesis and parthenogenesis in the phyla Rotifera, Platyhelminthes, Nematoda, Annelida, Mollusca, Chordata, and Arthropoda 


\section{Contributions}

\section{Chapter 2. Fundamental differences between females and males.}

I served as an expert in automictic reproductive systems, such as gynogenesis, androgenesis, and parthenogenesis, for this collaborative project. The knowledge I brought added to the hypothesis that universal differences between males and females are minute on the nuclear level. If there are no universal differences between males and females, the sexes probably evolved multiple times across evolutionary history (an idea that is contrary to current hypotheses in the field). This is a refereed book chapter, to be published in 2012 by the Centre for Gender Research at Uppsala University in the book Challenging popular myths of sex, gender, and biology. My co-authors on the soon-tobe published version of this chapter are Root Gorelick and Jessica Carpinone.

Chapter 3. Pre-karyogamic sexual selection: Mate choice inside an egg cell. I was one of the primary thinkers and writers of this manuscript. The first three authors, including me, contributed equally and were primary authors. The main idea of sexual selection inside an egg cell came to me as a direct result of my undergraduate work with gynogenesis and polyspermy. If sexual selection can occur within a fertilized egg, there may be more sexual selection occurring in sessile organisms than previously thought. This chapter was published in Ideas in Ecology and Evolution in 2011 (Appendix B). My co-authors on the published version of this paper were and Root Gorelick, Jessica Carpinone, and Sue Bertram. 
Chapter 4. Phylogenetic relationship of automictic reproductive systems:

Amphimixis, gynogenesis, parthenogenesis, and the gynogenetic bridge hypothesis.

I was the primary author and primary researcher of this project. After learning that all metazoans (except cnidarians and sea urchins) have arrested meiosis, I proposed the new hypothesis that the function of sperm is solely to reinitiate a paused meiosis in gynogens, and therefore gynogenesis should be an intermediate form between amphimixis and parthenogenesis. I did $\mathbf{8 0 \%}$ of the work, including organizing co-authors. Ross Young built the phylogeny of all gynogenetic phyla, and Root Gorelick provided several insights. 


\section{Glossary}

Amphimixis - plasmogamy and karyogamy

Androgenesis - plasmogamy between male and female gametes, but female nucleus is ejected

Asex/apomixis - any form of reproduction involving neither meiosis nor karyogamy Automixis - self sex

Endomitosis - chromosomal duplication without nuclear division

Gynogenesis - plasmogamy between male and female gametes, but male nucleus is ejected

Karyogamy - 'fusion' of nuclear membranes

Parthenogenesis - development of an egg without plasmogamy or karyogamy with a sperm

Plasmogamy - fusion of cellular membranes

Polyspermy - more than one sperm participates in plasmogamy with one egg

Sex - any form of meiosis and/or karyogamy 


\section{Chapter 1: Introduction}

Although many sexual organisms are amphimictic (karyogamy of egg and sperm nuclei from two separate diploid individuals), other modes of sexual reproduction occur more often than many biologists realize. Self-sexual parthenogenesis (including restitutional and complete automixis) is extremely common, occurring in thousands of species across almost all phyla, gynogenesis (plasmogamy between egg and sperm followed by the rejection of the male nucleus) though less common, occurs in about 60 species, and is wide spread across 7 phyla, and androgenesis (plasmogamy between egg and sperm followed by the rejection of the female nucleus) occurs in 3 species, each in distinct phyla (Beukeboom and Vrijenhoek, 1998, Pichot et al., 2001, Komaru et al., 1998, Mantovani and Scali, 1992). Gorelick and Carpinone (2009) believe that obligate apomixis does not exist. I therefore define sex as meiosis and/or karyogamy and limit my study to sexual forms of reproduction. Parthenogenesis, gynogenesis, and androgenesis may be facultatively apomictic in some lineages. However throughout this thesis, I am referring to automictic reproduction, unless otherwise indicated.

The individuals that I study are haploids, specifically nuclei inside gametes. I call haploid nuclei individuals following the notion put forth by Gorelick (unpublished manuscript), which argues that mitosis circumscribes individuals and sex demarcates new individuals. New individuals are created via both meiotic and karyogamic events in which there is invariably an associated epigenetic reset. Furthermore, in chapter two I show that haploid nuclei inside an egg cell are capable of independent actions, and are the crucial evolutionary unit, upon which selection acts.

How do the functions of males evolve over time? The fundamental functions of 
sperm can vary greatly from species-to-species, with (1) some depending on sperm solely to restart egg meiosis (i.e. automictic gynogens), (2) some depending on sperm to restart meiosis, restore ploidy, provide organelles, and to supplement turned-off alleles vis-à-vis imprinting (i.e. some amphimicts), and (3) some depending on males to donate their entire genome to the next generation, with no genetic contribution from females (i.e. androgens). I will examine how these varying modes of reproduction work and how they have evolved from one another.

Although reproduction may facultatively occur without meiosis (apomictically), my research encompasses exclusively sexual (meiotic; usually automictic) reproduction. Sex can be cryptic. Having offspring that are identical to a parent (clones) does not mean having no sex (no meiosis nor karyogamy) (Solari, 2002, Gorelick and Carpinone, 2009, Lahr, et. al., 2011). Furthermore, Gorelick and Heng, (2011) argued that automictic offspring are relatively more identical to their parents than are apomictic offspring. Automixis creates new individuals that are essentially identical to parents via one of several modes: (1) homozygous restitutional automixis (following meiosis a haploid nucleus doubles it's chromosomes), (2) heterozygous restitutional automixis (chromosomes are doubled before meiosis and crossing over occurs between identical pairs of chromosomes; aka premeiotic doubling), or (3) complete automixis (two haploid products from the same meiosis participate in karyogamy, offspring become more similar to parents over several generations). Figure 1.1 depicts these modes of restoring diploidy in parthenogens. 


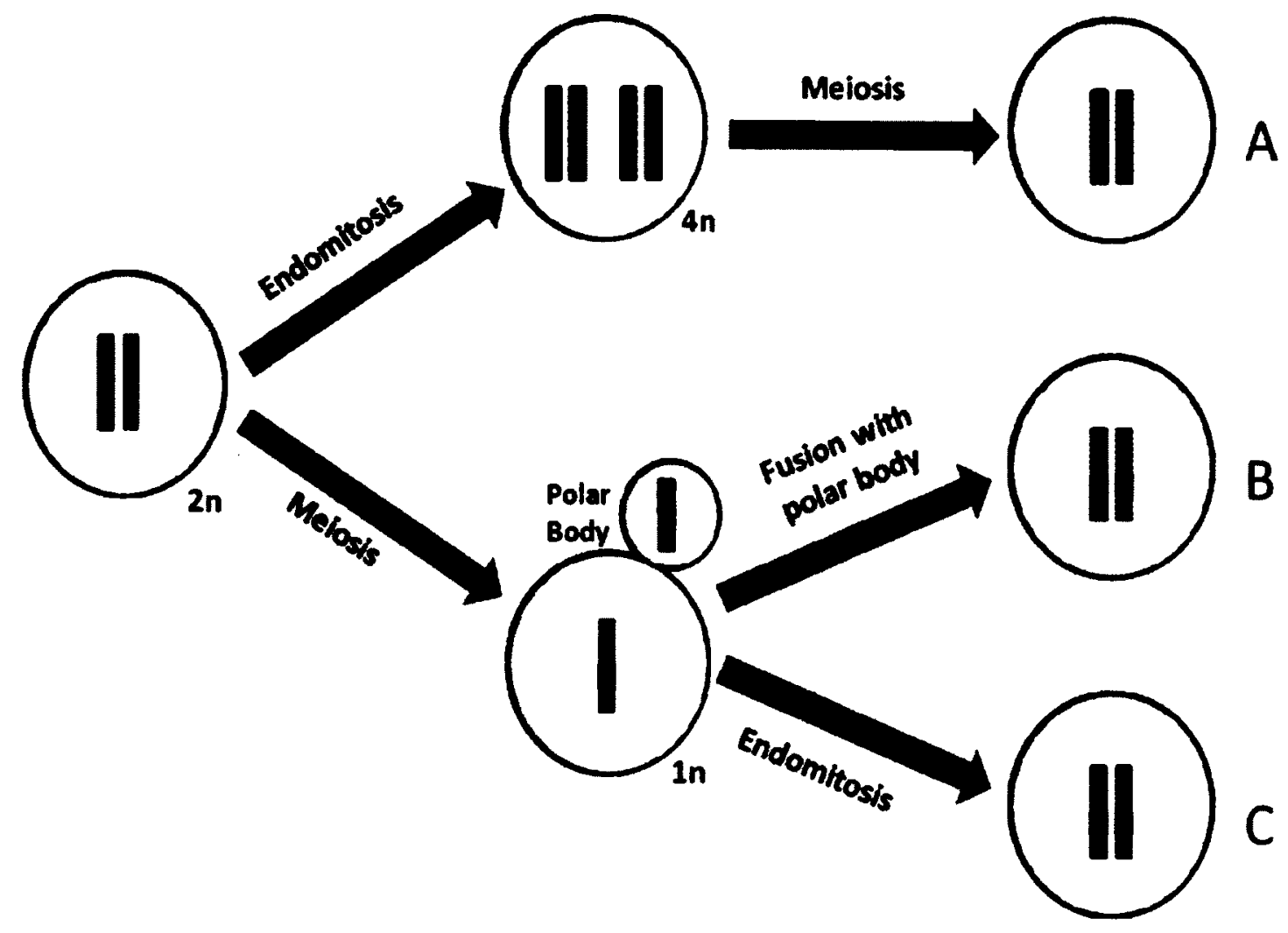

Figure 1.1: Restoration of diploidy in automictic parthenogens. Because of the cyclic nature of sex, heterozygotic and homozygotic restitutional automixis are essentially the same processes, except for intervening mitotic divisions. Circles represent nuclear membranes, grey and black rectangles represent chromosomes.

$\mathrm{A}=$ Heterozygotic restitutional automixis (pre-meiotic doubling)

- endomitosis followed immediately by meiosis

- offspring are heterozygous and identical to parent because sister chromosomes pair during crossing over so identical pieces are exchanged

$\mathrm{B}=$ Complete automixis

- meiosis followed immediately by karyogamy between two haploid products of the same reduction division

- offspring are heterozygous and different from parent

$\mathrm{C}=$ Homozygotic restitutional automixis

- meiosis followed immediately by endomitosis

- offspring are homozygous, therefore different from parent

- same as haplo-selfing (Knop, 2006) where after meiosis is complete, the haploid undergoes mitosis and the two daughter cells fuse. 
This thesis contains chapters on (1) defining males and females, (2) sexual selection inside an egg cell, and (3) evolutionary relationships of amphimixis, gynogenesis, and parthenogenesis. In chapter one, I discuss myths surrounding traditional definitions of males and females. I deconstruct previously proposed definitions of the sexes on both the diploid and haploid level and outline hypotheses that explain why maleness and femaleness only truly exists in haploid nuclei, at least for metazoans. This helps answer the question whether two sexes (anisogamy) evolved multiple times. Because I hypothesize that two sexes can only be distinguished in haploids, we should be able to find examples of haploid sexual selection. Therefore, in the subsequent chapter, I hypothesis that sexual selection occurs between haploid nuclei within an egg cell, looking at examples from sexual polyspermy, gynogenesis, amphimixis, parthenogenesis, and androgenesis. I investigate the requirements for pre-karyogamic sexual selection and apply existing theory of diploid sexual selection to sexual selection between haploid individuals inside an egg cell (roughly egg and sperm nuclei). In chapter three, I investigate the alternative haploid mating system of gynogenesis, where the egg nucleus rejects all sperm nuclei within the egg cell. I hypothesize that gynogenesis is an evolutionary bridge between ancestral (in the case of metazoans) amphimixis, and derived parthenogenesis and hypothesize that gynogens rely on sperm for the sole purpose of stimulating the resumption of arrested meiosis. For the remainder of this introduction, I provide a few more details about the three chapters.

In chapter one, I ask does femaleness and maleness actually exist, or is the notion of sex purely a social construct? I searched for universal differences between the sexes 
that can be used to define what it means to be male or female in all eukaryotes. It seems impossible to establish a universal feature of what it means to be male or female in diploid metazoans, or even just in humans (Fausto-Sterling, 2000). I therefore turned to haploid individuals. In the case of metazoans, this means roughly egg and sperm nuclei. Traditionally, sperm have been defined as short-lived, flagellated, small, and abundant; while eggs are the opposite (Bell, 1978). Yet, upon further inspection, these differences can be discounted. I hypothesize three differences between the haploid sexes. First, haploid sexes are distinguishable based on whether the meiosis that created them is symmetrical or asymmetrical. As far as known, male meiosis always results in four equal-sized sperm (symmetrical), while female meiosis results in one egg and two, or sometimes three, polar bodies (asymmetrical) from a single cell. Second, only sperm nuclei lack nuclear pores. Third, because of this lack of pores, only sperm shed their nuclear membrane without chromosomal duplication, forming a new "pro-nuclear membrane" out of egg endoplasmic reticulum.

Universal characteristics separating haploid males and females allow us to determine whether anisogamy has evolved more than once. Although it is generally believed that two sexes have evolved multiple times across taxa (Bell, 1978, Gorelick, 2003), supported by the anti- essentialist views for diploids presented in this chapter, I hypothesize that there may be universal differences between males and females that all haploid metazoans share, which, if supported, implies that the two sexes (anisogamy) evolved only once in metazoans.

In chapter two, I propose post-plasmogamic, pre-karyogamic sexual selection. When discussing sexual selection, biologists generally focus on pre-copulatory sexual 
selection (diploid mate selection) and pre-plasmogamic selection (typically cryptic diploid female selection of haploid sperm) (Darwin, 1871, Parker, 1970, Thornhill, 1983). However, as discussed in chapter one, universal sex differences do not exist in diploid metazoans, but may exist in haploids. What happens when these haploid female and male individuals interact within an egg following plasmogamy, but before karyogamy? I propose there is a third level of sexual selection occurring, postplasmogamic, pre-karyogamic selection, which is haploid mate selection within an egg. Here the "individuals" are haploid nuclei.

I devised necessary conditions for pre-karyogamic sexual selection and developed two hypothesized mechanisms of choice, i.e. traits a male nucleus must possess in order to better his chances of being chosen by a female. For pre-karyogamic sexual selection to occur, two requirements must be met: (1) female and male nuclei must be able to behave independently, not be under the same controls, and (2) there must be detectable differences between male pro-nuclei on which haploid female nuclei can base a decision. I hypothesize two ways male nuclei may differ from one another. First, males may differ in the proportion of male membrane retained during pro-nuclear formation. I call this the Trojan sperm hypothesis because males seemingly disguise themselves as females to become more attractive. Second, males may differ in the way they advertise their worth to females using mRNA signals. I call this the good haploid genes hypothesis. If differences between haploid females and males are fairly subtle, as I showed in chapter one, then pre-karyogamic sexual selection has the potential to occur whenever there is karyogamy. Amphimicts, gynogens, androgens, and parthenogens (recall that I am only considering automictic ones) can all have multiple female and male nuclei within their 
eggs (parthenogens have only female nuclei), between which karyogamy can occur. Every possible combination of karyogamy between two haploid nuclei occurs in nature: two female nuclei fuse in some gynogens and parthenogens, two male nuclei fuse in some androgens, and a male and a female nucleus fuse in amphimicts. If pre-karyogamic sexual selection occurs, plants, fungi and other taxa that have little or no pre-copulatory sexual selection may exhibit a great deal more sexual selection than previously thought, e.g. in sessile taxa.

If there are only minute differences between female and male haploids and if all haploids can participate in karyogamy with one another regardless of sex, why do we not see more variation in reproductive mode within lineages? In chapter three, I propose that gynogenetic lineages are not evolutionarily short-lived (cf. Schlupp, 2005). In gynogenesis, both sexes incur many of the traditional costs of sex, although no male DNA is passed on to future generations (Figure 1.2). I propose that gynogenesis is identical to amphimixis except with respect to the origin (female or male) of the nucleus that is rejected prior to karyogamy. I hypothesize that gynogenesis is as an evolutionary stepping-stone from amphimixis to automictic parthenogenesis. Note how Figures 1.1 and 1.2 are identical except for the sperm cell that only is used to restart paused egg meiosis. In gynogens, the female nucleus chooses to either fuse with another female nucleus (its polar body or polar nucleus, as in complete automixis) or restore ploidy with no karyogamy (either heterozygous or homozygous restitutional automixis). As mentioned in chapter two, this could be an example of pre-karyogamic sexual selection.

If gynogens are really an evolutionary intermediate between amphimixis and parthenogenesis, they should have close relatives that are both parthenogenetic and 
amphimictic. In chapter three, I test this hypothesis by collecting phylogenetic data on all gynogenetic animals and related parthenogenetic lineages.

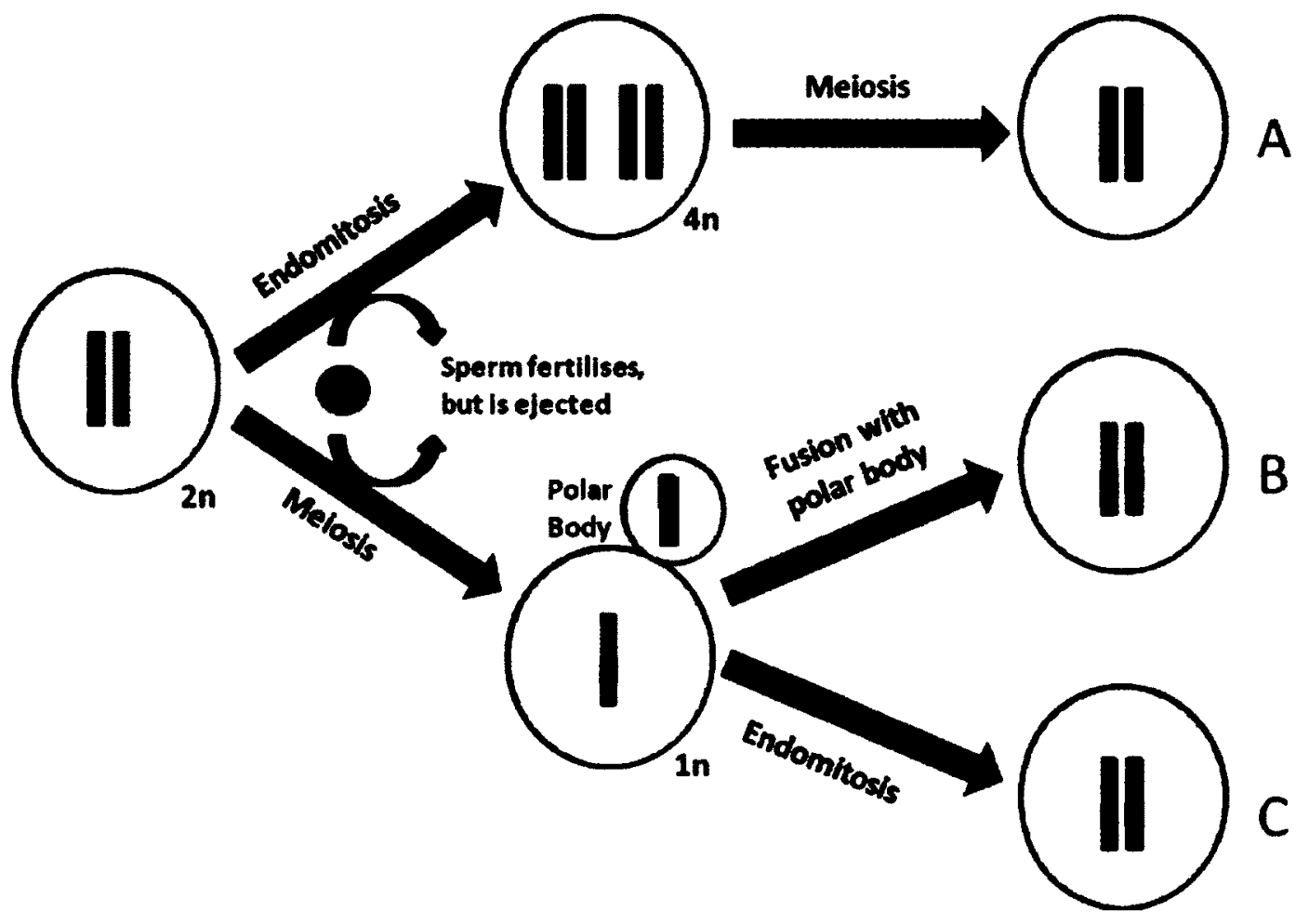

Figure 1.2: Restoration of diploidy in automictic gynogens. These processes are identical for parthenogens and gynogens except that gynogens have a sperm fertilize the egg prior to meiosis (plasmogamy without karyogamy). Circles represent nuclear membranes, grey and black rectangles represent chromosomes.

A = Heterozygotic restitutional automixis (pre-meiotic doubling)

$\mathrm{B}=$ Complete automixis

$\mathrm{C}=$ Homozygotic restitutional automixis 


\title{
Chapter 2: Fundamental differences between females and males?
}

\begin{abstract}
:
All well known putative differences between females and males are ambiguous or with many exceptions. There is no female-male dichotomy when looking at individuals who have two or more copies of each chromosome per nucleus (diploid) because there are many hermaphroditic species, intersex individuals, and species with environmental sex determination. Not all males have an intromittent organ, such as a penis. We are diploid anti-essentialists. Even standard female-male differences are illusory when looking at individuals with only one copy of each chromosome per nucleus (haploid), such as animal eggs and sperm. Not all sperm are mobile with flagella, short-lived, small, nor have a Ychromosome. Not all mitochondria nor other membrane-bound organelles are inherited from eggs. However, here we hypothesize four differences between haploid females and males. (1) Sperm are the only cells whose nuclei lack pores in their nuclear membranes. (2) Sperm nuclei uniquely contain certain proteins in their nuclear membranes. (3) Reduction from two-to-one copy of each chromosome per nucleus (meiosis) is always symmetrical in males, but never in females. (4) Eggs, not sperm, are the exclusive source of ribosomes (proteins that translate DNA into proteins). If applicable, the terms female and male fundamentally apply only to haploid cells and nuclei, not to diploid cells and nuclei. None of our four hypotheses has been well tested, hence we are reluctant haploid essentialists.
\end{abstract}


Hence, in regard to that most difficult question, what are the natural differences between the two sexes-a subject on which it is impossible in the present state of society to obtain complete and correct knowledge-while almost everybody dogmatizes upon it, almost all neglect and make light of the only means by which any partial insight can be obtained by it.

John Stuart Mill (1869, pp. 22).

\section{Introduction:}

John Stuart Mill's quote from The Subjugation of Women is as timely today as it was one-and-a-half centuries ago. He approached differences between females and males from a purely human perspective, focusing on political science and psychology. From a modern perspective, Mill conflated sex and gender and, possibly for that reason, favoured the role of nurture in the nature-nurture debates. By contrast, Charles Darwin, who was conservative with respect to sex (but very liberal with respect to race), especially in his epic The Descent of Man, and Selection in Relation to Sex (1871), favored nature in the nature-nurture debates. Our purpose is not to rekindle the nature-nurture false dichotomy, which is an unfortunate historical artifact - nature and nurture interact way too much for a meaningful dichotomy. Instead we show that an evolutionary biological perspective can highlight problems with the customary differences between females and males and possibly illuminate previously unsuspected differences.

A definition of females and males should transcend as many species as possible. The act of sex (meiosis), vis-à-vis production of gametes (eggs and sperm) that have half the usual complement of chromosomes, is an ancient phenomenon that evolved before the 
diversification of life into animals, fungi, plants, and protists (single-celled organisms that have nuclei and other internal cell membranes). All animals and plants (by which we mean land plants, such as mosses, ferns, conifers, and flowers) have distinct eggs and sperm. Therefore, biological definitions of female and male should transcend all or most animals and plants.

Standard definitions of female and male when applied to humans are problematic, as anybody studying trans-sexuality and trans-gender can attest. There is simply too much fluidity, plasticity, and variation in human genitalia. We need look no further that the continuum of human phallic lengths to see that clitoris and penis are really the same (homologous) organs (Fausto-Sterling, 2000). The location of the urinary opening is also variable, not always at the tip of the phallus in otherwise unambiguous males and not always near the base of the phallus in otherwise unambiguous females. For humans, Anne Fausto-Sterling (2000) unmasked the female-male false dichotomy, at least for our diploid stage in which every cell nucleus has two copies of each chromosome. After extending her argument to all animals and plants, we then ask whether there is a femalemale dichotomy for individuals with only one copy of each chromosome per nucleus (haploid), which for animals means for eggs and sperm.

Universal differences between the sexes are only expected if the two sexes only evolved once. Multiple independent evolution of two sexes from a single sex would imply that differences between females and males should vary between organisms. With multiple independent origins, is it is fair use the same labels - female and male - for the resulting two sexes? In such instances, terminology would conflate and confound evolutionarily distinct events. Multiple evolutionary origins corresponds with anti- 
essentialism, while single evolutionary origins corresponds with essentialism.

\section{Definitions:}

Our ideas will be easier to understand with the introduction of four technical biological terms describing a lifecycle (see glossary). All sexual organisms other than bacteria undergo the same cyclical process, known as alternation of generations. Begin by considering humans. Each cell nucleus in the zygote, embryo, fetus, child and adult has 46 chromosomes that come in 23 pairs - two copies of chromosome 1, two copies of chromosome 2, etc - one copy inherited from each parent. Such organisms are known as diploid, where the prefix 'di-' indicates that chromosomes come in twos. The diploid organism develops from the single-celled zygote all the way up to an adult by having each nucleus contain 46 chromosomes (a pair of each of 23 chromosomes), duplicating all 46 chromosomes, and then parsing those identical copies equally amongst two new nuclei. This copying process, preserving the number of chromosomes per nucleus, is called mitosis.

The diploid state alternates with the haploid state, in which each nucleus contains one copy of each chromosome. The prefix 'haplo-' means one. In humans and all other animals, haploid nuclei only exist in eggs and sperm (human eggs and sperm contain one copy of each of the 23 chromosomes). Not all haploids are single celled. Some plant stems and leaves can be composed of millions of cells with haploid nuclei, for example, the meter-long moss Dawsonia superba. These moss stems later produce haploid eggs and sperm via mitosis. The process by which an organism goes from diploid to haploid nuclei - i.e. halving the number of copies of chromosomes per nucleus - is called 
meiosis.

There are two ways that an organism goes from a haploid back to a diploid state. The most common way is fertilization, where an egg and a sperm nucleus fuse, thereby restoring two copies of each chromosome. While much rarer, and non-existent in mammals, the diploid state can be restored by a haploid nucleus spontaneously duplicating all of its chromosomes without subsequently parsing the chromosomes between two different nuclei.

\section{Deconstruction:}

We first examine traditional characterizations of female-male dimorphism, showing how these differences between the sexes break down in many instances. For a similar exposition applied to humans see Fausto-Sterling (2000). We first look at macroscopic and microscopic differences between diploid parts of the lifecycle. The macroscopic differences encompass genitalia, whereas microscopic differences encompass sex chromosomes $(\mathrm{XY})$ and inheritance of portions of cells that are enveloped by internal membranes, such mitochondria and chloroplasts. None of these circumscriptions of female and male work; many of these even fail in mammals.

Alternatively, assuming that eggs and sperm are well defined entities, we could try defining females as individuals that only produce eggs and males as individuals that only produce sperm. However, as Myra Hird (2006) has elegantly detailed, there is way too much transsex - such as temperaturedependent sex determination and sequential hermaphroditism - to make these 
viable definitions, something brought home beautifully by Isabella Rossellini's video vignettes under the umbrella Green Porno (www.sundancechannel.com/greenporno).

Instead of looking at diploid individuals, maybe we would be better off looking at haploid individuals. For animals, this relegates us to the world of eggs and sperm, while plants have huge multi-cellular haploid parts. Nonetheless, conventional female-male dichotomies fail here too. The notions of eggs as large, rare, immobile, passive, longlived entities and sperm as small, ubiquitous, mobile (with flagella), short-lived entities is incorrect in too many instances. What follows are details about female-male false dichotomies in both the diploid and haploid stage.

\section{Sexual differences in diploid individuals}

A penis or lack thereof does not distinguish males from females. In mammals, clitoris and penis are essentially the same organs. Anne Fausto-Sterling (2000) has done an extraordinary job detailing the false dichotomy between the sexes in humans, especially in light of the huge number (one-in-sixty) of intersexuals. While the typical human clitoris is shorter than the typical penis, some women have a clitoris that is sufficiently long to be used as an intromittent organ that can be inserted into female genitalia. It is more difficult to distinguish human females from males than it is in most other mammals because human males lack a penis bone, aka baculum. But not all male vertebrates have an intromittent organ. Male birds (except ducks) and amphibians lack any organ resembling a penis. Then there are some species in which males have a penis, but it is detachable: cephalopod (squid, octopus, etc) hectocotyli, Malabar ricefish 
spermatophores, and banana slugs in which one copulating partner gnaws off the other's penis. Seed plants have pollen, which is a detachable penis that grows through female tissues to deposit sperm near an egg. External genitalia are not a consistent difference between females and males across plants and animals, we will therefore have to look for more microscopic differences.

Female mammals (except for platypus and echidnas) have a pair of X chromosomes, while males have one $\mathrm{X}$ and one $\mathrm{Y}$ chromosome, with $\mathrm{Y}$ being shorter than $\mathrm{X}$. This is in diploid individuals. By contrast, mature mammalian eggs only have one $\mathrm{X}$ chromosome and sperm have either an $\mathrm{X}$ or $\mathrm{Y}$ chromosome. In birds, females are the sex with unequal length sex chromosomes, with $\mathrm{W}$ shorter than $\mathrm{Z}$. Male birds have two $\mathrm{Z}$ chromosomes. Different length sex chromosomes in either females or males is, however, very unusual, only occurring in mammals, birds, a few reptiles, a few insects, and a few plants. Almost all diploid animals and plants have both sex chromosomes of equal length, rendering this an unacceptable way to distinguish females from males.

Mitochondria - the metabolic power plants inside cells - are often said to be exclusively inherited from females, providing a way to distinguish female from male parents. While a better criterion than any of the ones we have thus far discussed, there are still lots of exceptions. Many plants inherit mitochondria from both parents, many from just their female parent, many others just from their male parent. Mitochondrial inheritance patterns are largely maternal in animals, with the primary exceptions seen in mollusks with doubly uniparental inheritance, known as DUI (Zouros et al., 1992). Female DUI mollusks inherit all their mitochondria from their female parents. Male DUI mollusks have most tissues in which mitochondria are from their female parent, as 
is typical, but their gonads have mitochondria from their male parent. Looking at diploid individuals will not allow for unambiguous differentiation of females and males.

Plus, as we will see below with ribosomes, determining sex by asking about inheritance of subcellular parts is not very practical insofar as requiring examination of individuals in two generations and being certain about parents of each offspring.

Maybe we would have better luck by simply defining females as individuals that produce eggs and males as individuals that produce sperm (Blute, 2010). While a seemingly simple solution, this also has major problems. What sex is a hermaphrodite, who either simultaneously or sequentially produces both eggs and sperm? What sex are fish, such as members of the genus Gobiodon, which includes the coral gobies, that can change from producing sperm to producing eggs back to producing sperm based on environmental cues, such as number of nearby individuals of the species producing eggs or sperm (Nakashima, et. al., 1996)? What sex should we call the many animals with environmental sex determination, such as turtles and crocodiles, who produce ovaries and eggs if as juveniles they are raised at one temperature, but who produce testes and sperm if raised at a different temperature?

There is no viable way to define the sexes for diploid plant and animal individuals. We therefore shift gears and ask whether there is such a thing as female and male haploids, including sperm and mature eggs.

\section{Sexual differences in haploid individuals}

Conventional wisdom holds that all eggs and sperm are haploid and that eggs and sperm can be readily distinguished. However, this is wrong. While most sperm are 
haploid, with very few exceptions, many eggs have additional copies of each chromosome (and so maybe should not be called gametes?). In almost all animals, egg nuclei start out with two copies of each chromosome, double that to four copies, and then later halve this to two copies and finally halve this again to become haploid (meiosis: $2 n \rightarrow 4 n \rightarrow 2 n \rightarrow 1 n$, where $n$ represents the base number of chromosomes, e.g. $n$ $=23$ in humans). This fluctuation in number of copies is a normal part of the process meiosis - that transitions organisms from diploid to haploid. In almost all animals except sea urchins and jellyfish (and their relatives), this process is arrested at some point in the process, before there is one copy per nucleus, and the process is only restored and completed once an egg is fertilized by a sperm (Austin, 1965).Thus, except in sea urchins and jellyfish, animal egg nuclei have either two or four copies of each chromosome when fertilized by a sperm whose nucleus has only one copy of each chromosome.

Even exempting sea urchins and jellyfish, requiring fertilization to halve their number of chromosomes is not a defining trait of females because there are many parthenogenetic (virgin birth) animals whose eggs complete meiosis without fertilization by sperm. In many animal groups, there exist a few species whose females manage to reduce their number of chromosomes down to one copy without fertilization. These individuals then take two of the four products of egg meiosis - namely an egg cell and a polar body - and fuse these together to form a diploid zygote.

In all plants, eggs and sperm are haploid at the time of fertilization, but this is largely because the process of halving chromosomes (meiosis) occurs long before production of eggs and sperm. Plants produce a large multi-cellular stage in which 
every nucleus is haploid. It is from this stage that egg and sperm are later produced via mitosis. Sometimes a given haploid plant will produce only eggs, sometimes only sperm, and sometimes both. As with diploid animals, haploid plants can thus be female, male, or hermaphrodite. Consequently, instead of asking whether haploid individuals are female or male, we will have to ask whether there are any fundamental and universal differences between eggs and sperm.

Before leaving the topic of sex differences between haploid individuals, we would be remiss to not presage that this tack does lead to one universal sexual difference: asymmetry (female) versus symmetry (male) in meiosis. We defer discussion of this topic to the section on criteria that may work universally for distinguishing females from males.

Sex differences between eggs and sperm

Eggs are usually conceived of as large, passive, immobile, uncommon, and longlived and sperm as small, active, mobile (propelled by flagella), common, and shortlived. Unfortunately, none of these generalities are universally true. Below, we devote a short paragraph to each of these false dichotomies.

Humans are typical in that eggs are few, large and very long-lived, while sperm are many motile, and short-lived. Most eggs are produced prior to birth in humans, i.e. they live for roughly a quarter to half a century - whereas sperm live for no more than one week. But sperm movement is not as efficient as many believe, largely moving from side-to-side (not forward) via their flagella (Martin, 1991). Eggs also travel substantial distance, through 
fallopian tubes.

In some species, sperm are giant (Matzke-Karasz, 2005). Some insects and cone-bearing seed plants produce enormous sperm with flagella. In these cone-bearing plants, sperm have thousands of flagella and grow to many times larger than the pollen grain that carried them to the female cone. In some small fruit flies (Drosophila), sperm are twelve times longer than the adult animals (Pitnick, et. al., 1995). On the other hand, insects with giant sperm usually produce very few sperm.

In some insects, males produce about the same number of sperm cells as females produce egg cells. Some species of ants produce colonies of several million individuals. A newly emerged (virgin) queen goes on a single mating flight during her lifetime, in which she mates with several males. She then lands on the ground, chews off her wings, and starts digging an underground colony from which she will never emerge and certainly never go on another mating flight. Over the next decade or two, she will form millions of eggs and fertilize them with the sperm that she stored from her one mating flight. Not only do these females produce roughly the same number of eggs as males produce sperm, but the sperm are longer-lived than the eggs.

Many animal and plant species have sperm that lack flagella. Flowering plants and conifers have sperm that lack flagella and are not independently motile. Their sperm are carried to the egg cell by the growing pollen tube, the erect detachable penis that grows through hollows in the female's tissues. Many groups of animals have amoeboid sperm, lacking flagella (Morrow, 2004), including species of segmented worms, round worms, flat worms, crustaceans, spiders, insects, and even one group of fish, the freshwater elephant fish. While amoeboid sperm are somewhat mobile, they are very different 
looking from sperm with flagella.

While sperm may seem more active than eggs, their nuclei are not. After fertilization, sperm nuclei are passive, but egg nuclei are not. Sperm nuclei - of which there may be many per egg cell in many species - are relatively sedentary once inside of an egg cell. By contrast, egg nuclei of at least one species of comb jelly (Beroe ovata) move about their own cytoplasm, querying other nuclei about suitability for fusing (Carre and Sardet, 1984). The path of the egg nucleus is very directed.

Thus far we have briefly debunked all the common female-male dichotomies... or at least showed that these dichotomies are only applicable to small subsets of species, certainly not all animals and plants. It turns out that there may be universal ways to distinguish females from males, but these other dichotomies, if they exist, will be highly nuanced, taking a highly magnified and well-trained eye to possibly differentiate females from males.

\section{Reconstruction:}

We hypothesize four fundamental differences between females and males, which only work for haploid individuals. First, only females contribute the subcellular machinery (ribosomes) responsible for translating DNA into proteins. Unfortunately this requires us to keep track of inheritance between subsequent generations, which is not a convenient way to

distinguish the sexes. Second, during the process of meiosis, both females and males go from one diploid nucleus to four haploid nuclei, however, in females, this cell division is always asymmetrical; in males it is always symmetrical. Third, only sperm have nuclei 
without any pores. All other cell nuclei have pores. Sperm nuclei also have some unique proteins and genes. Fourth, only sperm replace their nuclear membrane (without pores) without any chromosomal replication, replacing it with a membrane that has pores. Below, we devote a paragraph or two to each of these four hypothesized ways of distinguishing females from males. However, note that there is still a paucity of corroborative evidence for each hypothesis.

In most species, eggs are large and sperm are small. When there are exceptions, it turns out that sperm are relatively large, while eggs are still the relatively large cells that exist in all related species. This implies that there may be a reason for eggs being large. The difference in size is probably not due mitochondria or chloroplasts because inheritance of these organelles is not strictly maternal, and when these organelles are inherited paternally, eggs are still relatively large and sperm relatively small. The egg supplies the next generation with lots of cytoplasm, including all the biochemical machinery needed to carry out most metabolic functions. This includes internal membranes (endoplasmic reticulum) and ribosomes on many of those membranes. Ribosomes are huge globs of protein and RNA that translate the genetic code into proteins. Tinker with cellular machinery other than nuclei and mitochondria, such as ribosomes, and you can get a radically different organism. We hypothesize that ribosomes are strictly inherited from the maternal parent (egg), although new ribosomes are later made under control of the zygote's or embryo's DNA and hence may then have paternal contributions. This will confound using these cellular components as a defining characteristic of females versus males. A more operational way of defining the sexes would be helpful. 
We hypothesize that in males, meiosis is always symmetrical; in females, meiosis is always asymmetrical. In males, a nucleus with two of each chromosome undergoes a replication of each chromosome (up to four copies) followed by two successive partitions of those copies into four separate nuclei in separate cells. We hypothesize that the four male cells and four male nuclei are completely symmetrical and all completely functional. Females also undergo meiotic divisions, however, the four nuclei may be in one, two or four cells; the cells may be of different sizes from one another; and only one of the nuclei will go on to form the next generation. Occasionally two nuclei go on to the next generation in which case it is always because these two fuse with one another, rather than a sperm nucleus.

We briefly discuss one apparent exception to the previous paragraph, which on closer inspection turns out not to be an exception. Some plants with so-called tetrasporic meiosis seem to have somewhat more symmetrical meiosis, but even here meiosis is fundamentally asymmetrical. Tetrasporic meiosis results in one cell containing four haploid nuclei (Yadegari and Drews, 2004). However, one of these nuclei migrates to one side of the cell and will eventually give rise to an egg cell. Another nucleus moves towards the center of the cell and will eventually give rise to nutritional tissue (endosperm; product of double fertilization) that will not be inherited by the next generation. The remaining two nuclei move to the opposite end of the cell from the first cell and are effectively unused after fertilization are not passed along to the next generation. The asymmetry in female meiosis is still evident with tetrasporic species, but is more subtle.

We hypothesize that sperm are the only cells lacking nuclei pores (Iwamatsu, 
2000, Lu et. al., 2006). Most nuclei, including egg nuclei, have pores to allow messenger RNA out of the nucleus. This allows the information of the DNA code held in the chromosomes to be shuttled to the ribosomes, thereby providing a template for protein production. Various signals that turn on and off genes also need to travel in the opposite direction through these nuclear pores, as does DNA itself. When a nucleus replicates, the DNA comes from outside the nucleus. Nuclear pores are not only holes, but also the place where the nuclear envelope is contiguous with the internal cell membranes of the rest of the cell, namely the endoplasmic reticulum. Sperm nuclei are utterly atypical in lacking pores and being quite compact. Messenger RNA cannot leave a sperm nucleus, and chromosomes cannot be replicated in sperm. We do not know of any exceptions. However, the place to look for exceptions may be in sperm of ants in which the female stores mature sperm for a decade or two. Another place to look may be flowering plants whose pollen can stay viable for many decades, especially if the sperm cells have already differentiated in the pollen grain (so-called trisporic, and not bisporic, pollen). Sperm nuclei also contain proteins that only seem to be found in sperm, such as the protein lamin B (Poccia and Collas, 1997) and expression of the gene BOULE (Shah, et. al., 2010). This may be correlated with sperm lacking nuclear pores.

Lack of nuclear pores in sperm poses a quandary after fertilization. In all species in which people have looked, egg and sperm nuclei replicate all their chromosomes before their nuclei fuse with one another to form a zygote nucleus (sand dollars, rabbits, mice, and frogs (Simmel and Karnofsky, 1961, Oprescu and Thibault, 1965, Luthardt and Donahue, 1973, Graham, 1966). We therefore suspect that poreless sperm nuclei have to break open inside the egg cell and have all or a portion of their nuclear 
envelope replaced with a pore-laden nuclear envelope formed from the egg cell's internal membranes, aka the egg's endoplasmic reticulum. Once this occurs the sperm nucleus is called a pro-nucleus. Only then can and does the sperm replicate its chromosomes. This is also an event that is unique to sperm. During all other cell divisions, including meiosis and mitosis, nuclear membranes are only replaced after a replication of all chromosomes (Hartwell and Weinert, 1989). With sperm pro-nuclear formation, membranes are replaced without any intervening chromosomal replication, which occurs immediately after the new membrane is in place (Longo, 1987).

There does not yet exist a corpus of evidence for any of the above hypotheses for female- male differences between haploid individuals. But we also do not know of any evidence to debunk any of these hypotheses.

\section{Concluding remarks:}

How often have two sexes evolved from species with only one sex? For diploids, the standard answer is many times (e.g. Gorelick, 2003). This is completely consistent with utter lack of universal differences between female and male diploid individuals. Remember, multiple evolutionary origins correspond with anti-essentialism.

How often did two sexes evolve at the haploid level? Isogamous and anisogamous literally mean equal gametes and unequal gametes, respectively. Humans are anisogamous because eggs and sperm are different from one another. There are, however, many algae and fungi in which fertilization occurs between gametes that appear to be identical, which is termed isogamous. The first sentence of this paragraph then translates as: how often did anisogamy evolve? The standard answer is many times 
(Bell, 1978, Blute, 2010). However, if any of our four hypothesized universal differences between haploid females and males is supported, then anisogamy probably only evolved once. This both a biologically radical notion and also one that makes us haploid essentialists.

John Stuart Mill and Anne Fausto-Sterling were right: It is not easy telling the two sexes apart. Even though sex change is more difficult in mammals than in many other animals, sexual ambiguity is still prevalent, even in humans. One of our goals is to emphasize that this sexual ambiguity is real. From an evolutionary perspective, any reasonable way of distinguishing females from males fails unless we look at individuals whose cell nuclei are haploid. Thus we cannot distinguish females from males in adult animals, but can only distinguish females from males in animal gametes. Even if an adult (i.e. diploid) individual is naked, their sex is indeterminate. If evolutionary biology provides a cogent way of distinguishing the sexes - and it is not obvious yet if it can then this will require careful examination of single haploid cells and nuclei.

One reason for the ambiguity in distinguishing the sexes is that we insisted that definitions should apply as universally as possible. This forces us to look at some peculiar species, but that is the price that must be paid to come up with a universal and operational definition of the sexes. "Darwin admonished us not to ignore the 'oddities and peculiarities' of life as we see it today. It is by the analysis of such oddities that evolutionary history can be reconstructed." (Margulis and Sagan, 1988, pp. 26). It is also the price that must be paid because separate diploid sexes independently evolved multiple times from hermaphrodites. It is also possible that haploid females and males gametes (anisogamy) evolved independently multiple times from species with only one 
type of gamete (isogamy).

We hypothesize that there exists a female-male dichotomy only when examining haploid individuals. For animals, this means that eggs and sperm are conceptualized as individuals, albeit single-celled haploid individuals that may be dependent upon diploid individuals. For diploid individuals, there is no female-male dichotomy. We are thus diploid anti-essentialists, but reluctantly hypothesize an essentialist view of haploids. There is very little biological evidence in support of and none in opposition to our four hypothesized differences between haploid females and males (nuclear pores; nuclear proteins; symmetry of meiosis; inheritance of ribosomes). Further evidence could readily debunk any or all of these hypotheses. But existing biological evidence leaves us in the uncomfortable position of suspecting that there may be subtle but fundamental differences between haploid female and male individuals. 


\title{
Chapter 3: Post-plasmogamic, pre-karyogamic sexual selection: Mate choice inside an egg cell
}

\begin{abstract}
:
Intersexual selection is often categorized as pre-copulatory or post-copulatory mate choice by individuals of one sex over showy individuals of the other sex. We extend the framework of post-copulatory choice to include post-plasmogamic pre-karyogamic sexual selection. That is, selection of haploid nuclei within the microcosm of a single fertilized egg cell after sperm has entered an egg cell but before fusion of their nuclear membranes, in which an egg nucleus chooses a sperm nucleus with which to fuse. The role of sexual selection at this nuclear level is probably small in monospermic out-crossers, but large in polyspermic out-crossers. Post-plasmogamic pre-karyogamic sexual selection may also explain how the sperm nucleus is rejected in gynogens, and how the egg nucleus is rejected in androgens. We propose that male and female nuclei behave independently within an egg cell, and that post-plasmogamic pre-karyogamic mate choice is largely based on either (1) a pre-existing sensory bias for certain characteristics of the sperm pronuclear membrane, or (2) detection of good genes through signal (mRNA) detection.
\end{abstract}

\section{Introduction:}

Charles Darwin (1871) first introduced the idea of sexual selection to account for the differences in secondary sexual characteristics that could not be explained by natural selection. He defined sexual selection as differential reproductive success that results from variation among individuals in their success at obtaining mates. Darwin (1871) subdivided 
sexual selection into intrasexual selection, where one sex (typically males) competes aggressively with other members of the same sex for access to the opposite sex, and intersexual selection, where one sex (again typically males) competes with each other for the other sex's attention. Intrasexual selection usually results in the evolution of elaborate weaponry, aggressive behaviors, and defensive characteristics, while intersexual selection usually results in the evolution of exaggerated sexual signals and female preferences for those signals (Andersson, 1994). Although Darwin (1871) proposed his ideas to account for elaborate pre-copulatory sexual displays and preferences, his ideas have since been expanded to include forms of post-copulatory choice, such as sperm competition (Parker, 1970) and cryptic female choice (Thornhill, 1983). Sperm competition occurs when sperm from multiple males compete with each other for the opportunity to fertilize an ovum (Parker 1970, Birkhead and Møller, 1998). The result of sperm competition is evolution of male traits that increase the sperm's fertilization success including increased sperm number, increased sperm size, seminal fluids, sperm removal, and copulatory plugs or mate guarding (reviewed by Birkhead and Møller, 1998, Simmons, 2001, Snook, 2005). Sperm competition can be thought of as the post-copulatory (pre-fertilization) equivalent to intrasexual selection.

Cryptic female choice is the post-copulatory equivalent to intersexual selection (Thornhill, 1983, 1984). Eberhard (1996) defines cryptic female choice as the ability of females to consistently favor the copulatory partners that possess a particular trait that is lacking or less fully developed in other males. Cryptic female choice operates at several levels, including dumping sperm from previous mates (reviewed in Eberhard, 1996) and increasing the duration of copulation (Hoikkala and Crossley, 2000, Hoikkala et al., 2000). 
In the post-copulatory reproductive process, cryptic female choice can include increased sperm precedence (Edvardsson and Arnqvist, 2000). Cryptic female choice also operates after zygote formation, including at the egg laying stage (laying more eggs; Barbosa, 2009), at the developmental stage (through differential abortion of embryos; Hull, 1964, Willson and Burley, 1983), at the re-mating stage (enhanced resistance to future mates; King and Fischer, 2005), and at the offspring stage through differential investment into offspring who were sired by different males (Willson and Burley, 1983, Simmons, 1987, Burley, 1988, Eberhard, 1996,).

Here we extend this framework of sexual selection to include post-plasmogamic pre-karyogamic cryptic female choice of haploid nuclei within the microcosm of a single egg cell after entry of the sperm nucleus or nuclei into the egg (after plasmogamy), but before fusion of the egg and sperm nucleus (before karyogamy). Technically, egg and sperm nuclei (or pro-nuclei) do not usually fuse with one another, but instead their two nuclear membranes dissolve and are replaced with a single new nuclear membrane. Nonetheless, we will use the common vernacular of referring to karyogamy as nuclear or pro-nuclear fusion. We propose that in polyspermic outcrossers (multiple sperm nuclei within one egg), egg nuclei may be able to consistently favor sperm that possess a particular trait that is lacking or less fully developed in other sperm. Post-plasmogamic pre-karyogamic female choice within the microcosm of an egg cell would occur if the egg nucleus were to move about the cell and discriminate between multiple male nuclei before selecting one to fuse with. We hypothesize that this intersexual post-plasmogamic prekaryogamic choice may regularly occur in polyspermic out-crossers based on tantalizing evidence from ctenophores (comb jellies; Carré and Sardet, 1984). While it is theoretically 
possible for intrasexual selection and choice to exist inside an egg cell, conspicuously we do not see evidence for male-male nor female-female interactions within this egg microcosm.

Post-plasmogamic pre-karyogamic sexual selection has been very briefly mentioned by Tim Birkhead, but never fully developed. Birkhead (1998) includes a paragraph alluding to the possibility of post-plasmogamic pre-karyogamic sexual selection based on the intriguing work of Carré and Sardet (1984), which we also discuss below. Even more explicitly, albeit more succinctly, Birkhead and Brillard (2007) include two sentences on pro-nuclei choosing one another. A recent review of egg-sperm interactions (Karr et al., 2009) mentions nothing about post-plasmogamic pre-karyogamic sexual selection except to say that sperm nuclei may emit mRNA that egg nuclei can detect. None of the other major reviews of post-copulatory sexual selection or sexual choice-such as Eberhard (1996), Simmons (2001), Pizzari and Birkhead (2002), or Arnqvist and Rowe (2005) allude to anything even remotely resembling post-plasmogamic pre-karyogamic sexual selection. Therefore, in this paper, we develop the theoretical framework by which postplasmogamic pre-karyogamic female choice of haploid nuclei may occur. We present evidence showing the conditions of the framework, including independently behaving nuclei and differences between nuclei within an egg cell, especially with polyspermy. We also show how post-plasmogamic pre-karyogamic sexual selection may explain how the sperm nucleus is rejected in gynogens, and how the egg nucleus is rejected in androgens. And, finally, we briefly discuss how post-plasmogamic pre-karyogamic choice may make sexual selection more common than originally thought. 


\section{Post-plasmogamic pre-karyogamic sexual selection has the potential to exist:}

Two requirements must be met in order for post-plasmogamic pre-karyogamic sexual selection to occur. First, nuclei must be able to behave independently. Based on differences between egg and sperm nuclei in (1) presence of pores, (2) timing of nuclear membrane breakdown, and (3) timing of duplication and reduction events, we argue that male and female nuclei are controlled separately by nuclear rather than cytoplasmic factors. Because of this differential control between the two haploid sexes, egg nuclei may have the ability to choose sperm nuclei. Second, there must be detectable differences between sperm nuclei for post-plasmogamic pre-karyogamic female choice to have selective consequences. We argue these detectable differences are based on either the proportion of original male membrane that is replaced during pro-nuclear formation and/or differential mRNA signals (see Karr et al. 2009 and references therein, which we discuss below).

Can different nuclei within a single egg cell behave independently?

To consider selection inside an egg cell, we first must establish whether the nuclei inside an egg cell behave individually. If the nuclei inside an egg - both egg and sperm nuclei-are all controlled in the same manner by egg cytoplasmic factors, it would be inaccurate to characterize the male and female nuclei as being capable of independent actions and selection. Mate choice requires independent control by one individual doing the choosing and another individual being chosen, where the individuals here are haploid nuclei.

When the timing of chromatin condensation and decondensation, and the timing of 
nuclear envelope breakdown of the egg and sperm nuclei are considered, it becomes apparent that nuclei and pro-nuclei within an egg cell do in fact behave as individuals. In outcrossing animals, sperm almost always inseminate the egg at an arrested stage of meiosis (Wilson, 1925, Austin, 1965). The stage at which meiosis is arrested varies depending on the taxon; most vertebrates are arrested at metaphase II of meiosis at the time of plasmogamy (fusion of cellular membranes). At plasmogamy, egg chromosomes are condensed and lined up at the metaphase plate. When a sperm enters an egg, the sperm nucleus almost immediately undergoes a dispersal of its chromatin, while egg chromatin remains condensed (Longo, 1987, Wright and Longo, 1988). Wright and Longo (1988: 155) noted, "The sperm nucleus undergoes dispersion following its incorporation, resulting in a significant expansion of its volume. Concomitantly, the maternal chromatin, which is condensed, completes meiosis. How the paternal and maternal genomes are regulated to undergo such divergent processes, dispersion versus condensation, within a common cytoplasm has not been determined." Both male and female nuclei in the same cytoplasm act independently with respect to when their nuclear envelopes breakdown and their chromosomes decondense. We propose that the divergent processes of the egg and sperm nuclei prior to karyogamy can be explained by the presence/absence of nuclear pores. Because the sperm nucleus lacks pores upon plasmogamy, it can behave independently of the egg's cytoplasm.

We assert that sperm and egg nuclei act as truly separate individuals in that they are under separate (nuclear) control, as opposed to cytoplasmic control. It is important to note that sperm nuclei are usually only effective at karyogamy if they form a pro-nucleus. The process of pro-nuclear formation encompasses the breakdown of the poreless male nuclear 
membrane followed by the reformation of a new nuclear membrane composed mostly of porous female endoplasmic reticulum material. This event is the only instance in nature when nuclear membrane breakdown occurs in the absence of chromosomal reduction or duplication. We reject the usage of the term "pro-nucleus" to describe the egg nucleus prior to karyogamy because, unlike sperm nuclear envelopes, the egg nuclear envelopes only are replaced as part of a nuclear division, a parsing of half the chromosomes into two separate nuclei (Longo, 1985). The fact that the only place that nuclear envelope breakdown is ever observed prior to DNA replication occurs in males during pro-nuclear formation, shortly after it enters into the egg, confirms how sperm nuclei are able to evade the egg's cell cycle control. After, or sometimes during, chromatin dispersion, the sperm sheds its nuclear membrane (Longo, 1985). Normally, the tight constraints of the cell cycle, specifically the G2/M-phase checkpoint, would not allow for nuclear envelope breakdown to occur prior to DNA replication (Hartwell and Weinert, 1989, Murray, 1992, Sluder et al., 1995). However, the sperm evades the egg's intrinsic controls, likely because of its poreless membrane.

While formation of the sperm pro-nucleus is probably mediated at least in part by cytoplasmic factors originating from the egg's germinal vesicle (Moriya and Katagiri, 1976, Skoblina, 1976), a male pro-nuclear growth factor is also thought to exist (Thibault and Gérard, 1973, Motlik and Fulka, 1974, Trounson et al., 1977). Nuclear envelope breakdown is under cytoplasmic control in mitotic and meiotic cell divisions. Mitosispromoting factor is a cytoplasmic factor that normally drives a cell into a division by forcing nuclear envelope breakdown. However, this is not the case for pro-nuclei within an egg. Nuclear envelope breakdown of the male pro-nucleus and the female nucleus is under 
nuclear, not cytoplasmic, control (Sluder et al., 1995). Thus, from the time of sperm entry, to the formation of the sperm pro-nucleus, to the breakdown of the pro-nuclear envelope, sperm nuclei are under different controls from egg nuclei.

The fact that male and female nuclei are controlled separately within a single egg cell is essential to recognize if a discussion of post-plasmogamic pre-karyogamic sexual selection is to take place.

Do nuclei within a single egg cell have detectable differences?

For post-plasmogamic pre-karyogamic sexual selection, there must be some kind of detectable differences between male nuclei/pro-nuclei upon which a choosy egg nucleus can make a choice. We propose that differences between the multiple sperm nuclei/pronuclei in an egg cell may reside in the nuclear envelopes of the sperm pro-nuclei or in the signals sperm pro-nuclei send.

We hypothesize that sexual selection within an egg is most likely to occur when there are multiple sperm pro-nuclei within an egg cell, i.e. polyspermy. Polyspermy occurs in a wide variety of taxa including birds, reptiles, elasmobranch fishes, urodele amphibians, mollusks, arachnids, insects, bryozoans, and ctenophores (Nelson ,1953, Rothschild, 1954, Wourms, 1977, Carré and Sardet, 1984, Iwamatsu, 2000). Polyspermic organisms have evolved one or more mechanisms to allow multiple sperm, sometimes well over twenty and occasionally hundreds of sperm (Dean, 1906), to participate in plasmogamy with a single egg, yet still only allow one male pro-nucleus to participate in karyogamy with the female nucleus. Although it is often assumed that female nuclei simply fuse with the closest male pro-nucleus in polyspermic situations, there is strong 
evidence to suggest otherwise. In at least one species of comb jelly (Beroe ovata), the female nucleus within the polyspermic egg does not fuse with the first male nucleus that enters the cell, nor does it fuse with the closest. Instead, upon plasmogamy, the female Beroe ovata nucleus migrates within the egg cell-from male pro-nucleus to pronucleus - before finally fusing with just one (Carré and Sardet, 1984). The only data showing a female nucleus querying of multiple male pro-nuclei comes from this one species of comb jelly, and the purpose of this migration is unknown.

Why does the female not simply fuse with the closest male pro-nucleus or the male pro-nucleus that enters the cell first? This question is really the same as the more general one that has plagued evolutionary biologists for decades: why should females be choosy when they receive no obvious benefits from males except for their genetic contribution? Based on existing well-developed hypotheses for the evolution of female preference, we propose two hypotheses as likely candidates to explain evolution of post-plasmogamic prekaryogamic cryptic female choice that occurs within the microcosm of a fertilized egg cell:

(1) Females base their choice on a pre-existing bias for self, based on the mosaic characteristics of sperm pro-nuclear membrane, and (2) Females detect good genes via mRNA signals.

Our first hypothesis is based on sensory bias: that the chosen sperm contains the most female-like nuclear membrane. The sensory bias hypothesis suggests that female preferences are by-products of the underlying physiology of the female's sensory systems. Natural selection has molded the female's sensory systems, and males are proposed to have evolved traits that match the female's sensory system characteristics (Basolo, 1990, 1995, Endler and Basolo, 1998, Ryan, 1998). When sperm enter an egg cell, they shed 
their nuclear membrane and replace it with egg membrane material. In the process, some taxa, such as the sea urchin Arbacia (Longo, 1973) and the hamster (Yanagimachi and Noda, 1970), retain parts of their sperm nuclear envelope, thus, the newly formed pronucleus is a mosaic. Sperm retain part of their original nuclear membrane, with variation between sperm being a function of the amount and/or composition of nuclear membrane retained (Yanagimachi and Noda, 1970, Longo, 1976). There is a noticeable gap in the literature with regards to the function of replacing a sperm nucleus with a pro-nucleus. We argued elsewhere that sperm shed their nuclear membrane and replace it with one made from egg material because they need nuclear pores to complete DNA replication (Gorelick et al., 2012, Carpinone and Gorelick in review). Here we also hypothesize that the pronucleus may have a secondary function to deliver specific information to the female nucleus that aids in her mate choice. Sperm pro-nuclear membranes may provide the variation necessary for sexual selection to be possible. We suspect that in polyspermic organisms, the female selects the male that retains the least amount of sperm nuclear membrane (poreless verses porous membrane). The idea that there is selection pressure on sperm to be better female mimics comes from analyzing the conditions faced by the first sexual organisms. The first sexual organisms probably had sex with themselves (i.e. were automictic; Gorelick and Carpinone, 2009) and did not use sperm, but instead restored diploidy by either simply replicating all their chromosomes (endomitosis) or by the fusion of two haploid products of egg meiosis with one another. In such an ancestral condition, any invasion of the egg by another nucleus, a sperm nucleus, would have been detrimental. Early sexual organisms would have had eggs that fused with their own polar nuclei (Gorelick and Carpinone, 2009), which are virtually identical to the egg nucleus. This 
could be why females still prefer to fuse with something similar to self. In monospermic out-crossers, female nuclei have a choice between fusing with a polar nucleus or the sperm pro-nucleus. Because of self-incompatibility, however, eggs preferentially fuse with something that is similar to self, but not identical. We call this the Trojan sperm hypothesis: males don pro-nuclear membranes to 'mimic' females in order to be chosen for karyogamy, due to a pre-existing bias for the females to fuse with themselves.

We digress to discuss our somewhat unconventional definition of sex as either meiosis or karyogamy, especially in light of automixis. With this definition, most or possibly even all eukaryotes become facultatively sexual, at least if we accept reports of cryptic meiosis, especially in basal taxa (Solari, 2002, Gandolfi et al., 2003, Signorovitch et al., 2005, Cooper et al., 2007, Gorelick and Carpinone, 2009). This definition also means that parasex should count as sex (Forche et al., 2008, Gorelick and Carpinone, 2009). There is no difference between autogamy and complete automixis, except that automixis contains diploid mitotic divisions between karyogamy and meiosis. The notion that fusion of gametes defines sex is an anachronism, described before meiosis was elucidated. For example, Spencer (1863 [1890]) described how fusion of gametes defined individuals, while Braun (1853 [1851]) and Bütschli (1876) described how fusion of gametes rejuvenated a lineage, and they did this long before Hertwig (1890) elucidated that meiosis was a reduction division. We have also demonstrated that karyogamy is a modified form of meiosis (Gorelick and Carpinone, 2009), making the definition of sex as either meiosis or karyogamy both simple and general.

Our second hypothesis regarding the evolution of female choice on the nuclear level is based on the good genes hypothesis, with a positive genetic covariance between male 
displays and their viability (Iwasa et al. 1991, Jennions and Petrie 2000, Houle and Kondrashov, 2002). The good genes hypothesis also assumes that there is genetic variation in female preference, which results in covariance between preference and viability (Iwasa et al., 1991, Jennions and Petrie, 2000, Houle and Kondrashov, 2002). Preferences start out at a naturally selected optimum, but are then pushed from the optimum by selection for high viability. Males with very attractive displays indicate their higher overall viability to females more than males with less attractive displays. By preferring these males, females receive better genes that may be passed on to their offspring. The good genes hypothesis suggests that there is no direct selection on the preference. Instead, there is only direct selection for high viability. What we add to this existing sexual selection theory is that males could simply be individual sperm nuclei or pro-nuclei. In polyspermic organisms, we hypothesize that the female nucleus migrates to several pro-nuclei before selecting one. The female nucleus does not come into contact with male pro-nuclei, but enters into the "pro-nuclear zone", an area close to the pro-nucleus (Carré and Sardet, 1984). Once the female nucleus enters into the pro-nuclear zone, it commits to karyogamy with that particular pro-nucleus. During the period of female nuclear migration, male pro-nuclei contain decondensed DNA (Longo, 1985). It is plausible that male pro-nuclei are actively transcribing mRNA and that female nuclei can detect these mRNA signals and are using the quality or nature of these signals as a basis for their choice. There is also evidence that sperm nuclei, before they lose their nuclear membrane and decondense their chromosomes, emit mRNAs (Ostermeier et al., 2004, Krawetz, 2005, Miller et al., 2005, Ostermeier et al., 2005, Dadoune, 2009). In this case, males are actively advertising to females. We call this the good haploid genes hypothesis, which is like the sexy sperm 
hypothesis, but with the individuals being sperm nuclei or pro-nuclei, rather than entire sperm. Sexual selection for individual sperm nuclei/ pro-nuclei was briefly alluded to by Birkhead (1998) and Birkhead and Brillard (2007).

Implications of post-plasmogamic pre-karyogamic sexual selection for alternative sexual systems:

We next outline the implications of sexual selection inside the microcosm of an egg cell for polyspermic, gynogenetic, and androgenetic taxa, which may shed additional observability into post-plasmogamic pre-karyogamic sexual selection. The major implications for the theory developed herein are for polyspermy, which occur in virtually every animal group. Post- plasmogamic pre-karyogamic sexual selection is also applicable to gynogenesis, which occurs in almost 60 metazoan species spanning seven phyla, including chordates, mollusks, arthropods, rotifers, platyhelminthes, nematodes, and annelids (Beukeboom and Vrijenhoek, 1998), and androgenesis, which only occurs in two metazoan genera, Corbicula freshwater clams and Bacillus stick insects (Mantovani and Scali, 1992, Komaru et al., 1998). We focus our discussion on gynogenesis and androgenesis because they may be the easiest place to find evidence for post-plasmogamic pre-karyogamic sexual selection.

Implications of post-plasmogamic pre-karyogamic sexual selection for polysperms

Polyspermic organisms may be the most informative species in which to study postplasmogamic pre-karyogamic sexual selection. Not only can there be hundreds of male nuclei within a single egg cell, but these male nuclei may even be from different diploid 
males. Sexual selection theory predicts that when the number of males in a population is high and the variation between these males is great, females should be choosier (Emlen, 1976). Females should survey more individual males before choosing one with which to mate. Sexual selection should be low in monogamous systems, while high in polygamous systems (Emlen and Oring, 1977). These ideas can be applied to the microcosm of an egg cell, the only difference here being that the individuals involved are haploid nuclei and pro-nuclei, and that the population includes only those individuals within a given egg cell. Thus, in post-plasmogamic pre-karyogamic sexual selection, we predict that polyspermic polygamous female nuclei will be choosier and therefore migrate around the egg more compared to polyspermic monogamous female nuclei. Good test species include those from clades in which organisms show polyspermy in most species, but have varying degrees of (diploid) polygamous and monogamous matings. Amongst polyspermic vertebrates, female salamanders and birds mate with multiple males (Jordan, 1893, Blount, 1909, Fankhauser, 1932, Fankhauser and Moore, 1941, Petrie and Kempenaers, 1998, Gopurenko et al., 2006). Amongst polyspermic invertebrates, females mate with multiple males in those taxa that broadcast their sperm, such as bryozoans (Rothschild, 1954). These test species would enable a comparison of haploid female migration patterns between species that have (1) eggs containing multiple sperm from the same male and (2) eggs containing multiple sperm coming from multiple males.

Implications of post-plasmogamic pre-karyogamic sexual selection for gynogens

Formation of a pro-nucleus is a prerequisite for karyogamy between egg and sperm nuclei, however, failure to form a sperm pro-nucleus does not always lead to a lack of a 
viable zygote. Egg cells sometimes restore diploidy without incorporating a sperm's chromosomes. While egg meiosis in all animals (except cnidarians, sea urchins, and some starfish; Tarin, 2000) requires plasmogamy, zygote formation in over 50 species across seven phyla does not require karyogamy between male and female haploid nuclei (Beukeboom and Vrijenhoek, 1998). This situation is termed gynogenesis, where sperm are needed for the resumption of arrested egg meiosis (and maybe some epigenetic factors?), but where sperm chromosomes do not get passed on to the zygote. Gynogens are unisexual female hybrids whose eggs participate in plasmogamy but not karyogamy, with sperm. During gynogenesis, two egg nuclei can fuse to form a zygote, with no contribution from the sperm. Restitutional meiosis or pre-meiotic doubling of egg nuclei is also possible. In gynogenetic eggs, like the eggs of polysperms, and in all eggs that have arrested meiosis, there are multiple nuclei-both female and male nuclei/pro-nuclei-with which the female nuclei can participate in karyogamy. With polyspermy, female nuclei choose a male nucleus to associate/fuse with, whereas with gynogenesis, female nuclei choose another female nucleus (its own polar body or polar nucleus) to associate/fuse with. Why are gynogens not fusing with the sperm that fertilizes the egg, like their close relatives do? In at least one species of gynogenetic carp (Carassius auratus langsdorfii), the sperm that fertilizes the egg fails to form a pro-nucleus and is subsequently ejected (Yamashita et al. 1990). Sperm that fertilize gynogens should be able to form a pronucleus insofar as studies have shown that pro-nuclear formation is not a species-specific process (see Longo 1985 for a review). However, for some reason, in Carassius auratus langsdorfii, the pro-nucleus does not form. We hypothesize that all sperm fertilizers of gynogens are rejected by the egg (at least in part) because they fail to form pro-nuclei, 
which (as previously discussed) may be the basis of female choice. Sperm that fertilize gynogenetic eggs are compatible enough to induce completion of egg meiosis. If postplasmogamic pre-karyogamic sexual selection is occurring in gynogens, we predict that gynogenetic egg nuclei migrate, like in polyspermic amphimicts, to one or more nuclei within the egg cell. The male nuclei, however, have not formed pro-nuclei and therefore are not chosen for karyogamy because they are neither (1) exploiting the females preexisting bias for a porous membrane, nor (2) sending out enticing mRNA signals due to lack of nuclear pores. The gynogen rejects all male nuclei and restores ploidy either by endoduplication or by choosing another haploid female to fuse with (i.e. her polar body).

\section{Implications of post-plasmogamic pre-karyogamic sexual selection for androgens}

Female choice on the nuclear level seems plausible and maybe even likely for both polyspermic and gynogenetic organisms. Female nuclei can distinguish between different male nuclei (with polyspermy) and between male and female nuclei (with gynogenesis and outcrossing). Are female nuclei the only nuclei that choose between mates? This leads to questions surrounding androgenesis, where sexual role reversal may occur within an egg cell. So far, the only known obligate androgens found in the animal kingdom are in the genus Corbicula of freshwater clams. The eggs of these clams are readily fertilized by diploid, triploid, or tetraploid biflagellate sperm (biflagellate sperm is very peculiar in unikonts). Upon meiosis, the egg's genetic material is extruded as two (presumably) diploid polar bodies (Komaru et al., 1998). Androgenesis also occurs obligately in one conifer, Cupressus dupreziana, by means of diploid sperm (Pichot et al., 2001), and facultatively in Bacillus stick insects (Mantovani and Scali, 1992). Facultative androgens 
are fertilized by haploid sperm, and diploidy is restored, like in gynogens, either by endomitosis, or karyogamy between two haploid male pro-nuclei. Spontaneous androgenesis is rare, typically occurring via endomitosis of a single haploid sperm nucleus in some fish and angiosperms. In androgenesis, all egg nuclei are discarded as polar bodies or degenerate. Why are the female nuclei being rejected in these species? We hypothesize that male nuclei can occasionally exert choice over female nuclei by rejecting the female nucleus. Somehow, male nuclei within an egg manipulate the egg to reject itself. The mechanics behind this antithetical rejection of egg nuclei is unknown. We take the liberty here to hypothesize that male nuclei still take female endoplasmic reticulum material to form the pore-rich pro-nuclei needed for genome duplication, and, if there is selection of haploid male pro-nuclei by one another, pro-nuclei would also form the basis of sexual choice. However, we are not so adventurous to speculate whether haploid male pro-nuclei evaluate other male pro-nuclei based on proportion of female membrane, mRNA signals, or some other completely different system, or how it is settled which male does the choosing.

\section{Concluding Remarks:}

Pre-copulatory and post-copulatory sexual selection prior to plasmogamy have been extensively studied, however to the best of our knowledge, post-plasmogamic prekaryogamic sexual selection has never been considered, except for a few short sentences by Birkhead. This lack of study is probably due to technical difficulties in observing the behaviours of the nuclei and pro-nuclei within a single egg cell. We predict that the prevalence of post-plasmogamic pre-karyogamic sexual selection will be proportional to 
the number of sperm nuclei that enter an egg cell. It is easy enough to measure rates of polyspermy. The problem is that we know virtually nothing about how haploid nuclei inside of an egg cell move and how they might possibly choose one another. While it appears that it is usually the haploid egg nuclei that do most of the moving around the egg cell, as the haploid sperm nuclei remain around the periphery, there is too little data to know how general this pattern is. Do haploid egg nuclei prefer certain male mRNAs? If so, are these mRNA produced before or after sperm pro-nuclear formation? Do haploid egg nuclei prefer certain male pro-nuclear membranes? Does the ratio of native female-to-male content of these nuclear envelopes matter? Does it vary? Until data addressing these questions is amassed, it will remain impossible to make more specific testable predictions about the interaction of haploid nuclei inside a fertilized egg cell based on standard sexual selection theory.

We propose post-plasmogamic pre-karyogamic sexual selection exists based on previously recorded movements of female nuclei toward multiple male nuclei prior to karyogamy within a single egg cell (Carré and Sardet, 1984). Post-plasmogamic prekaryogamic sexual selection is indeed plausible because female and male nuclei within an egg are under their own nuclear control rather than under the control of the cytoplasm, and there is opportunity for differences between male nuclear/pro-nuclear membranes and signals. We should not summarily dismiss post- plasmogamic pre-karyogamic sexual selection, especially when analyzing organisms that have little or no pre-copulatory nor pre-plasmogamic selection, despite no definitive evidence for this theoretically reasonable construct. Instead of avoidance of polyspermy a lá Eberhard (1996) and Arnqvist and Rowe (2005), individual female eggs might tolerate or facilitate polyspermy and then 
choose sperm nuclei at a slightly later ontological date, after plasmogamy but before karyogamy. For example, post-plasmogamic pre-karyogamic sexual selection could easily exist in sessile organisms, such as bryozoans and plants-organisms in which sexual selection is thought to play relatively minor evolutionary roles (Morgan, 1927, Andersson, 1994). Therefore, sexual selection has the potential to be much more universal, occurring in many more organisms than generally believed. The implications of post-plasmogamic pre-karyogamic intersexual selection are the same as the implications for other forms of intersexual selection: the evolution of exaggerated sexual signals and female preferences for those signals (Andersson, 1994). In the case of post-plasmogamic pre-karyogamic sexual selection, these implications would include male nuclei being selected to either don more of the female's pro-nuclear membrane to 'mimic' females (Trojan sperm hypothesis) or male nuclei being selected to signal their good genes through enhanced mRNA emission (good haploid genes hypothesis), thereby actively advertising themselves to females. In turn, female nuclei would be selected to exhibit enhanced preferences for these pro-nuclear or mRNA signals. 


\title{
Chapter 4: Taxonomic relationships of diverse mating systems:
}

\section{Amphimixis, gynogenesis, parthenogenesis, and the gynogenetic bridge hypothesis}

\begin{abstract}
:
Automictic gynogenesis is an evolutionary intermediate between amphimixis and automictic parthenogenesis, I call this the gynogenetic bridge hypothesis. I predict that gynogens should have close parthenogenetic and amphimictic relatives. I test this by mapping automictic taxa that contain naturally occurring gynogenesis and parthenogenesis on to phylogenies. In all seven gynogenetic phyla (Chordata, Molluska, Arthropoda, Rotifera, Platyhelminthes, Nematoda, Annelida), 7 of 10 gynogenetic classes, and 11 of 16 gynogenetic orders, when a taxon contains gynogenetic lineages, it always includes parthenogenetic lineages. I test whether automictic gynogenesis and parthenogenesis co-occur in all nematode genera, finding that 3 of 4 lineages containing gynogenesis also contain parthenogenesis. Automictic parthenogenesis occurs in taxa that do not have automictic gynogenesis, but largely not vice versa. I argue that phylogenetic comparative methods are not applicable. However, phylogenetic mapping of character states qualitatively supports the hypothesis that automictic gynogenesis serves as an evolutionary intermediate between automictic parthenogenesis and amphimixis.
\end{abstract}

\section{Introduction:}

Gynogenesis is a mode of reproduction in which plasmogamy occurs between female and male gametes, followed by rejection of the male nucleus, resulting in female 
offspring that carry maternal DNA only. Parthenogenesis is female reproduction without plasmogamy with a male. Although apomictic (purely mitotic) parthenogenesis and gynogenesis are possible, for reasons explained below, I only consider automictic parthenogenesis and automictic gynogenesis, which are meiosis alternating with either endomitosis (restitutional automixis; pre-meiotic doubling) or karyogamy between products of the same reduction division (complete automixis). Automixis is not to be confused with autogamy (self fertilizing hermaphrodites).

Gynogenesis has intrigued evolutionary biologists since first discovered by Oscar Hertwig in 1911, as it reaps neither the benefits of automictic parthenogenesis (self sex) nor amphimixis (karyogamy between male and female nuclei). Courtship displays, courtship aggression, and secondary sexual characteristics are often involved in gynogenetic matings, and can carry enormous costs (Keegan-Rogers and Schultz, 1984). Copulation also increases the risk of exposure to disease from the partner (Schlupp, 2005). Gynogenetic females do not produce males, instead relying on sister species' to provide sperm. Therefore, gynogens do not incur the costs of producing males, yet incur all the costs associated with copulation. Gynogens are essentially selfers, therefore, mutations are not easily fixed, and Muller's ratchet runs quickly, like with their parthenogenetic relatives (Muller, 1964).

With all these costs, why does gynogenesis exist? To answer this, we must understand the detailed mechanics behind gynogenetic fertilization. Gynogenesis arises after routine plasmogamy between egg and sperm. In all metazoans, except cnidarians and sea urchins, meiosis is always arrested (albeit at various stages of progress) until plasmogamy (Austin, 1965). Automictic gynogens should be no different, plasmogamy 
should stimulate the completion of meiosis. Karyogamy follows the resumption of egg meiosis in amphimicts. However, karyogamy does not occur between gynogenetic eggs and sperm. I propose that this is because of incompatibilities between male and female haploid nuclei. Once plasmogamy occurs, stimulating the resumption of arrested meiosis, I propose that the female nucleus, now haploid, migrates towards the male nucleus to participate in karyogamy, as in amphimicts. However, instead, of the haploid female nucleus fusing with a haploid male nucleus, the female nucleus chooses to either fuse with another female nucleus (its polar nucleus, as in complete automixis) or to restore ploidy with no karyogamy (via pre-meiotic doubling or restitutional automixis). I argue that gynogens depend on males solely to stimulate the resumption of arrested meiosis, assuming that gynogenesis is automictic. Automictic gynogenesis may be an example of pre-karyogamic sexual selection, if the female nucleus is in fact examining, and choosing to reject the male nucleus/nuclei before restoring ploidy on her own (Gorelick, et al., 2011). The exact same processes are occurring in amphimicts, automictic gynogens, and automictic parthenogens - the only difference being which nucleus/nuclei the egg cell chooses to reject. Since female automictic gynogens depend on males only to induce the completion of meiosis and otherwise possess the ability to cycle through haploid and diploid life stages independently of males, females that evolved the ability to resume arrested meiosis without plasmogamy, would hypothetically make the evolutionary leap to the much less costly automictic parthenogenesis. Arrested meiosis is the only thing that separates automictic gynogens from automictic parthenogens (Figure 4.1). For this reason, I hypothesis that automictic gynogenesis is an evolutionary intermediate between amphimixis and automictic 
parthenogenesis. Like the triploid bridge hypothesis which argues that triploids are not an evolutionary dead end, but instead serve as an evolutionary intermediate between diploidy and tetraploidy (Bretagnolle and Thompson, 1995), gynogens are also not dead ends, and serve as an intermediates between amphimicts and parthenogens. Labeling automictic gynogens as an intermediate between amphimicts and automictic parthenogens comes with the prediction that lineages that reproduce with automictic gynogenesis should have close relatives that use amphimixis and automictic parthenogenesis. However, the converse is not necessarily true, that automictic parthenogens will always have close relatives that are automictic gynogens.

Although it is usually accepted or assumed that apomictic gynogenesis exists (Avise, 2008), theoretically it should not. In every phylum in which gynogenesis exists, plasmogamy occurs after meiosis has started and stimulates the resumption of meiosis. If gynogenesis were apomictic, a heterochronic shift in fertilization in relation to plasmogamy would have to occur along with a halt to the resumption of meiosis. Furthermore, if the function of plasmogamy by gynogens is to induce the completion of meiosis, an organism that has no meiosis in its lifecycle, should have no need for plasmogamy (unless the function of plasmogamy is solely to facilitate karyogamy, as in cnidarians and sea urchins). Gorelick and Carpinone (2009) argue that obligate apomixis does not exist in any longlived eukaryotic lineages and that many instances of putative apomixis are in fact examples of cryptic automixis. The same is probably true for gynogenesis, where most cases will be found to be cryptically automictic, either via complete or restitutional automixis. Gorelick and Carpinone (2009: 710, 719) also state that "The first sexual eukaryote must have been automictic...By automixis we mean that the first sexual organism must have had sex with 
itself" and that "unicellular eukaryotes may evolve back to a seemingly atavistic (derived) asexual state". The type of parthenogenesis that I hypothesize is associated with gynogenesis is highly derived automictic parthenogenesis (similar to what Gorelick and Carpinone, 2009, propose for unicellular eukaryotes). Derived parthenogenesis is not to be confused with ancestral parthenogenesis which can be seen in taxa independent of gynogenesis Therefore, apomictic lineages are excluded from my hypotheses. From this point forward, when I say 'gynogenesis' or 'parthenogenesis', I am referring to 'automictic gynogenesis' and 'automictic parthenogenesis' because I do not believe obligately apomictic forms exist.

I test the hypothesis that automictic gynogenesis is an evolutionary intermediate between amphimixis and automictic parthenogenesis in all seven gynogenetic phyla by compiling a list of all gynogenetic and parthenogenetic animal orders, and mapping these orders onto a phylogeny. I also collect reproductive information, on all genera of nematodes, some of which are gynogenetic, to map onto a phylogeny of the nematodes, because nematode phylogenies are well-resolved. 


\section{Amphimixis}

-Plasmogamy

-Karyogamy<smiles>[AlH2]</smiles>

Gynogenesis

-Plasmogamy

- Karfogany

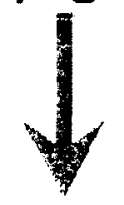

Parthenogenesis

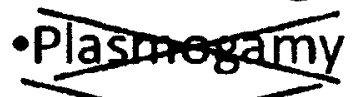

- Karpogany
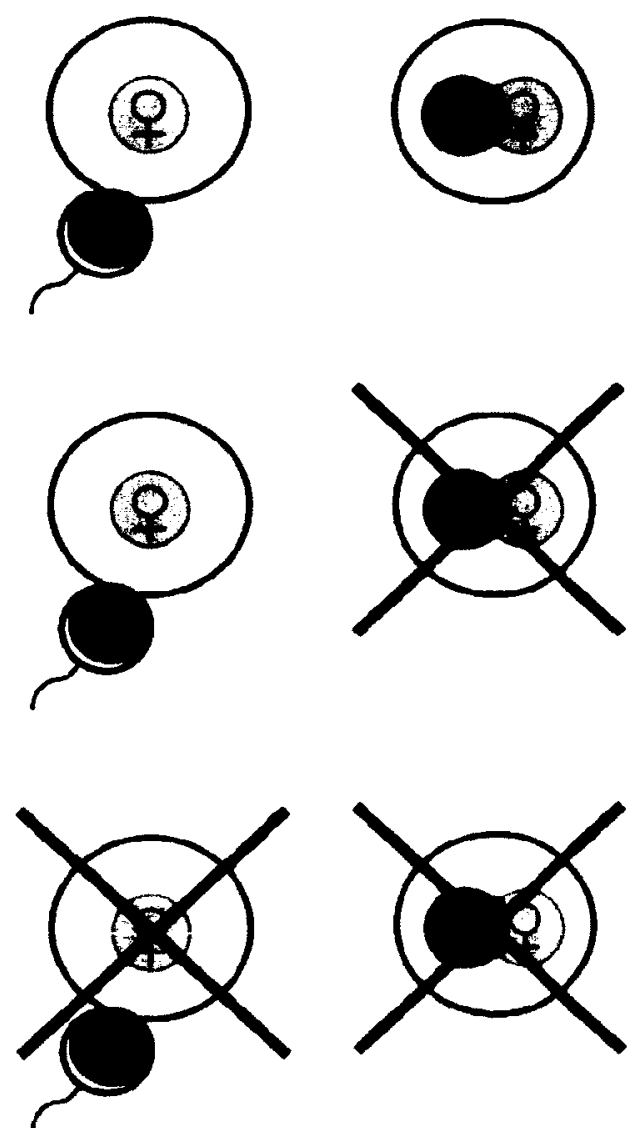

Figure 4.1: Evolutionary progression from amphimixis to parthenogenesis. Amphimicts rely on sperm both to reinitiate arrested meiosis (via plasmogamy) and to restore ploidy (via karyogamy). Automictic gynogens rely on sperm to reinitiate arrested meiosis but not to restore ploidy. Automictic parthenogens rely on sperm neither to reinitiate paused meiosis nor to restore ploidy, and thus, have evolved complete independence from sperm. Black-outlined circles represent cell membranes, blue and pink-outlined circles represent male and female nuclear membranes respectively.

\section{Methods:}

I collected information on reproductive modes including amphimixis, parthenogenesis, and gynogenesis of all metazoans. Thousands of species are amphimictic or parthenogenetic, yet only about 60 species are known to be gynogenetic. After building initial phylogenies and subsequently mapping reproductive modes, I concluded that gynogenetic taxa are too rare and sporadic across metazoans to allow for phylogenetic 
analysis (such as an ancestral character estimation) with an acceptable sample size/statistical power. In addition, the hypothesis that automictic gynogenesis is an evolutionary stepping stone towards highly derived automictic parthenogenesis, is problematic to test because while the reproductive mode (i.e. amphimixis, parthenogenesis, gynogenesis, or androgenesis) is usually observable, automixis, apomixes, and autogamy are often confused and/or indiscernible. While using phylogenetic comparative methods is not feasible, there are some important conclusions that can still be recognized from visible trends in the data collected from the literature. All sixteen metazoan orders containing gynogens were mapped on a phylogeny of the seven phyla containing these orders; Chordata, Arthopoda, Nematoda, Rotifera, Platyhelminthes, Molluska, and Annelida (Figure 4.2). The phylogeny used in Figure 4.2 is from Ross Young's undergraduate independent project (unpublished; summer 2011). Within the seven gynogenetic phyla, only classes containing either parthenogenesis or gynogenesis were expanded upon. The resulting data set contained 186 orders within 28 classes. The base of the tree was adapted from Anderson et. al.'s (2004) molecular study of metazoan relationships. The supertree was further resolved using morphological data and molecular data (including small and large subunits of rDNA and rRNA, mtDNA, protein alignments, amino acid positions, and hormone production) from 62 studies using current nomenclature. The phylogeny was produced using Mesquite. The phylogeny with all seven phyla that contain gynogenetic taxa shows the distribution of gynogenetic and parthenogenetic traits. The lack of branch lengths along with the small sample size make ancestral character estimation (ACE) impossible. The presence of classes including both gynogenetic and parthenogenetic lineages, although indicative of an evolutionary relationship, is also not 
compatible with an ACE. I chose the phylum Nematoda to further my exploration into the evolutionary relationship between parthenogenesis and gynogenesis because of the relatively small size of the phylum (approximately 240 genera), the relatively high incidence of gynogenesis $(0.6 \%)$, and the well resolved phylogeny. The nematode supertree used is based on a relevant portion of an existing molecular phylogeny based on small subunits of $18 \mathrm{~s}$ rDNA (Meldal et. al., 2007). A more recent consensus tree based on RNAi provided detailed information about the family Heterodera (Holterman et. al., 2009).

\section{Results and Concluding Remarks:}

Is it possible that gynogenesis is an evolutionary intermediate between amphimixis and parthenogenesis, or is gynogenesis simply an evolutionary dead end? From the evidence here, there is at least some connection between gynogenesis and parthenogenesis, however valid inferences can only be made assuming all gynogenetic and parthenogenetic metazoans within the data set are automictic. All phyla containing gynogenesis contain parthenogenesis, $70 \%$ of classes that contain gynogenesis also contain parthenogenesis, almost $69 \%$ of orders that contain gynogenesis contain parthenogenesis, and $75 \%$ of nematode genera that contain gynogenesis contain parthenogenesis (See Table 4.1 for summary, and Table 4.2, Figure 4.2, and Figure 4.3 for details). The phylogenies show that gynogenetic taxa often cluster with parthenogenetic taxa. Is this enough? Because branch lengths of the supertree (Figure 4.2) are unknown, the nematode phylogeny (Figure 4.3) is currently poorly resolved. Because there are too few gynogenetic species that are widely spread across multiple phyla, testing the gynogenetic bridge hypothesis via ancestral character estimation was out of the scope of this chapter. Yet, all is not lost. We can get a modicum of 
insight from simply gathering and organizing existing data on reproductive modes. First and foremost, the wide extent of gynogenesis and parthenogenesis shows that gynogenesis and parthenogenesis have arisen independently multiple times (Figure 4.2). Since I propose gynogenetic females are all meiotic, parthenogenetic animals that evolve from gynogenetic lineages should also be automictic.

In some phyla, there is evidence that parthenogenesis could have evolved from gynogenesis (namely in arthropods, nematodes, annelids, rotifers, and platyhelminthes). Every single time gynogenesis is present in an order in these phyla, parthenogenesis is also present. This pattern holds for nematodes, where almost every genus that contains gynogenetic species also contains parthenogenetic species.

Table 4.1: Summary of gynogenetic and parthenogenetic relationships.

\begin{tabular}{|l|l|}
\hline Classification & $\begin{array}{l}\text { Taxa containing gynogenesis } \\
\text { and parthenogenesis/Taxa } \\
\text { containing gynogenesis }\end{array}$ \\
\hline Phyla & $100 \%(7 / 7)$ \\
\hline Classes & $70 \%(7 / 10)$ \\
\hline Orders & $69 \%(11 / 16)$ \\
\hline Genera (Nematodes only) & $75 \%(3 / 4)$ \\
\hline
\end{tabular}

Why do some phyla contain orders of gynogens that always contain parthenogens, while other phyla contain orders of gynogens that never contain parthenogens (chordates, mollusks)? For the mollusks, this may be a vestige of insufficient data collection, because gynogenesis is extremely difficult to observe in nature, and as mentioned previously, amphimixis and gynogenesis, and autogamy and parthenogenesis are often confused or indiscernible. It is only with careful laboratory observation that gynogenesis can be pinpointed to a particular lineage (Schlupp, 2005). I predict that with more data on 
the reproductive modes, we may see gynogenesis linked with parthenogenesis in the mollusks.

It may be that gynogenesis is an intermediate between amphimixis and parthenogenesis in some phyla, yet not others, or it may be that the close relationship between gynogenesis and parthenogenesis in some phyla is purely coincidental. Assuming for a moment that chordates are the exception, what is stopping gynogenetic chordates (where there is no lack of reproductive data), specifically amphibians and bony fish (Osteichthyes), from becoming parthenogenetic especially when the cost of gynogenesis is relatively high, compared to parthenogenesis? Engelstädter (2008) lists many constraints on the evolution of parthenogenesis, including inbreeding depression, centriole inheritance and sex determination. Gynogens have overcome all these proposed constraints. The only obvious constraint on gynogens is resumption of meiosis. A parthenogenetic mutant should easily spread in fish and amphibian lineages, but this trend it is not observed (Schlupp, 2005). Though chordate gynogens are not observed to make the evolutionary transition to parthenogenesis, they could hypothetically return to automictic reproduction, if they begin to produce males and use male chromosomes to restore ploidy. In this sense, gynogenesis may be merely a temporary break from amphimixis in fish and amphibians.

Is it possible that fish and amphibians do not carry the inherent genetic capability to resume meiosis without plasmogamy? Not likely. The ancestors of all metazoans were able to resume meiosis without plasmogamy at least at one point (Gorelick and Capinone, 2009), and birds and reptiles are capable of parthenogenesis (Avise, 2008). All chordates must then inherently have the genetic ability to be automictic parthenogens. It is therefore 
a mystery that more parthenogenesis is not observed in chordates, especially fish and amphibians where we see gynogenesis. This leads to a fundamental question that plagues evolutionary biologists: Why have males at all? Why gonochorism? But these questions are beyond the scope of this chapter.

Automictic gynogens depend on males only for the resumption on meiosis. Therefore, I tested the hypothesis that gynogenesis is an evolutionary intermediate between amphimixis and parthenogenesis, the gynogenetic bridge hypothesis, by amassing data on reproductive modes and mapping these character states on phylogenies. Parthenogenesis is almost always associated with taxa that contain some gynogens. I argued that although there is no way at this time to rigorously test this hypothesis, there is sufficient evidence to support the hypothesis that gynogenesis can facilitate the evolutionary step to parthenogenesis

Table 4.2: Gynogenetic and parthenogenetic classes of the phyla Rotifera, Platyhelminthes, Nematoda, Annelida, Mollusca, Chordata, and Arthropoda. Parthenogenesis is always found when gynogenesis is present in rotifers, platyhelminthes, nematodes, annelids, and arthropods but gynogenesis is not always found when parthenogenesis is present. Here, bivalve mollusks, fish, and amphibians provide the only examples where gynogenesis is found in nature without parthenogenesis. Deep-sea mollusk orders Caudofoveata, Monoplacophora, Aplacophora, Scaphopoda were left out due to lack of information on reproductive modes. Parthenogenesis also occurs in the phyla Onychophara, Tardigrada, Gastrotricha, and Cnidaria, however, these phyla were not included here because they contain no known gynogenetic lineages. All classes contain amphimicts. (Bell, 1982, Vrijenhoek, Dawley, Cole and Bogart, 1989, Beukeboom and Vrijenhoek, 1998, Komaru, Kawagishi and Konishi, 1998, Trudgill and Blok, 2001, Maddison and Schulz, 2007, De Meeûs, Prugnolle and Agnew 2007, Avise, 2008).

\begin{tabular}{|l|l|c|c|}
\hline \multirow{2}{*}{ Phylum } & \multicolumn{2}{|c|}{ Class } & \multicolumn{2}{c|}{ Mode of Reproduction } \\
\cline { 3 - 4 } & & Gynogenesis & Parthenogenesis \\
\hline Rotifera & Monogononta & $\checkmark$ & $\checkmark$ \\
\cline { 3 - 4 } & Digononta & & \\
\hline
\end{tabular}




\begin{tabular}{|c|c|c|c|c|}
\hline & \multicolumn{2}{|l|}{ Bdelloidea } & & $\checkmark$ \\
\hline & \multicolumn{2}{|l|}{ Seisonidea } & & \\
\hline \multirow[t]{4}{*}{ Platyhelminthes } & \multicolumn{2}{|l|}{ Monogenea } & & $\checkmark$ \\
\hline & \multicolumn{2}{|l|}{ Trematoda } & & $\checkmark$ \\
\hline & \multicolumn{2}{|l|}{ Cestoda } & & $\checkmark$ \\
\hline & \multicolumn{2}{|l|}{ Turbellaria } & $\checkmark$ & $\checkmark$ \\
\hline Nematoda & \multicolumn{2}{|l|}{ Secernentae } & $\checkmark$ & $\checkmark$ \\
\hline \multirow[t]{4}{*}{ Annelida } & \multicolumn{2}{|l|}{ Polychaeta } & & $\checkmark$ \\
\hline & \multicolumn{2}{|l|}{ Clitellata } & $\checkmark$ & $\checkmark$ \\
\hline & \multicolumn{2}{|l|}{ Myzostomida } & & \\
\hline & \multicolumn{2}{|l|}{ Archiannelida } & & \\
\hline \multirow[t]{4}{*}{ Mollusca } & \multicolumn{2}{|l|}{ Bivalvia } & $\checkmark$ & \\
\hline & \multicolumn{2}{|l|}{ Cephalopoda } & & \\
\hline & \multicolumn{2}{|l|}{ Gastropoda } & & $\checkmark$ \\
\hline & \multicolumn{2}{|c|}{ Polyplacophora } & & \\
\hline \multirow[t]{7}{*}{ Chordata } & \multicolumn{2}{|l|}{ Agnatha } & & \\
\hline & \multicolumn{2}{|c|}{ Chondrichthyes } & & $\checkmark$ \\
\hline & \multicolumn{2}{|l|}{ Osteichthyes } & $\checkmark$ & \\
\hline & \multicolumn{2}{|l|}{ Amphibia } & $\checkmark$ & \\
\hline & \multicolumn{2}{|l|}{ Reptilia } & & $\checkmark$ \\
\hline & \multicolumn{2}{|l|}{ Aves } & & $\checkmark$ \\
\hline & \multicolumn{2}{|l|}{ Mammalia } & & \\
\hline \multirow[t]{2}{*}{ Arthropoda } & Sub-Phylum & Class & & \\
\hline & Chelicerata & Arachnida & $\checkmark$ & $\checkmark$ \\
\hline
\end{tabular}




\begin{tabular}{|c|c|c|c|}
\hline & Xiphosura & & \\
\hline & Pycnogonida & & \\
\hline \multirow[t]{4}{*}{ Myriapoda } & Chilopoda & & $\checkmark$ \\
\hline & Diplopoda & & $\checkmark$ \\
\hline & Pauropoda & & $\checkmark$ \\
\hline & Symphyla & & $\checkmark$ \\
\hline \multirow[t]{3}{*}{ Hexapoda } & Insecta & $\checkmark$ & $\checkmark$ \\
\hline & Entognatha & $\checkmark$ & $\checkmark$ \\
\hline & Diplura & & \\
\hline \multirow[t]{6}{*}{ Crustacea } & Branchiopoda & & $\checkmark$ \\
\hline & Remipedia & & \\
\hline & Cephalocarida & & \\
\hline & Maxillopoda & & $\checkmark$ \\
\hline & Ostracoda & & $\checkmark$ \\
\hline & Malacostraca & & $\checkmark$ \\
\hline
\end{tabular}




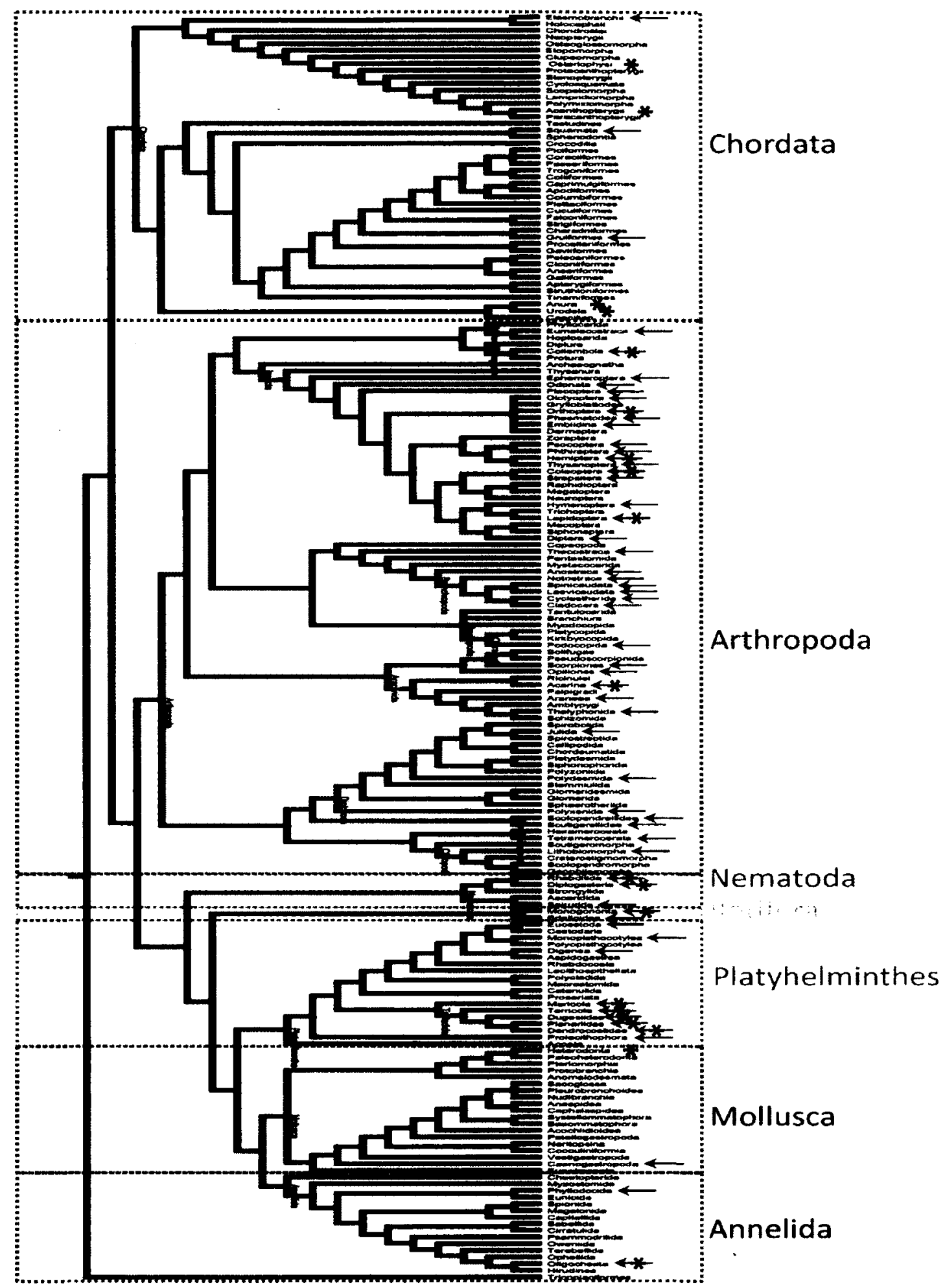

Figure 4.2: Detailed phylogeny of all orders in phyla containing gynogenetic species. Arrows indicate parthenogenesis, stars indicate gynogenesis occurs in an order. Except in the chordates and molluscs, every time gynogenesis occurs in an order so does parthenogenesis. Clusters of stars and arrows indicate good places to look for additional gynogenetic or parthenogenetic lineages. 


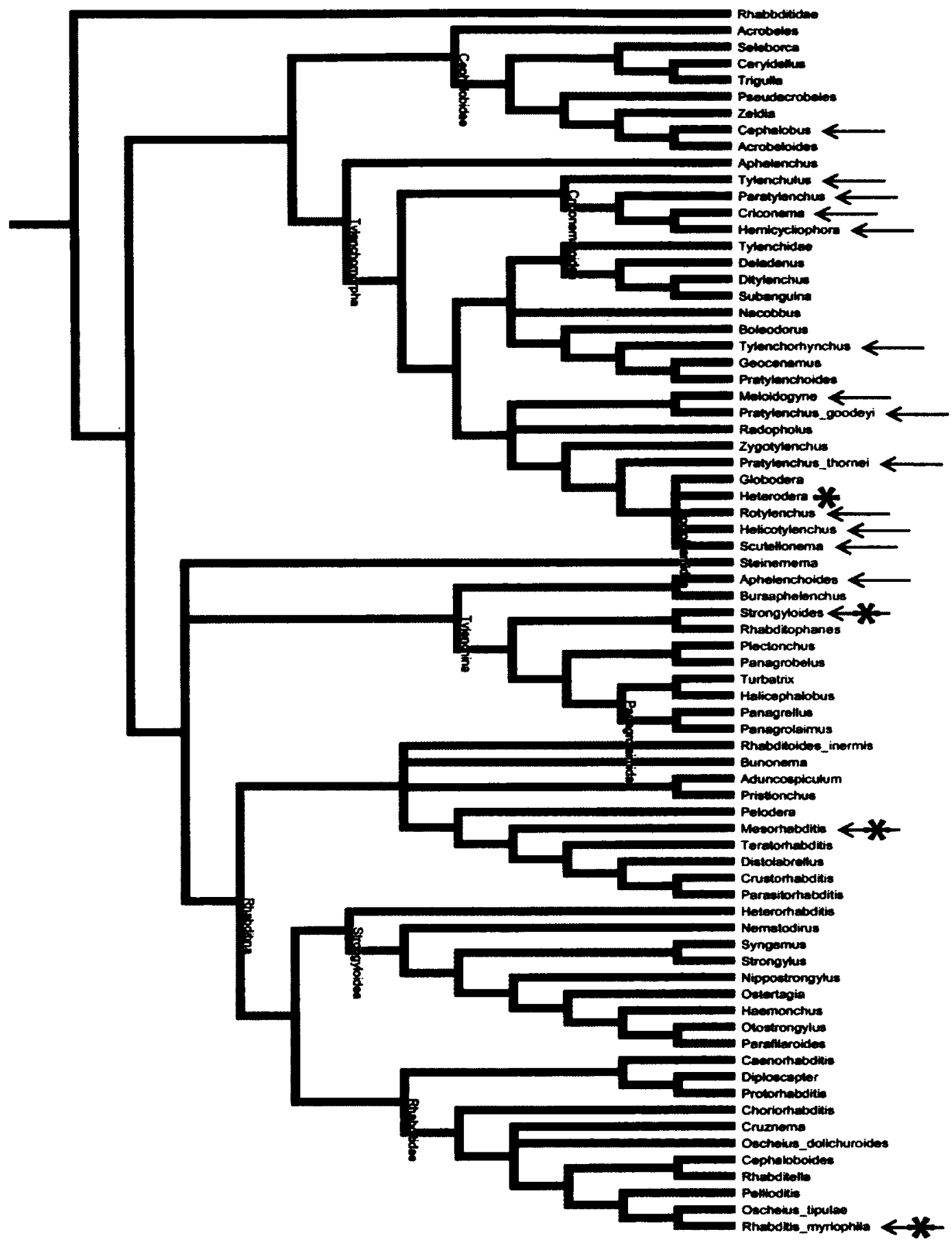

Figure 4.3: Detailed phylogeny of relevant nematode genera. Arrows indicate parthenogenesis, stars indicate gynogenesis occurs in an order. The families Enoplea, Desmodorida, Chromodorida, Monhysterida, and Spirurina, do not contain gynogenetic genera, therefore were not included. Heterodera is the only nematode genus that displays gynogenesis without parthenogenesis, however, all Hoploleamids are very extremely closely related, and phylogenetic relationships are not well established. Phylogeny adapted from Meldal et al.(2007) and Holterman et al.(2009).

63 


\section{Chapter 5: Discussion}

Do females and males really exist? Although it is clear that no distinction between the two sexes can be made in diploids, femaleness and maleness seems to exist in haploids vis-à-via composition of haploid membranes and the symmetry of meiosis. If universal traits exist that can be used to distinguish females from males across all taxa, then anisogamy may have only evolved once. If haploid females differ from haploid males, this allows for their independent actions inside a fertilized egg cell. Pre-karyogamic sexual selection has the potential to exist: haploid males and females behave independently of cytoplasmic control once inside an egg cell. The haploid nucleus that does the choosing (possibly each of them) discriminates probably based on composition of either their nuclear membranes (Trojan sperm hypothesis) or mRNA (good haploid genes hypothesis). If sexual selection is occurring inside an egg cell, we may be underestimating the amount of sexual selection that goes on, especially in sessile organisms, such as plants or bryozoans, for which we expect little pre-plasmogamic sexual selection. Gynogenesis may simply be an evolutionary example of haploid female nuclei making unconventional choices when choosing the sex of its partner haploid nucleus. My work indicates that gynogens may be an evolutionary stepping-stone between amphimixis and parthenogenesis, with gynogens depending on sperm solely to induce the completion of arrested egg meiosis.

I believe that meiosis first evolved as a mechanism to reduce polyploidy, and is maintained because of the associated reset of epigenetic signatures (Gorelick and Carpinone, 2009). I study how sex changes over time therefore, my thesis focused almost exclusively on the origin and evolution of unusual varieties of sex, not on the origin and 
maintenance of meiosis and karyogamy.

I put forward four hypothesized universal differences between haploid male and female metazoan individuals in chapter two; (1) females provide ribosomes to the zygote, (2) males have unique proteins on their nuclear membranes, (3) males lack nuclear pores and form pro-nuclear membranes, and (4) females have asymmetrical meiosis, males have symmetrical meiosis, yet, these hypotheses should not be weighted equally. The hypothesis that females provide ribosomes to the zygote, is not operational definition because ribosomes are not self replicating. New ribosomes are fabricated de novo from zygote/embryo DNA therefore have paternal contributions, making it impossible to track inheritance. My second hypothesized difference, unique proteins on sperm nuclear membranes, may be simply a function of the exceptional pore-less nature of male nuclear membranes, and there are no studies as of yet that show that after male gametogenesis, the four sperm actually do have an equal chance of contributing to subsequent generations. Thus, the last two hypothesized differences between haploid sexes - absence of nuclear membranes and asymmetry of meiosis - provide the crucial things to test. Furthermore, ribosomal inheritance, nuclear proteins, and the symmetry of meiosis are most likely nonadaptive random characters. The only hypothesized definition of the sexes described in chapter two that is likely to be selected upon (via post-plasmogamic, pre-karyogamic sexual selection) and to have evolutionary consequences is the lack of male nuclear pores and the associated formation of pro-nuclei. As discussed in chapter three, haploid males that do not form pro-nuclei are not selected by female nuclei for karyogamy within the microcosm of an egg cell (e.g. gynogenesis). Consequently, the hypothesis that haploid 
males nuclei may always lack pores is the most likely universal difference between the sexes.

In chapter three, I applied sexual selection theory to the microcosm inside an egg cell, focusing my attention on intersexual selection. I would like to clarify here that I do not think that intrasexual selection inside an egg cell is impossible. It is by all means theoretically possible for male-male, and/or female-female interactions to exist inside an egg cell, though we have not yet observed this. The two requirements for sexual selection to exist inside an egg cell (independent action of nuclei and detectable differences between membrane composition) are just as relevant to intrasexual selection as they are to intersexual selection. The best place to look for intrasexual selection inside an egg cell is in androgens and in parthenogens that are complete automicts.

Chapter three has, perhaps, the most potential for future work. The first future empirical work should consist of preliminary tests to discern whether post-plasmogamic, pre-karyogamic sexual selection is occurring in species other than Beroe ovata. A good place to start is in the pteridophytes (e.g. ferns and horsetails) and lycophytes (e.g. clubmosses and quillworts). Pteridophytes and lycophytes produce haploid gametophytes, multicellular organisms that produce eggs and sperm via mitosis. Since the gametophyte itself is produced via meiosis, one gametophyte mitotically produces multiple eggs and/or sperm that contain identical DNA. Sets of identical sperm and eggs can be used as replicates in an experiment in which one egg is fertilized by multiple different sperm. The prediction here is that if sexual selection is occurring within the egg cell, the female nucleus would choose the same male pro-nucleus every trial. The setback to this idea is that it is not known whether pteridophytes or lycophytes are naturally polyspermic, an 
essential requirement of this proposed experiment.

If it if found that post-plasmogamic, pre-karyogamic sexual selection does indeed occur within the microcosm of an egg cell, we can begin to look for factors that influence haploid female choice. The Trojan sperm hypothesis states that females are more likely to choose males whose pro-nuclei are most porous. This prediction could be tested by fluorescently marking membranes to determine the relative proportion of retained poreless male nuclear membrane of the chosen male compared to rejected males. Polyspermic Drosophilla may provide a decent test because fluorescent marking of different male pronuclear membranes has already been accomplished (Moehring Lab, University of Western Ontario, personal communication, May 2011). The good haploid genes hypothesis states that females are able to detect some signal from the male pro-nuclei either in the cytoplasm or directly on the nuclear membrane itself. This hypothesis could be tested using botanical models of self-incompatibility, and vertebrate models of major histocompatibility complexes.

In chapter four I proposed the gynogenetic bridge hypothesis, with the prediction that gynogenetic lineages should often be associated with parthenogenesis, but that parthenogenetic lineages would not necessarily be associated with gynogenesis. Parthenogenesis occurs in lineages lacking gynogenesis for three main reasons: (1) the gynogenetic ancestor has gone extinct, (2) the parthenogenesis in the lineage is an ancestral form, i.e. the lineage has always lacked males, or (3) parthenogenesis has arisen by a pathway other then via gynogenesis. Amphimicts rely on males to induce the completion of egg meiosis (plasmogamy) and to restore ploidy following this meiosis (via karyogamy). By contrast, gynogens depend on sperm to induce the completion of meiosis, 
but not to restore ploidy, while parthenogens are able to complete meiosis and restore ploidy in the absence of sperm (Figure 4.1). This proposed gynogenetic bridge is just one evolutionary pathway from amphimixis to parthenogenesis. Another bridge from amphimixis to parthenogenesis is via organisms that depend on sperm to restore ploidy but not to induce the completion of meiosis (Figure 5.1). Recall from chapter two that cnidarians and echinoids complete egg meiosis before plasmogamy with sperm (Tarin, 2000). These organisms provide a second, yet distinct, evolutionary stepping-stone to derived parthenogenesis (Figure 5.1). Cnidarians and echinoids, like gynogens, depend on sperm for only one of the two main functions: cnidarians and echinoids depend on sperm solely to restore ploidy, while gynogens depend on sperm solely to induce completion of egg meiosis. Plasmogamy in cnidarians and echinoids does not have a function on its own other than to facilitate karyogamy. I predict that since gynogenesis arises as a mechanism to enable completion of egg meiosis, gynogenesis should not occur in lineages which posses the ability to complete meiosis without sperm. Indeed, there are no known instances of gynogenesis in cnidarians nor echinoids. Gynogens plus cnidarians and echinoids provide separate evolutionary bridges from amphimixis to parthenogenesis. Furthermore parthenogenesis may be the ancestral state in eukaryotes (Gorelick and Carpinone, 2009). Therefore gynogens should have close parthenogenetic relatives, but not vice versa. Although out of the scope of chapter four, I am planning to test this prediction that gynogens should have close parthenogenetic relatives but not vise versa by building detailed phylogenies with branch lengths of lineages containing gynogenesis and performing ancestral character estimations. 


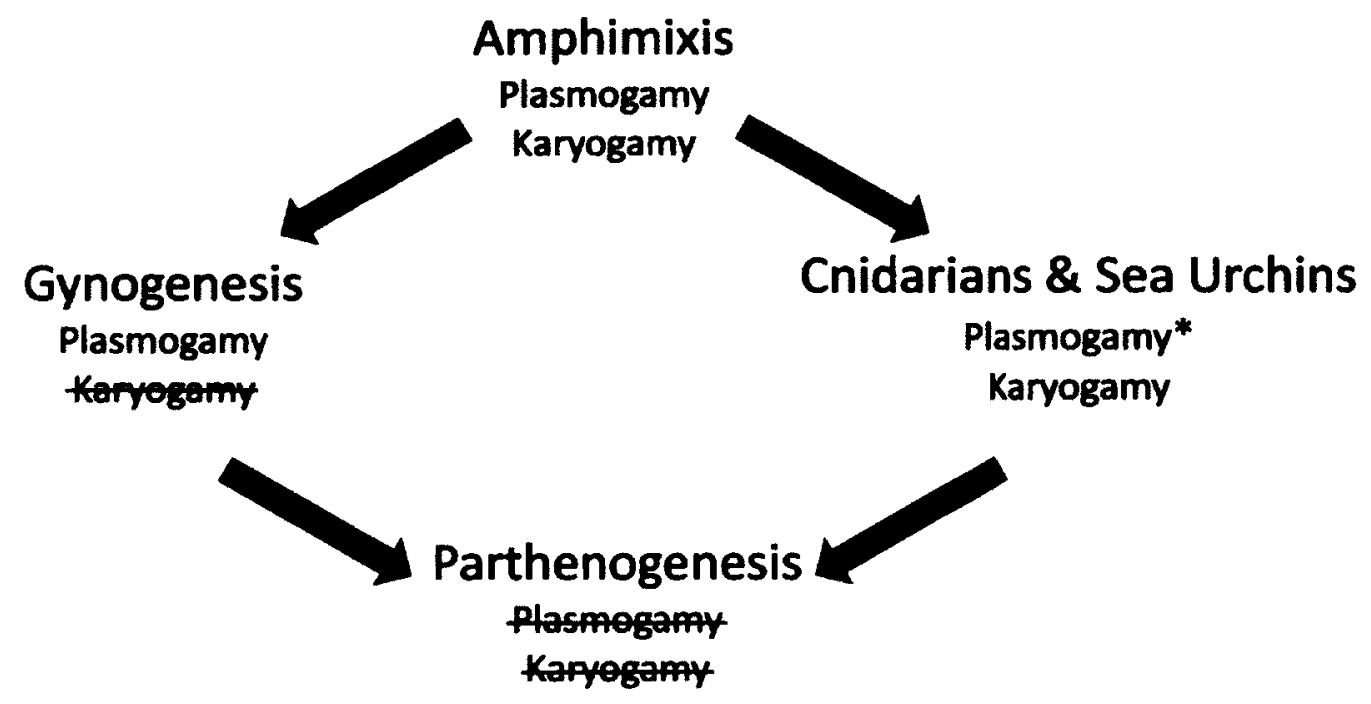

Figure 5.1: Proposed evolutionary bridges from amphimixis to parthenogenesis. Purple arrows indicate an evolutionary event enabling the lineage to complete meiosis without plasmogamy. Orange arrows indicate an evolutionary event enabling the lineage to restore ploidy without karyogamy. Amphimicts, other than cnidarians and echinoids, utilize sperm both to restore diploidy and to reinitiate meiosis. Parthenogens do not need sperm to restore diploidy nor to complete meiosis. Gynogens restore diploidy without karyogamy with sperm, but still rely on sperm to induce the completion of meiosis, while cnidarians and echinoids (opposed to gynogens) have evolved a mechanism to complete meiosis without sperm but not to restore diploidy. If gynogens evolve a mechanism to complete meiosis without sperm, they will make the transition to parthenogenesis, greatly reducing the costs of sex. Likewise if cnidarians and echinoids evolve a mechanism to restore diploidy without sperm, they too will make the transition to parthenogenesis. *Although plasmogamy is not crossed out, it is not needed for meiosis, instead, only to facilitate sperm entry for meiosis. 
Sex probably originated for rejuvenescence, including reduction division (Gorelick and Carpinone, 2009, Gorelick and Heng, 2011), but why are there numerous forms of reproduction, and are there really differences between the sexes? Haploid female and male individuals differ primarily in their nuclear membrane composition, a characteristic they may use to discern compatibility. It is via these preferences that new forms of reproduction, such as gynogenesis, can arise. The functions of males can change over evolutionary and ecological time, with, lineages cycling through or facultatively alternating between parthenogenesis, gynogenesis, androgenesis, and amphimixis. 


\section{References:}

Andersson, F. E., A. J. Córdoba \& M. Thollesson. (2004). Bilaterian phylogeny based on analyses of a region of the sodium-potassium ATPase $\beta$-subunit gene. Journal of Molecular Evolution, 58: 252-268.

Anderson, M. B. (1994). Sexual selection. Princeton New Jersey Press, Princeton, NJ.

Arnqvist, G. \& L. Rowe. (2005). Sexual conflict. Princeton University Press, Princeton, NJ.

Austin, C. R. (1965). Fertilization. Prentice-Hall, Edgewood Cliffs.

Avise, J. C. (2008). Clonality: The genetics, ecology, and evolution of sexual abstinence in vertebrate animals. Oxford University Press, NY.

Barbosa, F. (2009). Cryptic female choice by female control of oviposition timing in a soldier fly. Behavioral Ecology, 20: 957-960.

Basolo, A. L. (1990). Female preference predates the evolution of the sword in swordtail fish. Science, 250: 808-810.

Basolo, A. L. (1995). Phylogenetic evidence for the role of pre-existing bias in sexual selection. Proceedings of the Royal Society of London Series B-Biological Sciences, 259: 307-311.

Bell, G. (1978). The evolution of anisogamy. Journal of Theoretical Biology, 73: 247-270.

Bell, G. (1982). The masterpiece of nature: The evolution and genetics of sexuality. University of California Press, Berkeley, CA.

Beukeboom, L. W. \& R. C. Vrijenhoek. (1998). Evolutionary genetics and ecology of spermdependent parthenogenesis. Journal of Evolutionary Biology, 11: 755-782.

Birkhead, T. R. (1998). Cryptic female choice: criteria for establishing female sperm choice. Evolution, 52: 1212-1218.

Birkhead, T. R. \& J-P. Brillard. (2007). Reproductive isolation in birds: postcopulatory prezygotic barriers. Trends in Ecology \& Evolution, 22: 266-272.

Birkhead, T. R. \& A. P. Møller. (1998). Sperm competition and sexual selection. Academic Press, London.

Blute, M. (2010). Darwinian sociocultural evolution: solutions to dilemmas in cultural and social theory. Cambridge University Press, Cambridge.

Blount, M. (1909). The early development of the pigeon's egg, with special reference to polyspermy and the origin of the periblast nuclei. Journal of Morphology, 20: 1-64. 
Braun, A. (1853 [1851]). Reflections on the phenomenon of rejuvenescence in nature especially in the life and development of plants. In A. Henfrey (eds.) Biological and physiological memoirs, (pp.1-134). Ray Society, London.

Bretagnolle, F. \& J. D. Thompson. (1995). Gametes with the somatic chromosome number: mechanisms of their formation and role in the evolution of autopolyploid plants. New Phytologist, 129: 1-22.

Burley, N. (1988). The differential allocation hypothesis: an experimental test. American Naturalist, 132: 611- 628.

Bütschli, O. (1876). Studien über die ersten entwick-lungvorgange der eizelle, die zelltheilung und die conjungation der infusorien. Abhandlungen herausgegeben von der Senckenbergischen Naturforschenden Gesellschaft, 10:213-452.

Carpinone, J. \& R. Gorelick. (in review). Evolution of syngamy.

Carré, D. \& C. Sardet. (1984). Fertilization and early development in Beroe ovata. Developmental Biology, 105: 188-195.

Cooper, M. A., R. D. Adam, M. Worobey \& C.R. Sterling. (2007). Population genetics provides evidence for recombination in Giardia. Current Biology, 17: 1984-1988.

Dadoune, J-P. (2009). Spermatozoal RNAs: What about their functions? Microscopy Research and Technique, 72: 536-551.

Darwin, C. R. (1871). The descent of man and selection in relation to sex. John Murray, London.

Dean, B. (1906). Chimaeroid fishes and their development. Carnegie Institution of Washington, Washington, DC.

Eberhard, W. G. (1996). Female control: sexual selection by cryptic female choice. Princeton University Press, Princeton.

Edgecombe, G. D. \& G. Giribet, (2003). A new blind Lamyctes (Chilopoda: Lithobiomorpha) from Tasmania with an analysis of molecular sequence data for the LamyctesHenicops group. Zootcxa, 152: 1-23.

Edvardsson, M. \& G. Arnqvist. (2000). Copulatory courtship and cryptic female choice in red flour beetles Tribolium castaneum. Proceedings of the Royal Society of London Series BBiological Sciences, 267: 559-563.

Emlen, S. T. (1976). Lek organization and mating strategies in the bullfrog. Behavioral Ecology and Sociobiology, 1: 283-313. 
Emlen, S. T. \& L. W. Oring. (1977). Ecology, sexual selection, and evolution of mating systems. Science, 197: 215-223.

Endler, J. A. \& A. L. Basolo. (1998). Sensory ecology, receiver biases and sexual selection. Trends in Ecology \& Evolution, 13: 415-420.

Engelstädter, J. (2008). Constraints on the evolution of asexual reproduction. BioEssays, 30: 11381150.

Fankhauser, G. (1932). Cytological studies on egg fragments of the salamander Triton. II: The history of the supernumerary sperm nuclei in normal fertilization and cleavage of fragments containing the egg nucleus. Journal of Experimental Zoology, 62: 185-235.

Fankhauser, G. \& C. Moore. (1941). Cytological and experimental studies of polyspermy in the newt Triturus viridescens. I. Normal fertilization. Journal of Morphology, 68: 347-385.

Fausto-Sterling, A. (2000). Sexing the body: gender politics and the construction of sexuality. Basic Books, New York.

Feldheim, K. A., D. D. Chapman, D. Sweet, S. Fitzpatrick, P. A. Prodohl, M. S. Shivji \& B. Snowden. (2010). Shark virgin birth produces multiple viable offspring. Journal of Heredity, 129: 1-4.

Forche, A., K. Alby, D. Schaefer, A. D. Johnson, J. Berman \& R. J. Bennet. (2008). The parasexual cycle in Candida albicans provides an alternative pathway to meiosis for the formation of recombinant strains. PLoS Biology, 6: e110. DOI: 10.1371/journal.pbio.0060110.

Gandolfi, A., I. R. Sanders, V. Rossi \& P. Menozzi. (2003). Evidence of recombination in putative ancient asexuals. Molecular Biology and Evolution, 20: 754-761.

Goodchild, C. G. \& G. H. Irwin. (1971). Occurrence of Nematodes Rhabditis anomala and R. pellio in Oligochaetes Lumbricus rubellus and L. terrestris. Transactions of the American Microscopical Society, 90: 231-237.

Gopurenko, D., R. N. Williams, C. R. McCormick \& J. A. DeWoody. (2006). Insights into the mating habits of the tiger salamander (Ambystoma tigrinum tigrinum) as revealed by genetic parentage analyses. Molecular Ecology, 15: 1917-1928.

Gorelick, R. (2003). Evolution of dioecy and sex chromosomes via methylation driving Muller's ratchet. Biologcal Journal of the Linnean Society, 80: 353-368.

Gorelick, R. \& J. Carpinone. (2009). Origin and maintenance of sex: the evolutionary joys of self sex. Biological Journal of the Linnean Society, 98: 707-728.

Gorelick, R., L. J. Derraugh, J. Carpinone \& S. M. Bertram. (2011). Post-plasmogamic pre- 
karyogamic sexual selection: Mate choice inside an egg cell. Ideas in Ecology and Evolution, 4: 14-23.

Gorelick, R., J. Carpinone \& L. J. Derraugh. (2012). Fundamental differences between females and males? In M. Ah-King and A. Lee, (eds.) Challenging popular myths of sex, gender, and biology. In press.

Gorelick, R. \& H. Heng. (2011). Sex reduces genetic variation: A multidisciplinary review. Evolution, 65: 1088-1098.

Graham, C. F. (1966). The regulation of DNA synthesis and mitosis in multinucleate frog eggs. Journal of Cell Science, 1: 363-374.

Hartwell, L. H. \& T. A. Weinert. (1989). Checkpoints: controls that ensure the order of cell cycle events. Science, 246: 629-634.

Hertwig, O. (1890). Vergleich der ei-und samenbildung bei nematoden: eine grundlage für cellülare streitfragen. Archiv für mikroscopische Anatomie, 36: 1-138.

Hertwig, O. (1911). Die Radiumkrankheit tierischer Zellen [Radium disease of animal germ cells]. Archiv für mikroskopische Anatomie, 77: 97-164.

Hird, M. J. (2006). Animal transex. Australian Feminist Studies, 21: 35-50.

Hoikkala, A. \& S. Crossley. (2000). Copulatory courtship in Drosophila: behavior and songs of $D$. birchii and D. serrata. Journal of Insect Behavior, 13: 71-86.

Hoikkala, A., S. Crossley \& C. Castillo-Melendez. (2000). Copulatory courtship in Drosophila birchii and $D$. serrata, species recognition and sexual selection. Journal of Insect Behavior, 13: 361-373.

Holterman, M., G. Karssen, S. van den Elsen, H. van Megen, J. Bakker \& J. Helder. (2009). Small subunit rDNA-based phylogeny of the Tylenchida sheds light on relationships among some high-impact plant-parasitic nematodes and the evolution of plant feeding. Phytopathology, 99: 227-235.

Houle, D. \& A. S. Kondrashov. (2002). Coevolution of costly mate choice and conditiondependent display of good genes. Proceedings of the Royal Society of London Series BBiological Sciences, 269: 97-104.

Hughes, R. N. (1989). A functional biology of clonal animals. New York, Chapman \& Hall.

Hull, P. (1964). Partial incompatibility not affecting total litter size in the mouse. Genetics, 50: 563-570.

Iwamatsu, T. (2000). Fertilization in fishes. In J. J. Tarín \& A. Cano (eds.) Fertilization in 
protozoa and metazoan animals: cellular and molecular aspects, (pp. 89-145). SpringerVerlag, Berlin.

Iwasa, Y., A. Pomiankowski \& S. Nee. (1991). The evolution of costly mate preferences: The handicap' principle. Evolution, 45: 1431-1442.

Jennions, M. D. \& M. Petrie. (2000). Why do females mate multiply? A review of the genetic benefits. Biological Reviews, 75: 21-64.

Jordan, E. O. (1893). The habits and development of the newt (Diemyctylus viridescens). Journal of Morphology, 8: 269-366.

Karr, T. L., W. J. Swanson \& R. R. Snook. (2009). The evolutionary significance of variation in sperm-egg interactions. In T. R. Birkhead, D. J. Hosken \& S. Pitnick, (eds.) Sperm biology: an evolutionary perspective, (pp. 305-365). Academic Press, Burlington.

Keegan-Rogers, V. \& R. J. Schultz (1984). Differences in courtship aggression among six clones of unisexual fish. Animal Behaviour, 32: 1040-1044.

King, B. H. \& C. R. Fischer. (2005). Males mate guard in absentia through extended effects of postcopulatory courtship in the parasitoid wasp Spalangia endius (Hymenoptera: Pteromalidae). Journal of Insect Physiology, 51: 1340-1345.

Komaru, A., T. Kawagishi \& K. Konishi. (1998). Cytological evidence of spontaneous androgenesis in the freshwater clam Corbicula leana Prime. Development, Genes and Evolution, 208: 46-50.

Knop, M. (2006). Evolution of the hemiascomycete yeasts: On life styles and the importance of inbreeding. BioEssays, 28: 696-708.

Krawetz, S. A. (2005). Paternal contribution: new insights and future challenges. Nature Reviews Genetics, 6: 633-642.

Lahr D. J. G., P. L. Wegener, E. A. D. Mitchell, L. A. Katz \& E. Lara. (2011). The chastity of amoebae: Re-evaluating evidence for sex in amoeboid organisms. Proceedings of the Royal Society B-Biological Sciences, 278: 2081-2090.

Longo, F. J. (1973). Fertilization: a comparative ultrastructural review. Biology of Reproduction, 9: 149-215.

Longo, F. J. (1976). Derivation of membrane comprising male pro-nuclear envelope in inseminated sea urchin eggs. Developmental Biology, 49: 347-368.

Longo, F. J. (1985). Pro-nuclear events during fertilization. In C. B. Metz \& A. Monroy, (eds.) Biology of fertilization. Volume 3. The fertilization response of the egg, (pp. 251-298). Academic Press, Orlando. 
Longo, F. J. (1987). Fertilization. Chapman \& Hall, London.

Lu, P., H. Zheng \& Z. H. A. I. Zhonghe (2006) In vitro reassembly of nuclear envelopes and organelles in Xenopus egg extracts. Cell Research, 16: 632-640.

Luthardt, F. W. \& R. P. Donahue (1973) Pro-nuclear DNA synthesis in mouse eggs: an autoradiographic study. Experimental Cell Research, 82: 143-151.

Maddison, D. R. \& K. S. Schulz (eds.) (2007). The Tree of Life Web Project. URL: http://tolweb.org.

Majerus, M. (2003). Sex wars: Genes, bacteria, and biased sex ratios. Princeton University Press, Princeton, NJ.

Mantovani, B. \& V. Scali. (1992). Hybridogenesis and androgenesis in the stick-insect Bacillus rossius-grandii benaazzi (Insecta, Phasmotdea). Evolution, 46: 783-796.

Margulis, L. \& D. Sagan. (1988). Sex: the cannibalistic legacy of primordial androgynes. In R. Bellig \& G. Stevens, (eds.) The evolution of sex, (pp. 23-38). Harper \& Row, San Francisco.

Martin, E. (1991). The egg and the sperm: How science has constructed a romance based on stereotypical male-female roles. Signs, 16: 485-501.

Matzke-Karasz, R. (2005). Giant spermatozoon coiled in small egg: Fertilization mechanisms and their implications for evolutionary studies on Ostracoda (Crustacea). Journal of Experimental Zoology Part B Molecular and Developmental Evolution, 304B: 129-149.

de Meeûs T., F. Prugnolle \& P. Agnew. (2007). Asexual reproduction: genetics and evolutionary aspects. Cellular and Molecular Life Sciences, 64, 1355-1372.

Meldal, B. H. M., N. J. Debenham, P. De Ley, I. T. De Ley, J. R. Vanfleteren, A. R. Vierstraete, W. Bert, G. Borgonie, T. Moens, P. A. Tyler, M. C. Austen, M. L. Blaxter \& A. D. Rogers. (2007). An improved molecular phylogeny of the Nematoda with special emphasis on marine taxa. Molecular Phylogenetics and Evolution, 42: 622-636.

Mill, J. S. (1869 [2001]). The subjugation of women. Longmans, Green \& Co. [Transaction Publishers], London [New Brunswick, NJ], pp. 22.

Miller, D., G. C. Ostermeier \& S. A. Krawetz. (2005). The controversy, potential and roles of spermatozoa RNA. Trends in Molecular Medicine, 11: 156-163.

Morgan, T. H. (1927). Experimental embryology. Columbia University Press, New York.

Moriya, M. \& C. Katagiri. (1976). Microinjection of toad sperm into oocytes undergoing 
maturation division. Development, Growth \& Differentiation, 18: 349-356.

Morrow, E. H. (2004). How the sperm lost its tail: the evolution of aflagellate sperm. Biology Reviews, 79: 795-814.

Motlik, J. \& J. Fulka. (1974). Fertilization of pig follicular oocytes cultivated in vitro. Journal of Reproduction and Fertility, 36: 235-237.

Muller, H. J. (1964). The relation of recombination to mutation advance. Mutation Research, 1: 29.

Murray, A. W. (1992). Creative blocks: cell-cycle checkpoints and feedback controls. Nature, 359: $599-604$.

Nakashima, Y., T. Kuwamura \& Y. Yogo (1996). Both-ways sex change in monogamous coral gobies, Gobiodon spp. Environmental Biology of Fishes, 46: 281-288.

Nelson, O. (1953). Comparative embryology of the vertebrates. Blackstone, New York.

Neiman, M. (2004). Physiological dependence on copulation in parthenogenetic females can reduce the cost of sex. Animal Behaviour, 67: 811-822.

Normark, B. B. (2009). Unusual gametic and genetic systems. In T. R. Birkhead, D. J. Hosken \& S. Pitnick (eds.), Sperm biology: An evolutionary perspective, (pp. 507-538). Oxford, Elsevier.

Oliver, J. H. Jr. (1971). Parthenogenesis in mites and ticks (Arachnida: Acari). American Zoologist, 11: 283-299.

Olsen, M. W. (1960). Nine year summary of parthenogenesis in turkeys. Proceedings of the Society for Experimental Biology and Medicine, 105: 279-281.

Oprescu, S. \& C. Thibault. (1965). Duplication de l'ADN dans les œufs de lapine après la fécondation. Annales de Biologie Animale, Biochimie, Biophysique, 5: 151-156.

Ostermeier, G.C., D. Miller, J. D. Huntriss, M. P. Diamond \& S. A. Krawetz. (2004).

Reproductive biology: Delivering spermatozoan RNA to the oocyte. Nature, 429: 154.

Krawetz. (2005). A suite of novel human spermatozoal RNAs. Journal of Andrology, 26: 70-74.

Parker, G. A. (1970). Sperm competition and its evolutionary consequences in insects. Biological Reviews of the Cambridge Philosophical Society, 45: 525-567.

Petrie, M. \& B. Kempenaers. (1998). Extra-pair paternity in birds: explaining variation between species and populations. Trends in Ecology \& Evolution, 13: 52-58. 
Pichot, C., M. Maâtaoui, S. Raddi \& P. Raddi. (2001). Surrogate mother for endangered Cupressus. Nature, 412: 39.

Pitnick, S., G. S. Spicer \& T. A. Markow. (1995). How long is a giant sperm? Nature, 375: 109.

Pizzari, T. \& T. R. Birkhead. (2002). The sexually-selected sperm hypothesis: sex-biased inheritance and sexual antagonism. Biological Reviews, 77: 183-209.

Poccia, D. \& P. Collas, (1997). Nuclear envelope dynamics during male pro-nuclear development. Development, Growth and Differentiation, 39: 541-550.

Pointat, G. O. \& E. Hansen. (1983). Sex and reproductive modifications in nematodes. Helminthological Abstract - Series B, 52, 145-163.

Rothschild. (1954). Polyspermy. Quarterly Review of Biology, 29: 332-342.

Ryan, M.J. (1998). Sexual selection, receiver biases, and the evolution of sex differences. Science, 281: 1999-2003.

Scheller U. \& J. Adis. (2000). Possible parthenogenesis in Allopauropus (Myriapoda: Pauropoda). Fragmenta Faunistica, 43: 173-179.

Schlupp, I. (2005). The evolutionary ecology of gynogenesis. Annual Review of Ecology, Evolution and Systematics, 36: 399-417.

Shah, C., M. J. VanGompel, V. Naeem, Y. Chen, T. Lee, N. Angeloni, Y. Wang \& E. Y. Xu. (2010). Widespread presence of human BOULE homologs among animals and conservation of their ancient reproductive function. PLoS Genetics, 6: e1001022. DOI: 10.1371/journal.pgen.1001022.

Signorovitch, A. Y., S. L. Dellaporta \& L. W. Buss. (2005). Molecular signatures for sex in the Placozoa. Proceedings of the National Academy of Sciences of the United States of America, 102: 15518-15522.

Simmel, E. B. \& D. A. Karnofsky. (1961). Observations on the uptake of tritrated thymidine in the pro-nuclei of fertilized sand dollar embryo. Journal of Biophysical and Biochemical Cytology, 10: 59-65.

Simmons, L. W. (1987). Heritability of a male character chosen by females in the field crickets, Gryllus bimaculatus. Behavioral Ecology and Sociobiology, 21: 129-133.

Simmons, L. W. (2001). Sperm competition and its evolutionary consequences in the insects. Princeton University Press, Princeton.

Skoblina, M. N. (1976). Role of karyoplasm in the emergence of capacity of egg cytoplasm to induce DNA synthesis in transplanted sperm nuclei. Journal of Embryology and 
Experimental Morphology, 36: 67-72.

Sluder, G., E. A. Thompson, C. L. Rieder \& F. J. Miller. (1995). Nuclear envelope breakdown is under nuclear not cytoplasmic control in sea urchin zygotes. Journal of Cell Biology, 129: 1447-1458.

Snook, R. R. (2005). Sperm in competition: not playing by the numbers. Trends in Ecology \& Evolution, 20: 46-53.

Solari, A. J. (2002). Primitive forms of meiosis: the possible evolution of meiosis. BioCell, 26:113.

Spencer, H. (1863 [1890]). The principles of biology (volume 1). Williams \& Norgate [Appleton], London [New York].

Tarín, J. J. (2000). Fertilization in protozoa and metazoan animals: a comparative overview. In J.J. Tarín \& A. Cano (eds.), Fertilization in protozoa and metazoan animals: cellular and molecular aspects, (pp. 277-314). Springer-Verlag, Berlin.

Thibault, C. \& M. Gérard. (1973). Cytoplasmic and nuclear maturation of rabbit oocytes in vitro. Annales De Biologie Animale Biochimie Biophysique, 13: 145-156.

Thornhill, R. (1983). Cryptic female choice and its implications in the scorpionfly Harpobittacus nigriceps. American Naturalist, 122: 765-788.

Thornhill, R. (1984). Alternative female choice tactics in the scorpion fly Hylobittacus apicalis (Mecoptera) and their implications. American Zoologist, 24: 367-383.

Trounson, A. O., Willadsen, S. M. \& L. E. A. Rowson. (1977). Fertilization and development capability of bovine follicular oocyte matured in vitro and in vivo and transferred to the oviducts of rabbits and cows. Journal of Reproduction and Fertility, 51: 321-327.

Trudgill, D. L. \& V. C. Blok. (2001). Apomictic, polyphagous root-knot nematodes:

Exceptionally successful and damaging biotrophic root pathogens. Annual Review of Phytopathology, 39: 53-77.

Vrijenhoek, R. C., R. M. Dawley, C. J. Cole \& J. P. Bogart. (1989). A list of known unisexual vertebrates. In R. M. Dawley \& J. P. Bogart (eds.), Evolution and ecology of unisexual vertebrates (pp. 19-23). New York State Museum, Albany, NY.

Weeks, A. R., F. Marec, J. Breeuwer. (2001). A mite species that consists entirely of haploid females. Science, 292: 2479-2482.

Welch, D. \& M. Meselson. (2001). Rates of nucleotide substitution in sexual and anciently asexual rotifers. Proceedings of the National Academy of Sciences, USA, 98: 67206724. 
Whitfield, P. J. \& N. A. Evans, (1983). Parthenogenesis and asexual multiplication among parasitic platyhelminths. Parasitology 86: 121-160.

Willson, M. F. \& N. Burley. (1983). Mate choice in plants. Princeton University Press, Princeton.

Wilson, E .B. (1925). The cell in development and heredity (3rd edition). Macmillan, New York.

Wourms, J. P. (1977). Reproduction and development in chondrichthyan fishes. American Zoologist, 17: 379-410.

Wright, S. J. \& F. J. Longo. (1988). Sperm nuclear enlargement in fertilized hamster eggs is related to meiotic maturation of the maternal chromatin. Journal of Experimental Zoology, 247: 155-165.

Yadegari, R. \& G. N. Drews. (2004). Female gametophyte development. Plant Cell, 16: S133.

Yamashita, M., H. Onozato, T. Nakanishi \& Y. Nagahama. (1990). Breakdown of the sperm nuclear envelope is a prerequisite for male pro-nucleus formation: direct evidence from the gynogenetic crucian carp Carassius auratus langsdorfii. Developmental Biology, 137: $155-160$.

Yanagimachi, R. \& Y. D. Noda. (1970). Ultrastructural changes in the hamster sperm head during fertilization. Journal of Ultrastructure Research, 31: 465-485.

Zouros, E., K. R. Freeman, A. O. Ball \& G. H. Pogson. (1992). Direct evidence for extensive paternal mitochondrial DNA inheritance in the marine mussel Mytilus. Nature, 359: 412414. 
Appendix A: All parthenogenetic and gynogenetic phyla, classes, and orders in the animal kingdom (references included). "Y" signifies that gynogens or parthenogens exist in these taxa.

\begin{tabular}{|c|c|c|c|c|c|}
\hline Phylum & Class & Order & Gynogens & Parthenogens & Reference \\
\hline \multirow[t]{13}{*}{ Platyhelminthes } & \multirow[t]{2}{*}{ Monogenea } & Monopisthocotylea & & $\bar{Y}$ & De Meeas, 2007 \\
\hline & & Polyopisthocotylea & & & \\
\hline & \multirow[t]{2}{*}{ Trematoda } & Digenea & & $\bar{Y}$ & Whitfield \& Evans, 1983 \\
\hline & & Aspidogastrea & & & \\
\hline & \multirow[t]{2}{*}{ Cestoda } & Eucestoda & & $\bar{Y}$ & Whitfield \& Evans, 1983 \\
\hline & & Cestodaria & & & \\
\hline & \multirow[t]{7}{*}{ Turbellaria } & Acoela & & & \\
\hline & & Rhabdocoela & & & \\
\hline & & Macrostomida & & & \\
\hline & & Lecithoepitheliata & & & \\
\hline & & Polycladida & & & \\
\hline & & Prolecithophora & & $\bar{Y}$ & Bell, 1982 \\
\hline & & Tricladida & $\bar{Y}$ & $\bar{Y}$ & $\begin{array}{l}\text { Beukeboom \& Vrijenhoek, 1998; } \\
\text { Bell, } 1982\end{array}$ \\
\hline
\end{tabular}




\begin{tabular}{|c|c|c|c|c|c|}
\hline & & Proseriata & & & \\
\hline & & Catenulida & & & \\
\hline \multirow[t]{5}{*}{ Nematoda } & \multirow[t]{5}{*}{ Secernentae } & Rhabditida & $\bar{Y}$ & $\bar{Y}$ & Pointat \& Hansen, 1983; Bell, 1982 \\
\hline & & Ascaridida & & & \\
\hline & & Strongylida & & & \\
\hline & & Spirurida & & $\bar{Y}$ & De Meeûs, 2007 \\
\hline & & Diplogasteria & $\mathrm{Y}$ & $\bar{Y}$ & $\begin{array}{l}\text { Beukeboom \& Vrijenhoek, 1998; } \\
\text { Pointat \& Hansen, 1983; Bell, } 1982\end{array}$ \\
\hline \multirow[t]{10}{*}{ Annelida } & \multirow[t]{10}{*}{ Polychaeta } & Phyllodocida & & $\bar{Y}$ & Bell,1982 \\
\hline & & Eunicida & & & \\
\hline & & Spionida & & & \\
\hline & & Chaetopterida & & & \\
\hline & & Magelonida & & & \\
\hline & & Psammodrilida & & & \\
\hline & & Cirratulida & & & \\
\hline & & Opheliida & & & \\
\hline & & Capitellida & & & \\
\hline & & Oweniida & & & \\
\hline
\end{tabular}




\begin{tabular}{|c|c|c|c|c|c|}
\hline & & Terebellida & & & \\
\hline & & Sabellida & & & \\
\hline & & Myzostomida & & & \\
\hline & Clitellata & Oligocheata & $\bar{Y}$ & $\bar{Y}$ & $\begin{array}{l}\text { De Meeás, 2007; Beukeboom \& } \\
\text { Vrijenhoek, } 1998\end{array}$ \\
\hline & & Hirudinea & & & \\
\hline Rotifera & Monogononta & & $\bar{Y}$ & $\bar{Y}$ & $\begin{array}{l}\text { Beukeboom \& Vrijenhoek, 1998; } \\
\text { Welch \& Meselson, } 2001\end{array}$ \\
\hline & Bdelloldea & & & $\bar{Y}$ & Welch \& Meselson, 2001 \\
\hline Mollusca & Blvalvia & Protobranchia & & & \\
\hline & & Pteriomorphia & & & \\
\hline & & Paleoheterodonta & & & \\
\hline & & Heterodonta & $\bar{Y}$ & & Beukeboom \& Vrijenhoek, 1998 \\
\hline & & Anomalodesmata & & & \\
\hline & Gastropoda & Patellogastropoda & & & \\
\hline & Prosobranch & Cocculiniformia & & & \\
\hline & & Vestigastropoda & & & \\
\hline & & Neritopsina & & & \\
\hline
\end{tabular}




\begin{tabular}{|c|c|c|c|c|c|}
\hline & & Caenogastropoda & & $\bar{Y}$ & Bell,1982 \\
\hline & & Nudibranchia & & & \\
\hline & & Pleurobronchoidea & & & \\
\hline & & Cephalaspidea & & & \\
\hline & Gastropoda & Sacoglossa & & & \\
\hline & Opisthobranchia & Anaspidea & & & \\
\hline & & Acochlidioidea & & & \\
\hline & & Eupulmonata & & & \\
\hline & Gastropoda & Basommatophora & & & \\
\hline & Pulmonta & Systellommatophora & & & \\
\hline ppoda & Arachnida & Acarina & $\bar{Y}$ & $\mathrm{Y}$ & $\begin{array}{l}\text { Beukeboom \& Vrijenhoek, 1998; } \\
\text { Weeks, 2001; Bell, 1982; Oliver, } \\
1971\end{array}$ \\
\hline & & Amblypygi & & & \\
\hline & & Araneae & & $\bar{Y}$ & De Meeas, 2007 \\
\hline & & Opiliones & & $\bar{Y}$ & De Meeûs, 2007 \\
\hline & & Palpigradi & & & \\
\hline & & Pseudoscorpionida & & & \\
\hline
\end{tabular}




\begin{tabular}{|c|c|c|c|}
\hline & Ricinulei & & \\
\hline & Schizomida & & \\
\hline & Scorpiones & $\bar{Y}$ & De Meeas, 2007; Bell, 1982 \\
\hline & Solifugae & & \\
\hline & Thelyphonida & $\bar{Y}$ & Bell, 1982 \\
\hline Chilopoda & Scutigeromorpha & & \\
\hline & Lithobiomorpha & $\bar{Y}$ & $\begin{array}{l}\text { Edgecombe \& Giribet, 2003; Bell, } \\
1982\end{array}$ \\
\hline & Craterostigmomorpha & & \\
\hline & Scolopendromorpha & & \\
\hline & Geophilomorpha & & \\
\hline Diplopoda & Polyxenida & $\bar{Y}$ & Bell, 1982 \\
\hline & Callipodida & & \\
\hline & Julida & $\bar{Y}$ & Bell, 1982 \\
\hline & Polydesmida & $\bar{Y}$ & Bell, 1982 \\
\hline & Spirostreptida & & \\
\hline & Glomerida & & \\
\hline & Sphaerotheriida & & \\
\hline
\end{tabular}




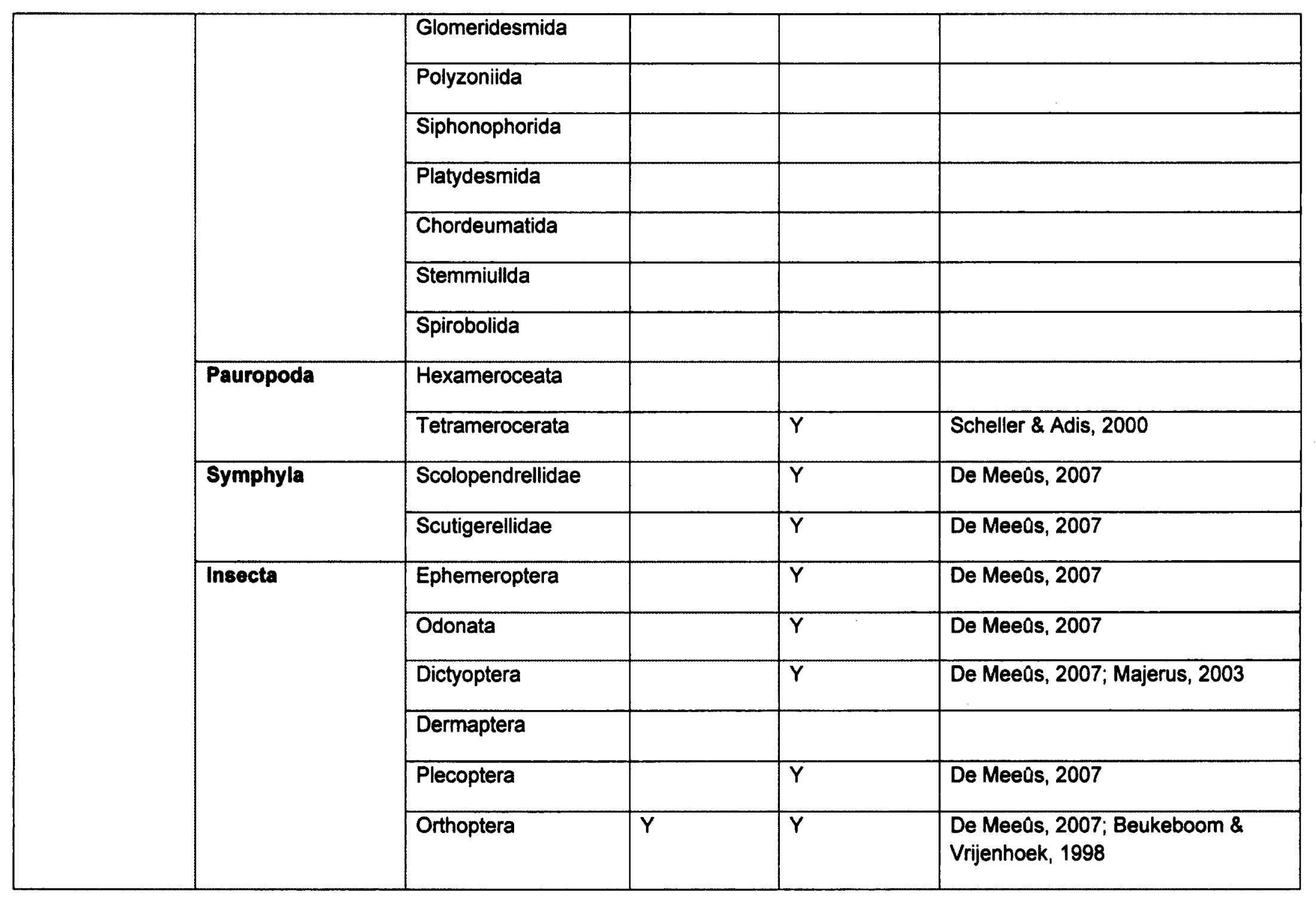




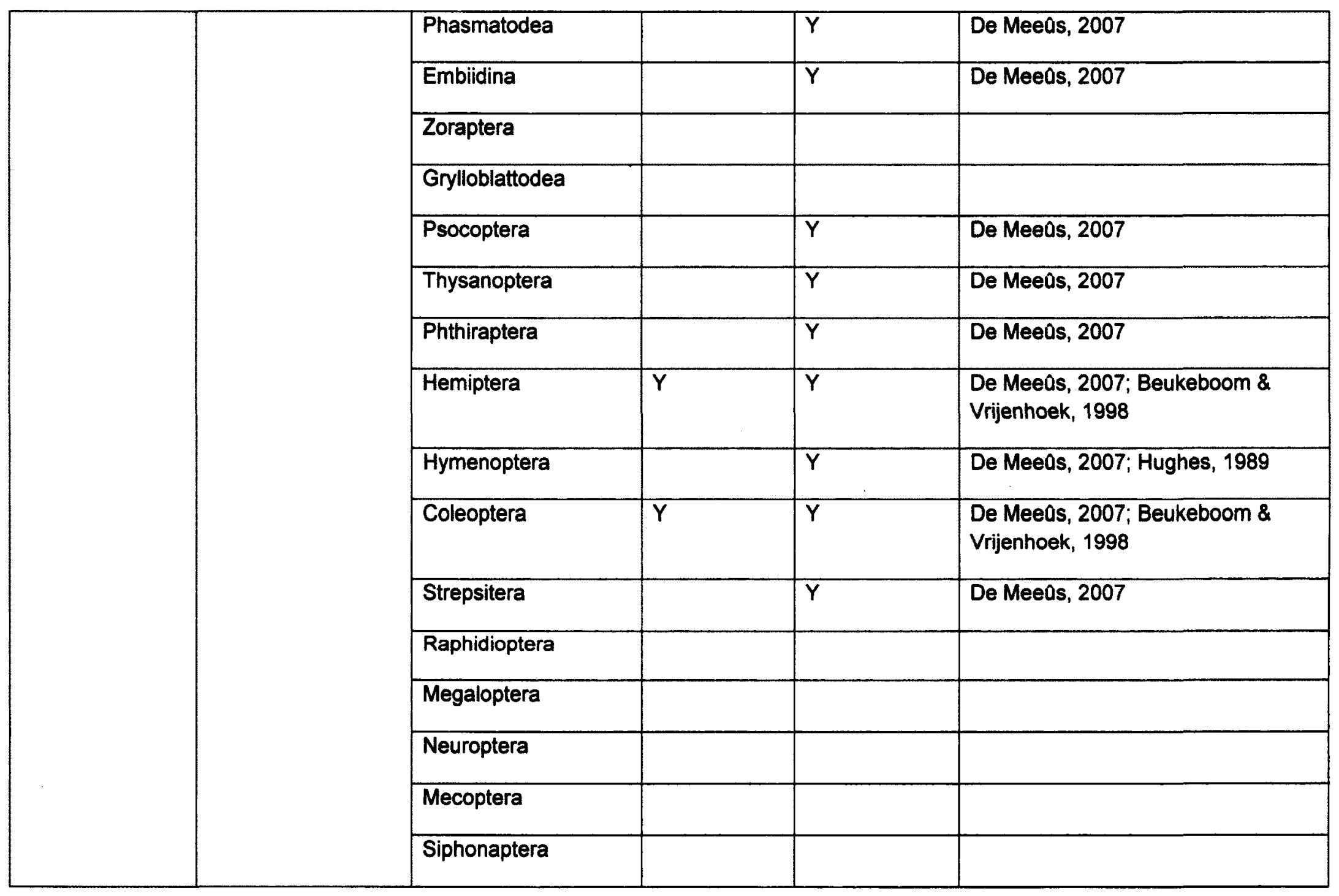




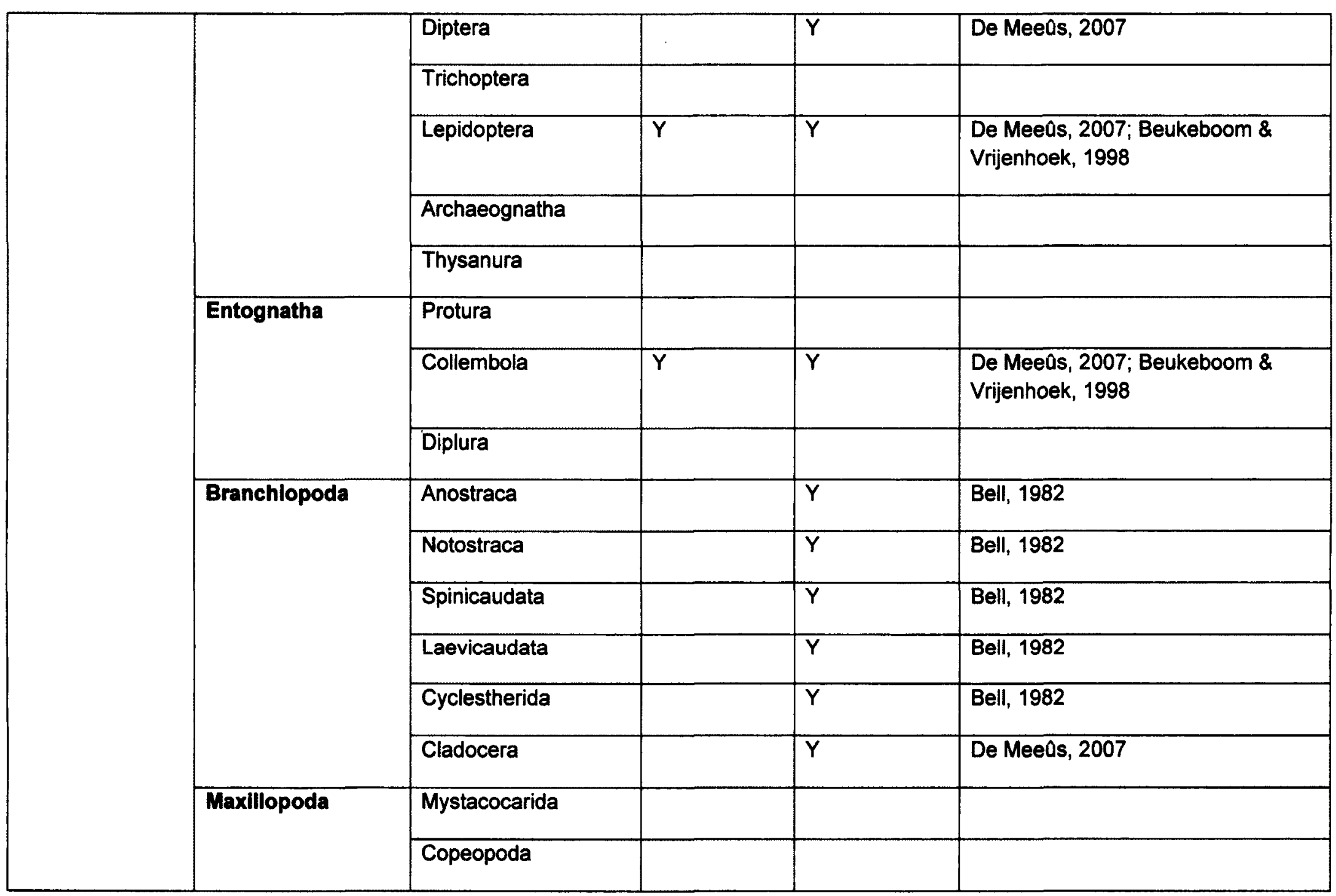




\begin{tabular}{|c|c|c|c|c|c|}
\hline & & Branchiura & & & \\
\hline & & Pentastomida & & & \\
\hline & & Thecostraca & & $\bar{Y}$ & De Meeus, 2007 \\
\hline & & Tantulocarida & & & \\
\hline & Ostracoda & Podocopida & & $\bar{Y}$ & Bell, 1982 \\
\hline & & Platycopida & & & \\
\hline & & Kirkbyocopida & & & \\
\hline & & Myodocopida & & & \\
\hline & Malacostraca & Eumalacostraca & & $\mathrm{Y}$ & De Meeus, 2007 \\
\hline & & Hoplocarida & & & \\
\hline & & Phyllocarida & & & \\
\hline Chordata & Amphibia & Anura & $\bar{Y}$ & & Beukeboom \& Vrijenhoek, 1998 \\
\hline & & Urodela & $\bar{Y}$ & & Beukeboom \& Vrijenhoek, 1998 \\
\hline & & Caecilian & & & \\
\hline & Reptllia & Crocodilia & & & \\
\hline & & Testudines & & & \\
\hline & & Sphenodontia & & & \\
\hline
\end{tabular}




\begin{tabular}{|c|c|c|c|}
\hline & Squamata & $\bar{Y}$ & De Meeus, 2007 \\
\hline \multirow[t]{16}{*}{ Aves } & Struthioniformes & & \\
\hline & Tinamiformes & & \\
\hline & Apterygiformes & & \\
\hline & Gavifformes & & \\
\hline & Columbiformes & & \\
\hline & Procellariiformes & & \\
\hline & Pelecaniformes & & \\
\hline & Ciconiiformes & & \\
\hline & Anseriformes & & \\
\hline & Falconiformes & & \\
\hline & Galliformes & $\mathrm{Y}$ & Olsen, 1960 \\
\hline & Gruiformes & & \\
\hline & Charadriiforms & & \\
\hline & Cuculiformes & & \\
\hline & Pisttacifromes & & \\
\hline & Strigiformes & & \\
\hline
\end{tabular}




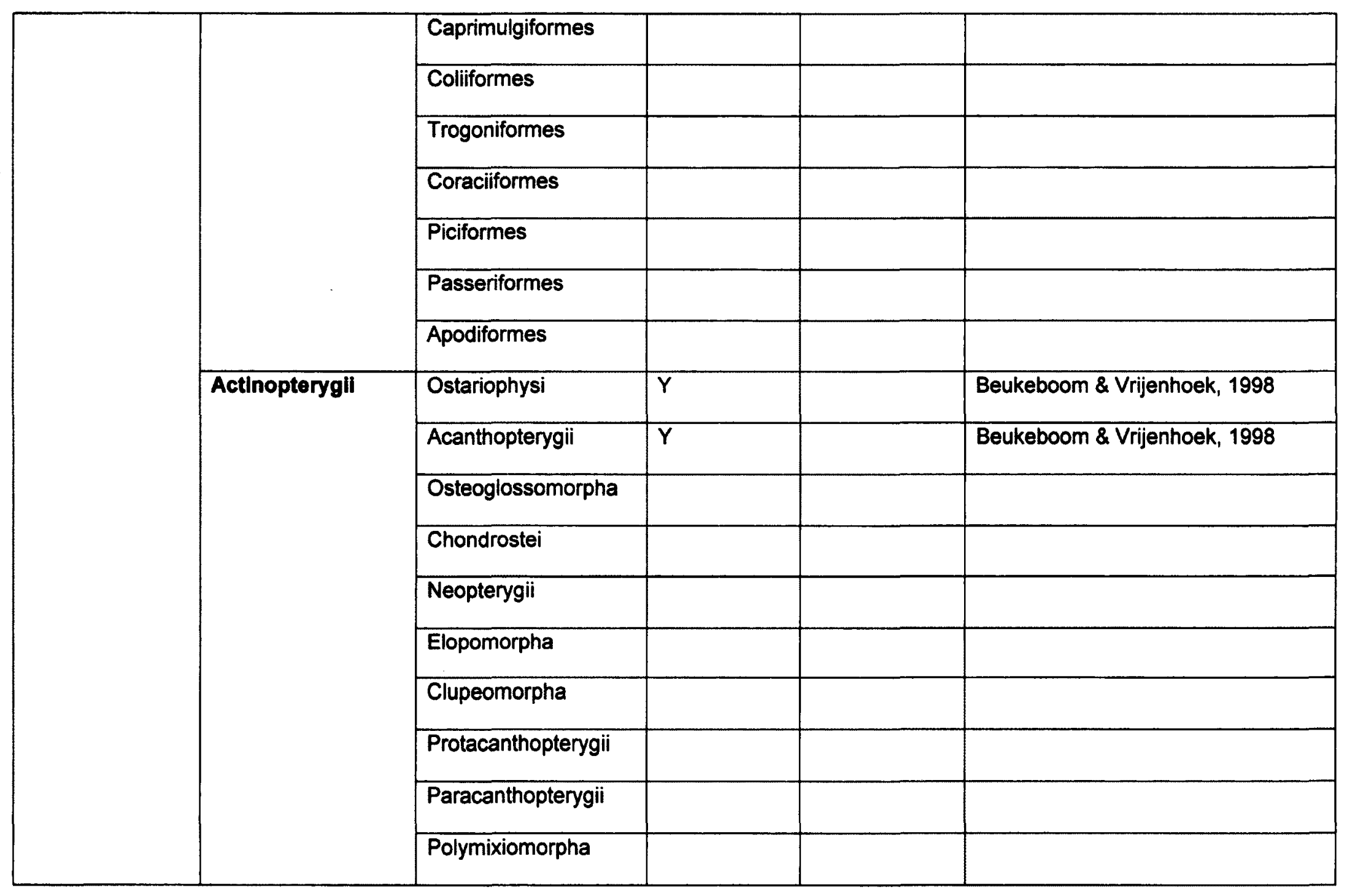




\begin{tabular}{|l|l|l|l|l|l|}
\hline & & Lampridiomorpha & & & \\
\cline { 3 - 6 } & & Scopelomorpha & & & \\
\cline { 3 - 6 } & & Cyclosquamata & & & \\
\cline { 3 - 6 } & Stenopterygii & & & \\
\cline { 3 - 6 } & Chondrichthyes & Elasmobranchii & & Y & Feldheim et. al., 2007 \\
\cline { 3 - 6 } & & Holocephali & & & \\
\hline
\end{tabular}


Appendix B: Gorelick, Derraugh, Carpinone, Bertram (2011). Post-plasmogamic, prekaryogamic sexual selection: Mate choice inside an egg cell. Ideas in Ecology and Evolution, 4: 14-23. 


\title{
cee
}

IDEA IN EODLOUY AND EVOLUTION 4: 14-23, 2011

doi: 10.4033/iee.2011.4.3.n

(c) 2011 The Author. (c) Ideas in Ecology and Evolution 2011

Received 12 April 2011; Accepted 30 August 2011

\section{New Idae}

\section{Post-plasmogamic pre-karyogamic sexual selection: mate choice inside an egg cell}

\author{
Root Gorelick $^{1,2}$, Lindsay Jackson Derraugh ${ }^{1}$, Jessica Carpinone ${ }^{1}$, and Susan M. Bertram \\ Root Gorelick (Root_Gorelick@carleton.ca),Dept. of Biology, and School of Mathematics \& Statistics, Carleton \\ University, 1125 Colonel By, Ottawa, Ontario, CANADA KIS $5 B 6$
}

Lindsay Jackson Derraugh (LindsayDerraugh@gmail.com), Dept. of Biology, Carleton University, 1125 Colonel By, Ottawa Ontario, CANADA K1S $5 B 6$

Jessica Carprinone (JessicaCarpinone@gmail.com), Dept. of Biology, Carleton University, 1125 Colonel By, Ottawa Ontario, CANADA KIS $5 B 6$

Susan M. Bertram (Sue_Bertram@carleton.ca), Dept. of Biology, Carleton University, 1125 Colonel By, Ottawa Ontario, CANADA KIS $5 B 6$

The first three authors contributed equally to the manuscript.

${ }^{2}$ Corresponding author

\begin{abstract}
Intersexual selection is often categorized as precopulatory or post-copulatory mate choice by individuals of one sex over showy individuals of the other sex. We extend the framework of post-copulatory choice to include post-plasmogamic pre-karyogamic sexual selection. That is, selection of haploid nuclei within the microcosm of a single fertilized egg cell after sperm has entered an egg cell but before fusion of their nuclear membranes, in which an egg nucleus chooses a sperm nucleus with which to fuse. The role of sexual selection at this nuclear level is probably small in monospermic out-crossers, but large in polyspermic outcrossers. Post-plasmogamic pre-karyogamic sexual selection may also explain how the sperm nucleus is rejected in gynogens, and how the egg nucleus is rejected in androgens. We propose that male and female nuclei behave independently within an egg cell, and that post-plasmogamic pre-karyogamic mate choice is largely based on either (1) a pre-existing sensory bias for certain characteristics of the sperm pronuclear membrane, or (2) detection of good genes through signal (mRNA) detection.
\end{abstract}

Key Words: Sexual selection, cryptic female choice, pronucleus, polyspermy, gynogenesis, androgenesis.

\section{Introduction}

Charles Darwin (1871) first introduced the idea of sexual selection to account for the differences in secondary sexual characteristics that could not be explained by natural selection. He defined sexual selection as differential reproductive success that results from variation among individuals in their success at obtaining mates. Darwin (1871) subdivided sexual selection into intrasexual selection, where one sex (typically males) competes aggressively with other members of the same sex for access to the opposite sex, and intersexual selection, where one sex (again typically males) competes with each other for the other sex's attention. Intrasexual selection usually results in the evolution of elaborate weaponry, aggressive behaviors, and defensive characteristics, while intersexual selection usually results in the evolution of exaggerated sexual 
signals and female preferences for those signals (Andersson 1994). Although Darwin (1871) proposed his ideas to account for elaborate pre-copulatory sexual displays and preferences, his ideas have since been expanded to include forms of post-copulatory choice, such as sperm competition (Parker 1970) and cryptic female choice (Thornhill 1983). Sperm competition occurs when sperm from multiple males compete with each other for the opportunity to fertilize an ovum (Parker 1970, Birkhead and Møller 1998). The result of sperm competition is evolution of male traits that increase the sperm's fertilization success including increased sperm number, increased sperm size, seminal fluids, sperm removal, and copulatory plugs or mate guarding (reviewed by Birkhead and Møller 1998, Simmons 2001, Snook 2005). Sperm competition can be thought of as the post-copulatory (pre-fertilization) equivalent to intrasexual selection.

Cryptic female choice is the post-copulatory equivalent to intersexual selection (Thornhill 1983, 1984). Eberhard (1996) defines cryptic female choice as the ability of females to consistently favor the copulatory partners that possess a particular trait that is lacking or less fully developed in other males. Cryptic female choice operates at several levels, including dumping sperm from previous mates (reviewed in Eberhard 1996) and increasing the duration of copulation (Hoikkala and Crossley 2000, Hoikkala et al. 2000). In the postcopulatory reproductive process, cryptic female choice can include increased sperm precedence (Edvardsson and Arnqvist 2000). Cryptic female choice also operates after zygote formation, including at the egg laying stage (laying more eggs; Barbosa 2009), at the developmental stage (through differential abortion of embryos; Hull 1964, Willson and Burley 1983), at the re-mating stage (enhanced resistance to future mates; King and Fischer 2005), and at the offspring stage through differential investment into offspring who were sired by different males (Willson and Burley 1983, Simmons 1987, Burley 1988, Eberhard 1996).

Here we extend this framework of sexual selection to include post-plasmogamic pre-karyogamic cryptic female choice of haploid nuclei within the microcosm of a single egg cell after entry of the sperm nucleus or nuclei into the egg (after plasmogamy), but before fusion of the egg and sperm nucleus (before karyogamy). Technically, egg and sperm nuclei (or pronuclei) do not usually fuse with one another, but instead their two nuclear membranes dissolve and are replaced with a single new nuclear membrane. Nonetheless, we will use the common vernacular of referring to karyogamy as nuclear or pronuclear fusion. We propose that in polyspermic outcrossers (multiple sperm nuclei within one egg), egg nuclei may be able to consistently favor sperm that possess a particular trait that is lacking or less fully developed in other sperm. Post-plasmogamic pre-karyogamic female choice within the microcosm of an egg cell would occur if the egg nucleus were to move about the cell and discriminate between multiple male nuclei before selecting one to fuse with. We hypothesize that this intersexual post-plasmogamic pre-karyogamic choice may regularly occur in polyspermic out-crossers based on tantalizing evidence from ctenophores (comb jellies; Carré and Sardet 1984). While it is theoretically possible for intrasexual selection and choice to exist inside an egg cell, conspicuously we do not see evidence for male-male nor female-female interactions within this egg microcosm.

Post-plasmogamic pre-karyogamic sexual selection has been very briefly mentioned by Tim Birkhead, but never fully developed. Birkhead (1998) includes a paragraph alluding to the possibility of post-plasmogamic pre-karyogamic sexual selection based on the intriguing work of Carré and Sardet (1984), which we also discuss below. Even more explicitly, albeit more succinctly, Birkhead and Brillard (2007) include two sentences on pronuclei choosing one another. A recent review of egg-sperm interactions (Karr et al. 2009) mentions nothing about post-plasmogamic prekaryogamic sexual selection except to say that sperm nuclei may emit mRNA that egg nuclei can detect. None of the other major reviews of post-copulatory sexual selection or sexual choice-such as Eberhard (1996), Simmons (2001), Pizzari and Birkhead (2002), or Arnqvist and Rowe (2005) -allude to anything even remotely resembling post-plasmogamic pre-karyogamic sexual selection. Therefore, in this paper, we develop the theoretical framework by which post-plasmogamic pre-karyogamic female choice of haploid nuclei may occur. We present evidence showing the conditions of the framework, including independently behaving nuclei and differences between nuclei within an egg cell, especially with polyspermy. We also show how postplasmogamic pre-karyogamic sexual selection may explain how the sperm nucleus is rejected in gynogens, and how the egg nucleus is rejected in androgens. And, finally, we briefly discuss how post-plasmogamic prekaryogamic choice may make sexual selection more common than originally thought.

\section{Post-plasmogamic pre-karyogamic sexual selection has the potential to exist}

Two requirements must be met in order for postplasmogamic pre-karyogamic sexual selection to occur. First, nuclei must be able to behave independently. Based on differences between egg and sperm nuclei in (1) presence of pores, (2) timing of nuclear membrane breakdown, and (3) timing of duplication and reduction events, we argue that male and female nuclei are 
controlled separately by nuclear rather than cytoplasmic factors. Because of this differential control between the two haploid sexes, egg nuclei may have the ability to choose sperm nuclei. Second, there must be detectable differences between sperm nuclei for post-plasmogamic pre-karyogamic female choice to have selective consequences. We argue these detectable differences are based on either the proportion of original male membrane that is replaced during pronuclear formation and/or differential mRNA signals (see Karr et al. 2009 and references therein, which we discuss below).

\section{Can different nuclei within a single egg cell behave independently?}

To consider selection inside an egg cell, we first must establish whether the nuclei inside an egg cell behave individually. If the nuclei inside an egg-both egg and sperm nuclei-are all controlled in the same manner by egg cytoplasmic factors, it would be inaccurate to characterize the male and female nuclei as being capable of independent actions and selection. Mate choice requires independent control by one individual doing the choosing and another individual being chosen, where the individuals here are haploid nuclei.

When the timing of chromatin condensation and decondensation, and the timing of nuclear envelope breakdown of the egg and sperm nuclei are considered, it becomes apparent that nuclei and pronuclei within an egg cell do in fact behave as individuals. In outcrossing animals, sperm almost always inseminate the egg at an arrested stage of meiosis (Wilson 1925, Austin 1965). The stage at which meiosis is arrested varies depending on the taxon; most vertebrates are arrested at metaphase II of meiosis at the time of plasmogamy (fusion of cellular membranes). At plasmogamy, egg chromosomes are condensed and lined up at the metaphase plate. When a sperm enters an egg, the sperm nucleus almost immediately undergoes a dispersal of its chromatin, while egg chromatin remains condensed (Longo 1987, Wright and Longo 1988). Wright and Longo (1988: 155) noted, "The sperm nucleus undergoes dispersion following its incorporation, resulting in a significant expansion of its volume. Concomitantly, the maternal chromatin, which is condensed, completes meiosis. How the paternal and maternal genomes are regulated to undergo such divergent processes, dispersion versus condensation, within a common cytoplasm has not been determined." Both male and female nuclei in the same cytoplasm act independently with respect to when their nuclear envelopes breakdown and their chromosomes decondense. We propose that the divergent processes of the egg and sperm nuclei prior to karyogamy can be explained by the presence/absence of nuclear pores.
Because the sperm nucleus lacks pores upon plasmogamy, it can behave independently of the egg's cytoplasm.

We assert that sperm and egg nuclei act as truly separate individuals in that they are under separate (nuclear) control, as opposed to cytoplasmic control. It is important to note that sperm nuclei are usually only effective at karyogamy if they form a pronucleus. The process of pronuclear formation encompasses the breakdown of the poreless male nuclear membrane followed by the reformation of a new nuclear membrane composed mostly of porous female endoplasmic reticulum material. This event is the only instance in nature when nuclear membrane breakdown occurs in the absence of chromosomal reduction or duplication. We reject the usage of the term "pronucleus" to describe the egg nucleus prior to karyogamy because, unlike sperm nuclear envelopes, the egg nuclear envelopes only are replaced as part of a nuclear division, a parsing of half the chromosomes into two separate nuclei (Longo 1985). The fact that the only place that nuclear envelope breakdown is ever observed prior to DNA replication occurs in males during pronuclear formation, shortly after it enters into the egg, confirms how sperm nuclei are able to evade the egg's cell cycle control. After, or sometimes during, chromatin dispersion, the sperm sheds its nuclear membrane (Longo 1985). Normally, the tight constraints of the cell cycle, specifically the $\mathrm{G}_{2}$ /M-phase checkpoint, would not allow for nuclear envelope breakdown to occur prior to DNA replication (Hartwell and Weinert 1989, Murray 1992, Sluder et al. 1995). However, the sperm evades the egg's intrinsic controls, likely because of its poreless membrane.

While formation of the sperm pronucleus is probably mediated at least in part by cytoplasmic factors originating from the egg's germinal vesicle (Moriya and Katagiri 1976, Skoblina 1976), a male pronuclear growth factor is also thought to exist (Thibault and Gérard 1973, Motlik and Fulka 1974, Trounson et al. 1977). Nuclear envelope breakdown is under cytoplasmic control in mitotic and meiotic cell divisions. Mitosis-promoting factor is a cytoplasmic factor that normally drives a cell into a division by forcing nuclear envelope breakdown. However, this is not the case for pronuclei within an egg. Nuclear envelope breakdown of the male pronucleus and the female nucleus is under nuclear, not cytoplasmic, control (Sluder et al. 1995). Thus, from the time of sperm entry, to the formation of the sperm pronucleus, to the breakdown of the pronuclear envelope, sperm nuclei are under different controls from egg nuclei.

The fact that male and female nuclei are controlled separately within a single egg cell is essential to recognize if a discussion of post-plasmogamic prekaryogamic sexual selection is to take place. 
Do nuclei within a single egg cell have detectable differences?

For post-plasmogamic pre-karyogamic sexual selection, there must be some kind of detectable differences between male nuclei/pronuclei upon which a choosy egg nucleus can make a choice. We propose that differences between the multiple sperm nuclei/pronuclei in an egg cell may reside in the nuclear envelopes of the sperm pronuclei or in the signals sperm pronuclei send.

We hypothesize that sexual selection within an egg is most likely to occur when there are multiple sperm pronuclei within an egg cell, i.e. polyspermy. Polyspermy occurs in a wide variety of taxa including birds, reptiles, elasmobranch fishes, urodele amphibians, mollusks, arachnids, insects, bryozoans, and ctenophores (Nelson 1953, Rothschild 1954, Wourms 1977, Carré and Sardet 1984, Iwamatsu 2000). Polyspermic organisms have evolved one or more mechanisms to allow multiple sperm, sometimes well over twenty and occasionally hundreds of sperm (Dean 1906), to participate in plasmogamy with a single egg, yet still only allow one male pronucleus to participate in karyogamy with the female nucleus. Although it is often assumed that female nuclei simply fuse with the closest male pronucleus in polyspermic situations, there is strong evidence to suggest otherwise. In at least one species of comb jelly (Beroe ovata), the female nucleus within the polyspermic egg does not fuse with the first male nucleus that enters the cell, nor does it fuse with the closest. Instead, upon plasmogamy, the female Beroe ovata nucleus migrates within the egg cell-from male pronucleus to pronucleus-before finally fusing with just one (Carré and Sardet 1984). The only data showing a female nucleus querying of multiple male pronuclei comes from this one species of comb jelly, and the purpose of this migration is unknown.

Why does the female not simply fuse with the closest male pronucleus or the male pronucleus that enters the cell first? This question is really the same as the more general one that has plagued evolutionary biologists for decades: why should females be choosy when they receive no obvious benefits from males except for their genetic contribution? Based on existing well-developed hypotheses for the evolution of female preference, we propose two hypotheses as likely candidates to explain evolution of post-plasmogamic pre-karyogamic cryptic female choice that occurs within the microcosm of a fertilized egg cell: (1) Females base their choice on a pre-existing bias for self, based on the mosaic characteristics of sperm pronuclear membrane, and (2) Females detect good genes via mRNA signals.

Our first hypothesis is based on sensory bias: that the chosen sperm contains the most female-like nuclear membrane. The sensory bias hypothesis suggests that female preferences are by-products of the underlying physiology of the female's sensory systems. Natural selection has molded the female's sensory systems, and males are proposed to have evolved traits that match the female's sensory system characteristics (Basolo 1990, 1995, Endler and Basolo 1998, Ryan 1998). When sperm enter an egg cell, they shed their nuclear membrane and replace it with egg membrane material. In the process, some taxa, such as the sea urchin Arbacia (Longo 1973) and the hamster (Yanagimachi and Noda 1970), retain parts of their sperm nuclear envelope, thus, the newly formed pronucleus is a mosaic. Sperm retain part of their original nuclear membrane, with variation between sperm being a function of the amount and/or composition of nuclear membrane retained (Yanagimachi and Noda 1970, Longo 1976). There is a noticeable gap in the literature with regards to the function of replacing a sperm nucleus with a pronucleus. We argued elsewhere that sperm shed their nuclear membrane and replace it with one made from egg material because they need nuclear pores to complete DNA replication (Gorelick et al. 2012, Carpinone and Gorelick in review). Here we also hypothesize that the pronucleus may have a secondary function to deliver specific information to the female nucleus that aids in her mate choice. Sperm pronuclear membranes may provide the variation necessary for sexual selection to be possible. We suspect that in polyspermic organisms, the female selects the male that retains the least amount of sperm nuclear membrane (poreless verses porous membrane). The idea that there is selection pressure on sperm to be better female mimics comes from analyzing the conditions faced by the first sexual organisms. The first sexual organisms probably had sex with themselves (i.e. were automictic; Gorelick and Carpinone 2009) and did not use sperm, but instead restored diploidy by either simply replicating all their chromosomes (endomitosis) or by the fusion of two haploid products of egg meiosis with one another. In such an ancestral condition, any invasion of the egg by another nucleus, a sperm nucleus, would have been detrimental. Early sexual organisms would have had eggs that fused with their own polar nuclei (Gorelick and Carpinone 2009), which are virtually identical to the egg nucleus. This could be why females still prefer to fuse with something similar to self. In monospermic out-crossers, female nuclei have a choice between fusing with a polar nucleus or the sperm pronucleus. Because of self-incompatibility, however, eggs preferentially fuse with something that is similar to self, but not identical. We call this the Trojan sperm hypothesis: males don pronuclear membranes to 'mimic' females in order to be chosen for karyogamy, due to a pre-existing bias for the females to fuse with themselves.

We digress to discuss our somewhat unconventional definition of sex as either meiosis or karyogamy, 
especially in light of automixis. With this definition, most or possibly even all eukaryotes become facultatively sexual, at least if we accept reports of cryptic meiosis, especially in basal taxa (Solari 2002, Gandolfi et al. 2003, Signorovitch et al. 2005, Cooper et al. 2007, Gorelick and Carpinone 2009). This definition also means that parasex should count as sex (Forche et al. 2008, Gorelick and Carpinone 2009). There is no difference between autogamy and complete automixis, except that automixis contains diploid mitotic divisions between karyogamy and meiosis. The notion that fusion of gametes defines sex is an anachronism, described before meiosis was elucidated. For example, Spencer (1863 [1890]) described how fusion of gametes defined individuals, while Braun (1853 [1851]) and Butschli (1876) described how fusion of gametes rejuvenated a lineage, and they did this long before Hertwig (1890) elucidated that meiosis was a reduction division. We have also demonstrated that karyogamy is a modified form of meiosis (Gorelick and Carpinone 2009), making the definition of sex as either meiosis or karyogamy both simple and general.

Our second hypothesis regarding the evolution of female choice on the nuclear level is based on the good genes hypothesis, with a positive genetic covariance between male displays and their viability (Iwasa et al. 1991, Jennions and Petrie 2000, Houle and Kondrashov 2002). The good genes hypothesis also assumes that there is genetic variation in female preference, which results in covariance between preference and viability (Iwasa et al. 1991, Jennions and Petrie 2000, Houle and Kondrashov 2002). Preferences start out at a naturally selected optimum, but are then pushed from the optimum by selection for high viability. Males with very attractive displays indicate their higher overall viability to females more than males with less attractive displays. By preferring these males, females receive better genes that may be passed on to their offspring. The good genes hypothesis suggests that there is no direct selection on the preference. Instead, there is only direct selection for high viability. What we add to this existing sexual selection theory is that males could simply be individual sperm nuclei or pronuclei. In polyspermic organisms, we hypothesize that the female nucleus migrates to several pronuclei before selecting one. The female nucleus does not come into contact with male pronuclei, but enters into the "pronuclear zone", an area close to the pronucleus (Carré and Sardet 1984). Once the female nucleus enters into the pronuclear zone, it commits to karyogamy with that particular pronucleus. During the period of female nuclear migration, male pronuclei contain decondensed DNA (Longo 1985). It is plausible that male pronuclei are actively transcribing mRNA and that female nuclei can detect these mRNA signals and are using the quality or nature of these signals as a basis for their choice. There is also evidence that sperm nuclei, before they lose their nuclear membrane and decondense their chromosomes, emit mRNAs (Ostermeier et al. 2004, Krawetz 2005, Miller et al. 2005, Ostermeier et al. 2005, Dadoune 2009). In this case, males are actively advertising to females. We call this the good haploid genes hypothesis, which is like the sexy sperm hypothesis, but with the individuals being sperm nuclei or pronuclei, rather than entire sperm. Sexual selection for individual sperm nuclei/ pronuclei was briefly alluded to by Birkhead (1998) and Birkhead and Brillard (2007).

\section{Implications of post-plasmogamic pre-karyogamic sexual selection for alternative sexual systems}

We next outline the implications of sexual selection inside the microcosm of an egg cell for polyspermic, gynogenetic, and androgenetic taxa, which may shed additional observability into post-plasmogamic prekaryogamic sexual selection. The major implications for the theory developed herein are for polyspermy, which occur in virtually every animal group. Postplasmogamic pre-karyogamic sexual selection is also applicable to gynogenesis, which occurs in almost 60 metazoan species spanning seven phyla, including chordates, mollusks, arthropods, rotifers, platyhelminthes, nematodes, and annelids (Beukeboom and Vrijenhoek 1998), and androgenesis, which only occurs in two metazoan genera, Corbicula freshwater clams and Bacillus stick insects (Mantovani and Scali 1992, Komaru et al. 1998). We focus our discussion on gynogenesis and androgenesis because they may be the easiest place to find evidence for post-plasmogamic prekaryogamic sexual selection.

\section{Implications of post-plasmogamic pre-karyogamic sexual selection for polysperms}

Polyspermic organisms may be the most informative species in which to study post-plasmogamic prekaryogamic sexual selection. Not only can there be hundreds of male nuclei within a single egg cell, but these male nuclei may even be from different diploid males. Sexual selection theory predicts that when the number of males in a population is high and the variation between these males is great, females should be choosier (Emlen 1976). Females should survey more individual males before choosing one with which to mate. Sexual selection should be low in monogamous systems, while high in polygamous systems (Emlen and Oring 1977). These ideas can be applied to the microcosm of an egg cell, the only difference here being that the individuals involved are haploid nuclei and pronuclei, and that the population includes only those 
individuals within a given egg cell. Thus, in postplasmogamic pre-karyogamic sexual selection, we predict that polyspermic polygamous female nuclei will be choosier and therefore migrate around the egg more compared to polyspermic monogamous female nuclei. Good test species include those from clades in which organisms show polyspermy in most species, but have varying degrees of (diploid) polygamous and monogamous matings. Amongst polyspermic vertebrates, female salamanders and birds mate with multiple males (Jordan 1893, Blount 1909, Fankhauser 1932, Fankhauser and Moore 1941, Petrie and Kempenaers 1998, Gopurenko et al. 2006). Amongst polyspermic invertebrates, females mate with multiple males in those taxa that broadcast their sperm, such as bryozoans (Rothschild 1954). These test species would enable a comparison of haploid female migration patterns between species that have (1) eggs containing multiple sperm from the same male and (2) eggs containing multiple sperm coming from multiple males.

\section{Implications of post-plasmogamic pre-karyogamic sexual selection for gynogens}

Formation of a pronucleus is a prerequisite for karyogamy between egg and sperm nuclei, however, failure to form a sperm pronucleus does not always lead to a lack of a viable zygote. Egg cells sometimes restore diploidy without incorporating a sperm's chromosomes. While egg meiosis in all animals (except cnidarians, sea urchins, and some starfish; Tarín 2000) requires plasmagamy, zygote formation in over 50 species across seven phyla does not require karyogamy between male and female haploid nuclei (Beukeboom and Vrijenhoek 1998). This situation is termed gynogenesis, where sperm are needed for the resumption of arrested egg meiosis (and maybe some epigenetic factors?), but where sperm chromosomes do not get passed on to the zygote. Gynogens are unisexual female hybrids whose eggs participate in plasmogamy but not karyogamy, with sperm. During gynogenesis, two egg nuclei can fuse to form a zygote, with no contribution from the sperm. Restitutional meiosis or pre-meiotic doubling of egg nuclei is also possible. In gynogenetic eggs, like the eggs of polysperms, and in all eggs that have arrested meiosis, there are multiple nuclei-both female and male nuclei/pronuclei-with which the female nuclei can participate in karyogamy. With polyspermy, female nuclei choose a male nucleus to associate/fuse with, whereas with gynogenesis, female nuclei choose another female nucleus (its own polar body or polar nucleus) to associate/fuse with.

Why are gynogens not fusing with the sperm that fertilizes the egg, like their close relatives do? In at least one species of gynogenetic carp (Carassius auratus langsdorfii), the sperm that fertilizes the egg fails to form a pronucleus and is subsequently ejected (Yamashita et al. 1990). Sperm that fertilize gynogens should be able to form a pronucleus insofar as studies have shown that pronuclear formation is not a speciesspecific process (see Longo 1985 for a review). However, for some reason, in Carassius auratus langsdorfii, the pronucleus does not form. We hypothesize that all sperm fertilizers of gynogens are rejected by the egg (at least in part) because they fail to form pronuclei, which (as previously discussed) may be the basis of female choice. Sperm that fertilize gynogenetic eggs are compatible enough to induce completion of egg meiosis. If post-plasmogamic pre-karyogamic sexual selection is occurring in gynogens, we predict that gynogenetic egg nuclei migrate, like in polyspermic amphimicts, to one or more nuclei within the egg cell. The male nuclei, however, have not formed pronuclei and therefore are not chosen for karyogamy because they are neither (1) exploiting the females pre-existing bias for a porous membrane, nor (2) sending out enticing mRNA signals due to lack of nuclear pores. The gynogen rejects all male nuclei and restores ploidy either by endoduplication or by choosing another haploid female to fuse with (i.e. her polar body).

\section{Implications of post-plasmogamic pre-karyogamic sexual selection for androgens}

Female choice on the nuclear level seems plausible and maybe even likely for both polyspermic and gynogenetic organisms. Female nuclei can distinguish between different male nuclei (with polyspermy) and between male and female nuclei (with gynogenesis and outcrossing). Are female nuclei the only nuclei that choose between mates? This leads to questions surrounding androgenesis, where sexual role reversal may occur within an egg cell. So far, the only known obligate androgens found in the animal kingdom are in the genus Corbicula of freshwater clams. The eggs of these clams are readily fertilized by diploid, triploid, or tetraploid biflagellate sperm (biflagellate sperm is very peculiar in unikonts). Upon meiosis, the egg's genetic material is extruded as two (presumably) diploid polar bodies (Komaru et al. 1998). Androgenesis also occurs obligately in one conifer, Cupressus dupreziana, by means of diploid sperm (Pichot et al. 2001), and facultatively in Bacillus stick insects (Mantovani and Scali 1992). Facultative androgens are fertilized by haploid sperm, and diploidy is restored, like in gynogens, either by endomitosis, or karyogamy between two haploid male pronuclei. Spontaneous androgenesis is rare, typically occurring via endomitosis of a single haploid sperm nucleus in some fish and angiosperms. In androgenesis, all egg nuclei are discarded as polar bodies or degenerate. Why are the female nuclei being rejected in these species? We hypothesize that male 
nuclei can occasionally exert choice over female nuclei by rejecting the female nucleus. Somehow, male nuclei within an egg manipulate the egg to reject itself. The mechanics behind this antithetical rejection of egg nuclei is unknown. We take the liberty here to hypothesize that male nuclei still take female endoplasmic reticulum material to form the pore-rich pronuclei needed for genome duplication, and, if there is selection of haploid male pronuclei by one another, pronuclei would also form the basis of sexual choice. However, we are not so adventurous to speculate whether haploid male pronuclei evaluate other male pronuclei based on proportion of female membrane, mRNA signals, or some other completely different system, or how it is settled which male does the choosing.

\section{Closing Remarks}

Pre-copulatory and post-copulatory sexual selection prior to plasmogamy have been extensively studied, however to the best of our knowledge, post-plasmogamic pre-karyogamic sexual selection has never been considered, except for a few short sentences by Birkhead. This lack of study is probably due to technical difficulties in observing the behaviours of the nuclei and pronuclei within a single egg cell. We predict that the prevalence of post-plasmogamic pre-karyogamic sexual selection will be proportional to the number of sperm nuclei that enter an egg cell. It is easy enough to measure rates of polyspermy. The problem is that we know virtually nothing about how haploid nuclei inside of an egg cell move and how they might possibly choose one another. While it appears that it is usually the haploid egg nuclei that do most of the moving around the egg cell, as the haploid sperm nuclei remain around the periphery, there is too little data to know how general this pattern is. Do haploid egg nuclei prefer certain male mRNAs? If so, are these mRNA produced before or after sperm pronuclear formation? Do haploid egg nuclei prefer certain male pronuclear membranes? Does the ratio of native female-to-male content of these nuclear envelopes matter? Does it vary? Until data addressing these questions is amassed, it will remain impossible to make more specific testable predictions about the interaction of haploid nuclei inside a fertilized egg cell based on standard sexual selection theory.

We propose post-plasmogamic pre-karyogamic sexual selection exists based on previously recorded movements of female nuclei toward multiple male nuclei prior to karyogamy within a single egg cell (Carré and Sardet 1984). Post-plasmogamic prekaryogamic sexual selection is indeed plausible because female and male nuclei within an egg are under their own nuclear control rather than under the control of the cytoplasm, and there is opportunity for differences between male nuclear/pronuclear membranes and signals. We should not summarily dismiss postplasmogamic pre-karyogamic sexual selection, especially when analyzing organisms that have little or no pre-copulatory nor pre-plasmogamic selection, despite no definitive evidence for this theoretically reasonable construct. Instead of avoidance of polyspermy a lá Eberhard (1996) and Arnqvist and Rowe (2005), individual female eggs might tolerate or facilitate polyspermy and then choose sperm nuclei at a slightly later ontological date, after plasmogamy but before karyogamy. For example, post-plasmogamic prekaryogamic sexual selection could easily exist in sessile organisms, such as bryozoans and plants-organisms in which sexual selection is thought to play relatively minor evolutionary roles (Morgan 1927, Andersson 1994). Therefore, sexual selection has the potential to be much more universal, occurring in many more organisms than generally believed. The implications of postplasmogamic pre-karyogamic intersexual selection are the same as the implications for other forms of intersexual selection: the evolution of exaggerated sexual signals and female preferences for those signals (Andersson 1994). In the case of post-plasmogamic prekaryogamic sexual selection, these implications would include male nuclei being selected to either don more of the female's pronuclear membrane to 'mimic' females (Trojan sperm hypothesis) or male nuclei being selected to signal their good genes through enhanced mRNA emission (good haploid genes hypothesis), thereby actively advertising themselves to females. In turn, female nuclei would be selected to exhibit enhanced preferences for these pronuclear or mRNA signals.

\section{Acknowledgments}

Thanks to Simone Immler and Hanne Løvlie, who provided many constructive comments. Thanks to the Natural Sciences and Engineering Research Council of Canada (NSERC) for Discovery Grants to RG and SMB.

\section{Referees}

Simone Immler-simone.immler@ebc.uu.se

Uppsala University

Hanne Lovlie - hanne.lovlie@zoologi.su.se

Stockholm University

\section{References}

Andersson, M.B. 1994. Sexual selection. Princeton New Jersey Press, Princeton, NJ.

Arnqvist, G. and L. Rowe. 2005. Sexual conflict. Princeton University Press, Princeton. 
Austin, C.R. 1965. Fertilization. Prentice-Hall, Edgewood Cliffs.

Barbosa, F. 2009. Cryptic female choice by female control of oviposition timing in a soldier fly. Behavioral Ecology 20: 957-960. CrossRef

Basolo, A.L. 1990. Female preference predates the evolution of the sword in swordtail fish. Science 250: 808-810. CrossRef

Basolo, A.L. 1995. Phylogenetic evidence for the role of pre-existing bias in sexual selection. Proceedings of the Royal Society of London Series B-Biological Sciences 259: 307-311. CrossRef

Beukeboom, L.W. and R.C. Vrijenhoek. 1998. Evolutionary genetics and ecology of sperm-dependent parthenogenesis. Journal of Evolutionary Biology 11: 755-782. CrossRef

Birkhead, T.R. 1998. Cryptic female choice: criteria for establishing female sperm choice. Evolution 52: 1212-1218. CrossRef

Birkhead, T.R. and A.P. Møller. 1998. Sperm competition and sexual selection. Academic Press, London.

Birkhead, T.R. and J-P. Brillard. 2007. Reproductive isolation in birds: postcopulatory prezygotic barriers. Trends in Ecology \& Evolution 22: 266-272. CrossRef

Blount, M. 1909. The early development of the pigeon's egg, with special reference to polyspermy and the origin of the periblast nuclei. Journal of Morphology 20: 1-64. CrossRef

Braun, A. 1853 [1851]. Reflections on the phenomenon of rejuvenescence in nature especially in the life and development of plants. Pages 1-341 in A. Henfrey, editors. Biological and physiological memoirs, Ray Society, London.

Burley, N. 1988. The differential allocation hypothesis: an experimental test. American Naturalist 132: 611628. CrossRef

Bütschli, O. 1876. Studien über die ersten entwicklungvorgange der eizelle, die zelltheilung und die conjungation der infusorien. Abhandlungen herausgegeben von der Senckenbergischen Naturforschenden Gesellschaft 10: 213-452.

Carpinone, J. and R. Gorelick. in review. Evolution of syngamy.

Carré, D. and C. Sardet. 1984. Fertilization and early development in Beroe ovata. Developmental Biology 105: 188-195.

Cooper, M.A., Adam, R.D., Worobey, M., and C.R. Sterling. 2007. Population genetics provides evidence for recombination in Giardia. Current Biology 17: 1984-1988. CrossRef

Dadoune, J-P. 2009. Spermatozoal RNAs: What about their functions? Microscopy Research and Technique 72: 536-551. CrossRef
Darwin, C.R. 1871. The descent of man and selection in relation to sex. John Murray, London.

Dean, B. 1906. Chimaeroid fishes and their development. Carnegie Institution of Washington., Washington DC.

Eberhard, W.G. 1996. Female control: sexual selection by cryptic female choice. Princeton University Press., Princeton.

Edvardsson, M. and G. Arnquist. 2000. Copulatory courtship and cryptic female choice in red flour beetles Tribolium castaneum. Proceedings of the Royal Society of London Series B-Biological Sciences 267: 559-563. CrossRef

Emlen, S.T. 1976. Lek organization and mating strategies in the bullfrog. Behavioral Ecology and Sociobiology 1: 283-313. CrossRef

Emlen, S.T. and L.W. Oring. 1977. Ecology, sexual selection, and evolution of mating systems. Science 197: 215-223. CrossRef

Endler, J.A. and A.L. Basolo. 1998. Sensory ecology, receiver biases and sexual selection. Trends in Ecology \& Evolution 13: 415-420. CrossRef

Fankhauser, G. 1932. Cytological studies on egg fragments of the salamander Triton. II. The history of the supernumerary sperm nuclei in normal fertilization and cleavage of fragments containing the egg nucleus. Journal of Experimental Zoology 62: 185-235. CrossRef

Fankhauser, G. and C. Moore. 1941. Cytological and experimental studies of polyspermy in the newt Triturus viridescens. I. Normal fertilization. Joumal of Morphology 68: 347-385. CrossRef

Forche, A., Alby, K., Schaefer, D., Johnson, A.D., Berman, J., and R.J. Bennet. 2008. The parasexual cycle in Candida albicans provides an alternative pathway to meiosis for the formation of recombinant strains. PLoS Biology 6: e1 10. CrossRef

Gandolfi, A., Sanders, I.R., Rossi, V., and P. Menozzi. 2003. Evidence of recombination in putative ancient asexuals. Molecular Biology and Evolution 20: 754761. CrossRef

Gopurenko, D., Williams, R.N., McCormick, C.R., and J.A. DeWoody. 2006. Insights into the mating habits of the tiger salamander (Ambystoma tigrinum tigrinum) as revealed by genetic parentage analyses. Molecular Ecology 15: 1917-1928. CrossRef

Gorelick, R. and J. Carpinone. 2009. Origin and maintenance of sex: the evolutionary joys of self sex. Biological Journal of the Linnean Society 98 : 707-728. CrossRef

Gorelick, R., Carpinone, J., and L.J. Derraugh. 2012. Fundamental differences between females and males? Pages in M. Ah-King and A. Lee, editors. Challenging popular myths of sex, gender, and biology. 
Hartwell, L.H. and T.A. Weinert. 1989. Checkpoints: controls that ensure the order of cell cycle events. Science 246: 629-634. CrossRef

Hertwig, O. 1890. Vergleich der ei- und samenbildung bei nematoden: eine grundlage fur cellulare streitfragen. Archiv furr mikroscopische Anatomie 36: 1138.

Hoikkala, A. and S. Crossley. 2000. Copulatory courtship in Drosophila: behavior and songs of $D$. birchii and $D$. serrata. Journal of Insect Behavior 13: 71-86. CrossRef

Hoikkala, A., Crossley, S., and C. Castillo-Melendez. 2000. Copulatory courtship in Drosophila birchii and $D$. serrata, species recognition and sexual selection. Journal of Insect Behavior 13: 361-373. CrossRef

Houle, D. and A.S. Kondrashov. 2002. Coevolution of costly mate choice and condition-dependent display of good genes. Proceedings of the Royal Society of London Series B-Biological Sciences 269: 97-104. CrossRef

Hull, P. 1964. Partial incompatibility not affecting total litter size in the mouse. Genetics 50: 563-570.

Iwamatsu, T. 2000. Fertilization in fishes. Pages 89-145 in J.J. Tarin and A. Cano, editors. Fertilization in protozoa and metazoan animals: cellular and molecular aspects, Springer-Verlag, Berlin.

Iwasa, Y., Pomiankowski, A., and S. Nee. 1991. The evolution of costly mate preferences. II. The 'handicap' principle. Evolution 45: 1431-1442. CrossRef

Jennions, M.D. and M. Petrie. 2000. Why do females mate multiply? A review of the genetic benefits. Biological Reviews 75: 21-64. CrossRef

Jordan, E.O. 1893. The habits and development of the newt (Diemyctylus viridescens). Journal of Morphology 8: 269-366. CrossRef

Karr, T.L., Swanson, W.J., and R.R. Snook. 2009. The evolutionary significance of variation in sperm-egg interactions. Pages 305-365 in T.R. Birkhead, D.J. Hosken, and S. Pitnick, editors. Sperm biology: an evolutionary perspective, Academic Press, Burlington.

King, B.H. and C.R. Fischer. 2005. Males mate guard in absentia through extended effects of postcopulatory courtship in the parasitoid wasp Spalangia endius (Hymenoptera: Pteromalidae). Journal of Insect Physiology 51: 1340-1345. CrossRef

Komaru, A., Kawagishi, T., and K. Konishi. 1998. Cytological evidence of spontaneous androgenesis in the freshwater clam Corbicula leana Prime. Development, Genes and Evolution 208: 46-50. CrossRef

Krawetz, S.A. 2005. Paternal contribution: new insights and future challenges. Nature Reviews Genetics 6: 633-642. CrossRef
Longo, F.J. 1973. Fertilization: a comparative ultrastructural review. Biology of Reproduction 9: 149215.

Longo, F.J. 1976. Derivation of membrane comprising male pronuclear envelope in inseminated sea urchin eggs. Developmental Biology 49: 347-368. CrossRef

Longo, F.J. 1985. Pronuclear events during fertilization. Pages 251-298 in C.B. Metz and A. Monroy, editors. Biology of fertilization. Volume 3. The fertilization response of the egg, Academic Press, Orlando.

Longo, F.J. 1987. Fertilization. Chapman \& Hall, London.

Mantovani, B. and V. Scali. 1992. Hybridogenesis and androgenesis in the stick-insect Bacillus rossiusgrandii benaazzi (Insecta, Phasmotdea). Evolution 46: 783-796. CrossRef

Miller, D., Ostermeier, G.C., and S.A. Krawetz. 2005. The controversy, potential and roles of spermatozoal RNA. Trends in Molecular Medicine 11: 156-163. CrossRef

Morgan, T.H. 1927. Experimental embryology. Columbia University Press, New York.

Moriya, M. and C. Katagiri. 1976. Microinjection of toad sperm into oocytes undergoing maturation division. Development, Growth \& Differentiation 18: $349-356$. CrossRef

Motlik, J. and J. Fulka. 1974. Fertilization of pig follicular oocytes cultivated in vitro. Journal of Reproduction and Fertility 36: 235-237. CrossRef

Murray, A.W. 1992. Creative blocks: cell-cycle checkpoints and feedback controls. Nature 359: 599604. CrossRef

Nelson, O. 1953. Comparative embryology of the vertebrates. Blackstone, New York.

Ostermeier, G.C., Miller, D., Huntriss, J.D., Diamond, M.P., and S.A. Krawetz. 2004. Reproductive biology: delivering spermatozoan RNA to the oocyte. Nature 429: 154-154. CrossRef

Ostermeier, G.C., Goodrich, R.J., Moldenhauer, J.S., Diamond, M.R., and S.A. Krawetz. 2005. A suite of novel human spermatozoal RNAs. Journal of Andrology 26: 70-74.

Parker, G.A. 1970. Sperm competition and its evolutionary consequences in insects. Biological Reviews of the Cambridge Philosophical Society 45: 525-567. CrossRef

Petrie, M. and B. Kempenaers. 1998. Extra-pair paternity in birds: explaining variation between species and populations. Trends in Ecology \& Evolution 13: 52-58. CrossRef

Pichot, C., Maâtaoui, M., Raddi, S., and P. Raddi. 2001. Surrogate mother for endangered Cupressus. Nature 412: 39-39. CrossRef

Pizzari, T. and T.R. Birkhead. 2002. The sexuallyselected sperm hypothesis: sex-biased inheritance 
and sexual antagonism. Biological Reviews 77: 183209. CrossRef

Rothschild. 1954. Polyspermy. Quarterly Review of Biology 29: 332-342.

Ryan, M.J. 1998. Sexual selection, receiver biases, and the evolution of sex differences. Science 281: 1999 2003. CrossRef

Signorovitch, A.Y., Dellaporta, S.L., and L.W. Buss. 2005. Molecular signatures for sex in the Placozoa. Proceedings of the National Academy of Sciences of the United States of America 102: 15518-15522. CrossRef

Simmons, L.W. 1987. Heritability of a male character chosen by females in the field crickets, Gryllus bimaculatus. Behavioral Ecology and Sociobiology 21: 129-133. CrossRef

Simmons, L.W. 2001. Sperm competition and its evolutionary consequences in the insects. Princeton University Press, Princeton.

Skoblina, M.N. 1976. Role of karyoplasm in the emergence of capacity of egg cytoplasm to induce DNA synthesis in transplanted sperm nuclei. Journal of Embryology and Experimental Morphology 36: 67-72.

Sluder, G., Thompson, E.A., Rieder, C.L., and F.J. Miller. 1995. Nuclear envelope breakdown is under nuclear not cytoplasmic control in sea urchin zygotes. Journal of Cell Biology 129: 1447-1458. CrossRef

Snook, R.R. 2005. Sperm in competition: not playing by the numbers. Trends in Ecology \& Evolution 20: 4653. CrossRef

Solari, A.J. 2002. Primitive forms of meiosis: the possible evolution of meiosis. BioCell 26: 1-13.

Spencer, H. 1863 [1890]. The principles of biology (volume 1). Williams \& Norgate [Appleton], London [New York].

Tarín, J.J. 2000. Fertilization in protozoa and metazoan animals: a comparative overview. Pages 277-314 in J.J. Tarín and A. Cano, editors. Fertilization in protozoa and metazoan animals: cellular and molecular aspects, Springer-Verlag, Berlin.

Thibault, C. and M. Gérard. 1973. Cytoplasmic and nuclear maturation of rabbit oocytes in vitro. Annales De Biologie Animale Biochimie Biophysique 13: 145-156. CrossRef

Thornhill, R. 1983. Cryptic female choice and its implications in the scorpionfly Harpobittacus nigriceps. American Naturalist 122: 765-788. CrossRef

Thornhill, R. 1984. Alternative female choice tactics in the scorpion fly Hylobittacus apicalis (Mecoptera) and their implications. American Zoologist 24367 383.

Trounson, A.O., Willadsen, S.M., and L.E.A. Rowson. 1977. Fertilization and development capability of bovine follicular oocyte matured in vitro and in vivo and transferred to the oviducts of rabbits and cows. Journal of Reproduction and Fertility 51: 321-327. CrossRef

Willson, M.F. and N. Burley. 1983. Mate choice in plants. Princeton University Press, Princeton.

Wilson, E.B. 1925. The cell in development and heredity (3rd edition). Macmillan, New York.

Wourms, J.P. 1977. Reproduction and development in chondrichthyan fishes. American Zoologist 17: 379410.

Wright, S.J. and F.J. Longo. 1988. Sperm nuclear enlargement in fertilized hamster eggs is related to meiotic maturation of the maternal chromatin. Journal of Experimental Zoology 247: 155-165. CrossRef

Yamashita, M., Onozato, H., Nakanishi, T., and Y. Nagahama. 1990. Breakdown of the sperm nuclear envelope is a prerequisite for male pronucleus formation: direct evidence from the gynogenetic crucian carp Carassius auratus langsdorfii. Developmental Biology 137: 155-160. CrossRef

Yanagimachi, R. and Y.D. Noda. 1970. Ultrastructural changes in the hamster sperm head during fertilization. Journal of Ultrastructure Research 31: 465-485. CrossRef 